\title{
Exercise-induced muscle damage: morphological, biochemical and functional aspects
}

Citation for published version (APA):

van der Meulen, J. H. (1991). Exercise-induced muscle damage: morphological, biochemical and functional aspects. [Doctoral Thesis, Maastricht University]. Rijksuniversiteit Limburg. https://doi.org/10.26481/dis.19911212jm

Document status and date:

Published: 01/01/1991

DOI:

10.26481/dis.19911212jm

Document Version:

Publisher's PDF, also known as Version of record

\section{Please check the document version of this publication:}

- A submitted manuscript is the version of the article upon submission and before peer-review. There can be important differences between the submitted version and the official published version of record.

People interested in the research are advised to contact the author for the final version of the publication, or visit the DOI to the publisher's website.

- The final author version and the galley proof are versions of the publication after peer review.

- The final published version features the final layout of the paper including the volume, issue and page numbers.

Link to publication

\footnotetext{
General rights rights.

- You may freely distribute the URL identifying the publication in the public portal. please follow below link for the End User Agreement:

www.umlib.nl/taverne-license

Take down policy

If you believe that this document breaches copyright please contact us at:

repository@maastrichtuniversity.nl

providing details and we will investigate your claim.
}

Copyright and moral rights for the publications made accessible in the public portal are retained by the authors and/or other copyright owners and it is a condition of accessing publications that users recognise and abide by the legal requirements associated with these

- Users may download and print one copy of any publication from the public portal for the purpose of private study or research.

- You may not further distribute the material or use it for any profit-making activity or commercial gain

If the publication is distributed under the terms of Article $25 \mathrm{fa}$ of the Dutch Copyright Act, indicated by the "Taverne" license above, 
Exercise-induced muscle damage: morphological, biochemical and functional aspects 


\title{
Exercise - induced muscle damage: morphological, biochemical and functional aspects
}

\author{
PROEFSCHRIFT \\ ter verkrijging van de graad van doctor \\ aan de Rijksuniversiteit Limburg te Maastricht, \\ op gezag van de Rector Magnificus Prof. Mr. M.J. Cohen, \\ volgens het besluit van het College van Dekanen, \\ in thet openbaar te verdedigen \\ op donderdag 12 december 1991 om 14.00 uur \\ door \\ Jacob Hendrikus van der Meulen \\ geboren te Akkrum op 15 november 1956
}


Promotor:

Co-promotor:

Beoordelingscommissie:
Dr. H. Kuipers

Prof. dr. F. Spaans (voorzitter)

Prof. dr. J.W. Arends

Dr. P.R. Bär (Rijksuniversiteit Utrecht)

Dr. H.A. Keizer

Prof. dr. R.H. Rozendal (Vije Universiteit Amsterdam)

Prof. dr. A.d. Sargeant (Universiteit vanAmsterdam)

CIP-DATA KONINKLIJKE BIBLIOTHEEK DEN HAAG

Meulen, J.H. van der

Exercise-induced muscle damage : morphological, biochemical and functional aspects $/ \mathrm{J}$. H. van der Meulen.

- [S.1. : s.n.]

Thesis Maastricht. ISBN 90-9004594-5

Subject heading : muscle damage

De uitgave van dit proefschrift werd mede mogelijk gemaakt door financiële steun van Bayer Nederland b.v.

\section{Philips}

Jan Dekkerstichting \& Dr Ludgardine Bouwmanstichting

Lay-out: Eric van Breda / JvdM

Druk: $\quad$ Datawyse, Maastricht / Krips Repro, Meppel 
as oantinken oan Heit foar Mem 


\section{Contents}

\section{Chapter 1: General introduction}

1.1 Introduction 1

1.2 Muscle damage, morphological features 2

1.3 Factors contributing to exercise-induced muscle damage 4

1.4 Features related to exercise-induced muscle damage 8

1.5 Aims and outline of the present study 12

Chapter 2: A forced lengthening exercise model for eliciting muscle damage in the rat tibialis anterior muscle

$\begin{array}{lll}2.1 & \text { Summary } & 15 \\ 2.2 & \text { Introduction } & 15 \\ 2.3 & \text { Description of the exercise apparatus and exercise protocol } & 16 \\ 2.4 & \text { Results and Discussion } & 19 \\ 2.5 & \text { Conclusions } & 22\end{array}$

Chapter 3: Relationship between muscle length and muscle damage with forced lengthening contractions in the rat tibialis anterior muscle

$\begin{array}{lll}3.1 & \text { Summary } & 23 \\ 3.2 & \text { Introduction } & 23 \\ 3.3 & \text { Material and Methods } & 24 \\ 3.4 & \text { Results } & 27 \\ 3.5 & \text { Discussion } & 31\end{array}$

Chapter 4: Muscle compliance in relation with forced lengtheninginduced damage in the rat tibialis anterior muscle

$\begin{array}{lll}4.1 & \text { Summary } & 35 \\ 4.2 & \text { Introduction } & 35 \\ 4.3 & \text { Material and Methods } & 36 \\ 4.4 & \text { Results } & 38 \\ 4.5 & \text { Discussion } & 42\end{array}$ 
Chapter 5: Peripheral adaptation after one bout of forced lengthening in the rat tibialis anterior muscle

$\begin{array}{llr}5.1 & \text { Summary } & 45 \\ 5.2 & \text { Introduction } & 45 \\ 5.3 & \text { Material and Methods } & 46 \\ 5.4 & \text { Results } & 48 \\ 5.5 & \text { Discussion } & 50\end{array}$

Chapter 6: High energy phosphates, IMP and glycogen in the rat tlblalls anterior muscle after forced lengthening and Isometric contractions

6.1 Summary 53

6.2 Introduction 53

6.3 Material and Methods 54

6.4 Results 57

6.5 Discussion 60

Chapter 7: Relationship between exercise-induced muscle damage and enzyme release in male and female rats

7.1

Summary $\quad 63$

7.2 Intraduction 63

7.3 Material and Methods 64

$\begin{array}{lll}7.4 & \text { Results } & 67\end{array}$

$\begin{array}{lll}7.5 & \text { Discussilion } & 72\end{array}$

Chapter 8: Quantitative aspects of secondary changes in male and female rat soleus muscle after exercise of different duration

$\begin{array}{llr}8.1 & \text { Summary } & 77 \\ 8.2 & \text { Introduction } & 77 \\ 8.3 & \text { Material and Methods } & 78 \\ 8.4 & \text { Results } & 81 \\ 8.5 & \text { Discussion } & 81\end{array}$

Chapter 9: General discussion $\quad B 7$

References $\quad 91$

$\begin{array}{ll}\text { Samenvatting } & 103\end{array}$

$\begin{array}{lr}\text { Curriculum vitae } & 107\end{array}$

$\begin{array}{lr}\text { List of publications } & 109\end{array}$

$\begin{array}{ll}\text { Nawoord } & 111\end{array}$ 


\section{General introduction}

\subsection{INTRODUCTION}

Approximately $40 \%$ of the total body mass consists of skeletal muscle, allowing the body to move and to interact with its environment. One of the characteristic features of skeletal muscle is its plasticity which enables the muscle to adjust to changes in functional demands. Fibres can change their metabolic potential without alterations in the fibre type (Luginbuhl et al., 1984; Hoppeler, 1987). Fibres can also change from one type into another by changes in isoforms of myosin heavy and light chains (Luginbuhl et al., 1984; Howald et al., 1985; Hoppeler, 1987). Muscle fibre length can be adjusted by adding or deleting sarcomeres at the distal ends of the myofibrils in order to maintain optimum sarcomere length in the resting state (Goldspink et al., 1974). In response to strength training the volume of muscle fibres may change (MacDougall et al., 1982) or may lead to the development of new fibres (Appell et al., 1988). Otherwise, disuse results in a decrease of muscle fibre volume leading to atrophy (Appell, 1990).

When the muscle is metabolically or mechanically challenged, damage may occur (Clarkson, 1990). Muscle damage in man is reflected in delayed onset muscle soreness (DOMS), decreased strength, stiffness, swelling and microscopical changes (Clarkson et al., 1986; Davies and White, 1981, 1982; Fridén et al., 1986; Jones et al., 1987; Newham, 1988; Newham et al., 1983c). Studies in animals and man show that the basis of muscle damage is structural damage to the myofibrils (Fridén et al, 1981, 1983b; Ogilvie et al., 1988). The structural damage may range from mild to severe (Hoppeler, 1986). With mild damage focal structural damage or focal necrosis can be found (Armstrong et al., 1983; Fridén et al., 1983b; Kuipers et al., 1983; Ogilvie et al., 1988). In severe cases muscles can be seriously injured and rhabdomyolysis may occur (Geller, 1973; Milne, 1988). In man rhabdomyolysis has been reported after long distance running, military training, epileptic insult, trauma, dehydration, anaesthesia and alcohol abuse (Gronert, 1980; Rowland and Penn, 1972). Severe muscle damage may result in myoglobinuria, renal failure and ultimately in death (Bartsch et al., 1977; Hamilton et al., 1972). Because muscle soreness and rhabdomyolysis in man is usually preceded by a symptom-poor interval, the final outcome cannot reliably be predicted in an early stage. In wild animals that were chased, but also in horses and in pigs that were stressed, rhabdomyolysis has frequently been reported (Bartsch et al. 1977; Smith and Jones, 1966).

Although many studies have been performed, relatively little is known about the origin and subsequent pathophysiological mechanism of exercise-induced muscle damage, potentially resulting in rhabdomyolysis. In addition, features of muscle damage, such as enzyme release, stiffness, swelling and pain are not well explained. Extreme types of muscle damage have medical and economical conse- 
quences. To prevent these, more knowledge about factors that are involved in muscle damage and rhabdomyolysis is essential. By knowing more about the pathophysiology, possibilities for prevention or treatment may be identified.

\subsection{MUSCLE DAMAGE, MORPHOLOGICAL FEATURES}

Direct evidence of exercise-induced muscle damage is provided by light and electron microscopical examination. To distinguish exercise-induced muscle damage from damage that is caused by trauma, exercise-induced muscle damage is also called micro-injury (Armstrong, 1990). The features of exercise-induced muscle damage follow a typical time pattern. The initial or primary damage is followed by secondary changes, which includle an inflammatory response. The initial changes consist of ultrastructural damage to the myofibre constituents (Stauber, 1989).

\section{Initial or primary damage}

In 1981 Fridén and co-workers were among the first who reported focal areas of streaming, broadening and disruption of the Z-discs in eccentrically exercised muscles of man, a finding that was confirmed in later studies (Fridén, 1984b; Fridén et al., 1983b; "Newham et al., 1983b). Also in animal studies damage to the contractile elements was found, consisting of a disarray of the banding pattern that appears as a widening of $\mathrm{A}$ - and $\mathrm{l}$-bands in discrete regions of the myofibres (Armstrong et al., 1983; Newham et al., 1983b; Ogilvie of al., 1988). Other initial changes that have been described after exercise include myofibrillar disruption (Fridén et al., 1981), broken fibres (Stauber et al., 1988), cytoskeletal changes (Fridén et al., 1984), displacement of organelles (Hikida et al., 1983; Newham et al.. 1983b), mitochondrial changes (Hoppeler, 1986) and vacuolization (Kuipers et al., 1983). In addition, disruptions of the sarcolemma, as indicated by the absence of a clear delineation in some regions between adjacent muscle fibres has been reported (Armstrong et al., 1983; Fridén et al., 1983b).

\section{Secondary changes}

Secondary changes have already been reported in animal studies in the early sixties (Altland and Highman, 1961; Garbus et al., 1964; Highman and Altland, 1963) and later they have been demonstrated in man as well (Hikida et al., 1983; Round of al., 1987). Armstrong (1990) subdivides the period in which secondary changes occur into the autogenetic stage and the phagocytic stage that follows the autogenefic stage. During the autogenetic stage proteolytic and lipolytic systems begin the process of degrading cellular structures (Duncan, 1987; Furuno and Goldberg, 1986; Goodman, 1987). During the phagocytic stage phagocytic cells invade the injured sites. In the literature the phagocytic stage is referred to as necrosis, inflammation, infiltration, or delayed muscle damage (Stauber, 1989).

The infiltrating mononuclear cells consist almost exclusively of macrophages and leukocytes, that are assumed to remove damaged fibre components and to facilitate regeneration (Armstrong et al., 1983; Hikida et al., 1983; Jones et al. 1986; 
Kuipers et al., 1983; Round et al., 1987). The leukocytes include neutrophils, lymphocytes and monocytes (Hikida et al. 1983). Occasionally also erythrocytes were found in muscle fibres (Hikida et al., 1983). Stauber et al. (1988) charactertzed the infiltrated cells by means of immunohistochemical techniques as cells that were myogenic in origin. To a lesserextent lymphocytes were involved. The inflammatory cells do not only infiltrate muscle fibres but they can also be found in connective tissue of endomysial; perimysial and perivascular regions (Round et al., 1987).

Additional secondary changes that are associated with muscle overload are muscle fibres with basophilic subsancolemmal staining (Kuipers et al, 1983) and muscle fibre swelling (Fridén et al., 1986; Peeze Binkhorst et al, 1989). Regions with basophilic staining were primarily found in the periphery of muscle fibres and were assumed to reflect clusters of abnormal, enlarged mitochondria (Kuipers etal, 1983). The change of the polygonal shape of normal muscle fibres into a more rounded shape is presumably the result of cellular swelling caused by disturbances in ion homeostasis in the myofibres leading to water shifts (Fridén et al, 1981,1983b). In addition, in animals secondary changes are associated with an increase in lysosomal proteolytic enzyme activity (Vihko et al, 1978a; b; Salminen, 1985).

Similar to primary damage, secondary changes do not involve all muscle fibres and fibres are not affected over their entire length, but changes are restricted to small segments (Armstrong et al., 1983; Kuipers et al., 1983). In animal muscles that show signs of damage less than $5 \%$ of the total number of muscle fibres are affected (Armstrong et al., 1983; Highman and Altand, 1963; Kuipers et al., 1983; Ogilvie et al., 1988; Stauber et al., 1990; Vihko et al., 1979). In human muscles more extensive levels of muscle damage have been found (Fridén et al., 1983b; Jones et al., 1986; Warhol et al., 1985). This discrepancy can partlly be attributed to different experimental and analytical techniques used, i.e. fibres that appear non-injured with light microscopy may show ultrastructural damage with electron microscopy. In addition, species differences cannot be excluded.

Some studies in man have followed the extent of muscle damage after exercise. Fridén et al. (1983b, 1984) and Newham et al. (1983b) noted that 3 days post-exercise more damage was found than immediately post-exercise. The area of damage within fibres as well as the number of damaged fibres increased. Hikida of al. (1983) showed that more damage was found 1 and 3 days post-exercise than 15 min and 5 and 7 days post-exercise. Jones of al. (1986) found most extensive damage 9-14 days post-exercise compared with 3 and 4 days post-exercise. In rats Kuipers et al. (1983) found a gradual increase in the number of affected fibres until 3 days post-exercise, thereafter a decrease. Armstrong et al. (1983) confirmed this time course by measuring glucose-6-phosphate dehydrogenase (G-6-PDase) activity in the injured muscles. G-6-PDase activity is used as marker for intlammation since inflammatory cells possess high levels of activity of this enzyme.

In studies in which the damaged fibre lypes were determined, it seems that one specific fibre type is affected. In the animal studies of Armstrong el al. (1983), Kuipers et al. (1983), and Vitho of al. (1978a, b) only type I fibres were found to be affected, while Lieber and Fridén (1988) showed that only type IIB fibres were 
damaged. In human studies of Friden (1984a), Fridën et al. (1983b) and Jones et al. (1986) only lype ft fibres were damaged. Although no clear explanation is available for the damage to one specific fibre type, it has been suggested that some fibre types are more susceptible than others. In their study, Friden et al. (1983b) attributed the finding that only type $\| \mathrm{B}$ were damaged to the fact that type / fibres with their broader $Z$-lines may have firmer mechanical connections between the contractile units (Prince et al., 1981; Sjöström et al., 1982a, b). Furthermore it may be attributed to selective recruitment which is determined by the type, duration and severity of exercise (Armstrong et al., 1977, 1982; Gardiner et al., 1982; Walmsley et al., 1978).

\section{Regeneration}

The process of muscle degeneration is followed by muscle regeneration (Allbrook, 1981; Carlson and Faulkner, 1983). Regeneration is evidenced by the presence of mitotic cells (Armstrong et al., 1983; Darr and Schultz, 1987), myoblasts, myotubes and central nuclei (Faulkner et al., 1989; Warhol et al., 1985) and ribosomes indicating protein synthesis (Ebbeling and Clarkson, 1989; Fridén etal., 1983b). In regeneration the satellite cells play an important role. Satellite cells lay between the sarcolemma and the basal membrane (Campion, 1984). The satellite cells differentiate into myoblasts which fuse into myotubes that fill the damaged muscle tibre area. It is sugglested that the basal membrane functions as a scaffold (Carlson and Faulkner, 1983). However, the basal membrane is not a static structure as previously thought, but can quite rapidly change during myotibre degeneration and regeneration (Gulati et al., 1983). Furthermore, it is indicated that the endomysium surrounding the individual muscle fibres plays an important role for orientating the muscle fibres during regeneration (Fritz and Stauber, 1988). Mitotic activity of satellite cells occurs mainly at or near the site of damage, but it has been shown that many dividing cells have migrated from unaffected areas to injured parts of the muscle (Schultz et al., 1985).

In the literature no unequivocal results about the time course of regeneration are reported. Different investigations report completion of regeneration within one week (Fridén et al., 1983b, Kuipers et al., 1983), 12 days (Armstrong et al., 1983), 30 days (McCully and Faulkner, 1985) and 8-12 weeks (Warhol et al., 1985). Factors that might influence regeneration are strain and muscle differences (Irintchev and Wernig, 1987), age (Brooks and Faulkner, 1990; Kasparek and Snider, 1985b) and the severity of damage.

\subsection{FACTORS CONTRIBUTING TO EXERCISE-INDUCED MUSCLE DAMAGE}

Various types of exercise have been shown to elicit muscle damage, i.e. short intense eccentric exercise as well as exhaustive endurance exercise at medium intensity (Hoppeler, 1986). Two major components have been proposed to initiate the events leading to primary muscle damage, namely a mechanical and a metabolic component (Armstrong, 1990). 


\section{Mechanical component}

Studies that compared the effect of different types of exercise with the same duration and intensity on the amount of damage showed that eccentric exercise was most effective in eliciting muscle damage (Armstrong et al., 1983, McCully and Faulkner, 1985). Compared with concentric and isometric exercise, in eccentric exercise less energy is used at a given power output (Abbott elt al, 1952; Asmussen, 1952; Davies and Barnes, 1972b; Knuttgen et al., 1971). In addition, in eccentric exercise less fibres are recruited resulting in a greater force in individual fibres (Bigland and Lippold, 1954; Basmajian, 1967; Asmussen, 1952; Bigland-Ritchie and Woods, 1976). This implies that the tension developed in the stimulated fibres is greater in eccentric than in concentric and isometric exercise. Based on this, it is generally assumed that a mechanical component plays an important role for eliciting primary muscle damage (Armstrong et al., 1983; Fridén et al., 1981, 1983b).

When an activated muscle is stretched and submitted to tension, different components could break: the connective tissue between adjacent inyofibres, the basall lamina, the plasma membrane, and sarcomeres that may also disrupt the adjacent sarcoplasmic reticulum or the plasma membrane (Stauber, 1989). In addition, the inability of the contractile elements to relax at the appropriate speed could result in a rigor-type state. If only one fibre (myofibre rigor)' or one myofibril (induction of segmental hypercontraction) were involved in the rigor, then shear stress would develop between adjacent units and rupture or myofilament damage could easily result. Support for this explanation is found in several studies in which eccentric exercise was used. Fridén et al. (1981, 1983b) and Ogilvie et al. (1988) found damage to the contractile elements and disruption of the sarcolemma.

Further support for a mechanical component is found in the observation that weight-bearing activities, such as running, elicit more damage than non-weightbearing activities such as swimming and cycling (Berg and Haralambie, 1978; Critz and Cunningham, 1972; Noakes, 1987). In addition, McCully and Faulkner (1986) demonstrated the importance of contraction velocity and tension produced during forced lengthening contractions on the amount of muscle damage. Furthermore, Clarkson et al. $(1982,1985)$ reported that in different isometric exercise regimens only differing in tension levels, the greatest $\mathrm{CK}$ release, a marker for muscle damage, was found in exercise with the greatest tension levels. A specific type of mechanical stress that has been proposed to contribute to muscle damage is intramuscular pressure (Fridén et al., 1988). In muscles located within a compartment higher intramuscular pressures were found to be associated with greater increases in plasma enzyme activities.

\section{Metabolic component}

During prolonged submaximal exercise insufficient mitochondrial respiration has been proposed to play a role in initiating muscle damage (Armstrong, 1990; Ebbeling and Clarkson, 1989). Energy substrates and oxygen are essential to generate ATP via oxidative phosphorylation in order to maintain the balance between ATP generation and ATP use. When the muscle suffers a temporary oxygen 
deficit ATP is mainly generated by anaerobic glycolysis resulting in the production of lactate and a decrease of intracellular $\mathrm{pH}$ which may compromise normal cell function. in support of this, damage, similar to exercise-induced muscle damage has been found aftier a prolonged period of ischemia (Harris et al., 1986; Hoppeler, 1986; Sịöström at al., 1987).

It has beeri suggested that depletion of substrates for energy metabolism may also initiate muscle damage (Noakes, 1987). Janssen et al. (1989) found an increase in muscle damage in marathon runners after approximately $30 \mathrm{~km}$ of running and speculated that after exceeding a certain distance, glycogen depletion leads to an impaired aerobic metabolism and an increase of muscie damage. Other studies, however, suggest that muscle damage is not necessarily associated with glycogen depletion (O'Reilly et al., 1987). Although it has been suggested that oxygen deficit, energy depletion and the production of metabolites might act as primary factor for initiating exercise-induced muscie damage, there are several arguments against a primary role for these factors. The most important argument is that in concentrically exercised muscles less damage was found, while more energy and oxygen were required and more lactate was produced than in eccentrically exercised muscles. Furthermore, it is suggested that muscle damage associated with endurance running may be caused by forces put on the muscles and that metabolic changes may exacerbate the damage. Jennische (1985) showed that the combination of glycogen depletion and ischaemia may lead to an increased vulnerability of the muscle to encounter damage.

Another metabolic factor that might contribute to muscle damage is the formation of free radicals. After exhaustive exercise at a level known to induce muscle damage, increased levels of free radicals have been reported (Davies et al., 1982). Zerba et al. (1990) showed disorganization of sarcomeres immediately following lengthening contractions that could partially be prevented when the muscles were treated with a free radical scavenger.

A factor that has also to be considered is high temperature. Baracos et al. (1984) showed that high local temperatures in the muscles can have deleterious effects on protein degradation. Eccentric exercise is not only associated with high forces on muscle fibres, but also with considerable heat production (Sargeant and Dolan, 1987; Nadel ot al., 1972).

Summing up all the available evidence the factor(s) initiating primary damage remain(s) to be established. It seems that for inducing primary damage a mechanical factor is of primary importance and that muscle temperature and metabolic state may also play a role, especially after prolonged exercise.

\section{Initlation of secondary changes}

Although metabolic factors are assumed not to play a major role in eliciting initial damage, they are assumed to play a rale for initiating secondary changes. Calcium seems to play a pivotal rolle (Armstrong, 1990). In rats that ran on a treadmill, reduction of the calcium influx through the sarcoplasmic reticulum has been shown to be effective in preventing histological muscle damage (Amelink et al., 1990), while 
Duan et al. (1990) have shown that elevations in muscle mitochondrial calcium content were probably related to the extent of histological damage in working muscles.

The origin of an increased sarcoplasmic calcium accumulation might be an increased permeability or the inability of the sarcoplasmic reticulum to extrude intracellular calcium. The mitochondria may accumulate calcium which impairs cellular respiration and ATP production (Drahota et al., 1965; Wrogemann and Pena, 1976). Studies concerning chemical-induced muscle damage have shown that calcium is involved in phospholipase A2-mediated injury to the sarcolemma and other membrane structures, and in ultrastructural damage to myofilaments (Duncan and Jackson, 1987; Jackson et al., 1984). In addition, high calcium concentration enhances the activation of calcium-activated proteases (Mellgren, 1987) and may stimulate production of free radicals, which cause peroxidation of membrane lipids (Braughler, 1988; Sjödin et al., 1990). Furthermore Hattori and Takahashi (1982) showed a calcium-induced weakening of the Z-line: Calcium has also been sug. gested to cause muscle contracture (Ogilvie et al., 1988).

Another metabolic factor implicated in the secondary changes are the lysosomal enzymes, since the lysomal activity has been found to be most marked 3-5 days after exercise (Salminen et al., 1984; Vihko et al., 1978b)

\section{Training and muscle damage}

The most certain way to prevent exercise-induced muscle damage is to avoid physical exercise. However, it has also been demonstrated that when exercise is repeated, fewer signs of muscle damage are seen (Fridén et al., 1983a; Schwane and Armstrong, 1983). In addition, symptoms related to muscle damage, such as a reduced strength and soreness, decreased after several weeks of training (Fridén et al., 1983a).

Different mechanisms for reducing damage have been proposed. The first one is a metabolic alteration. For example, an increased number and size of mitochondria would result in a greater ATP availability (Davies and Barnes, 1972a; Scrimgeour et al., 1986). Structural adaptation, however, has received more support. An increase in number of sarcomeres and Z-line synthesis has been proposed by Fridén et al. (1983a). A third explanation that has been suggested is an improved co-ordination (Klausen and Knuttgen, 1971).

Not only regular training but even one single bout of eccentric exercise has been shown to reduce muscle damage in subsequent exercise (for review, see Ebbeling and Clarkson, 1989). It has been proposed that after the first exercise bout the connective tissue was strengthened (Clarkson and Tremblay, 1988; Newham et all, 1987) or that stress susceptible fibres were replaced by stronger ones (Armstrong et al., 1983). However, other studies indicate that adaptation can take place without eliciting muscle damage (Schwane and Armstrong, 1983; Clarkson and Tremblay, 1988). Therefore, a satisfactory explanation is still lacking. 


\subsection{FEATURES RELATED TO EXERCISE-INDUCED MUSCLE DAMAGE}

Phenomena, related to muscle damage after muscular overload are delayed onset muscle soreness, swelling, decreased strength, decreased range of motion, muscle shortening and enzyme release (Clarkson, 1990).

\section{Delayed onset muscle soreness and swelling}

The most typical complaint after unaccustomed exercise is muscle soreness (Armstrong, 1984; Fridén, 1984b; Schwane et al., 1983). Fatigue or initial soreness occurs during the terminal stage of exercise or immediately thereatter and subsides within a few hours. The initial soreness is accompanied by stiffness and decreased strength. Delayed onset muscle soreness (DOMS), which is quite different from the initial soreness starts a few hours to a day after exercise and peaks $48-72 \mathrm{~h}$ after exercise after which a complete recovery occurs within one week. The muscles are firm, tender and weak (Abraham, 1977). In a number of studies the extent and time course of DOMS is related to fibre damage (Fridén et al., 1983b; Hough, 1902), connective tissue damage (Abraham, 1977; Asmussen, 1956; Komi and Buskirk, 1972; Komi and Rusko, 1974; Newham et al., 1983c), muscle spasm (DeVries, 1966) and swelling (Bobbert et al., 1986; Brendstrup, 1962).

Swelling of muscles has been observed in a number of studies (Fridén et al., 1986,1988 ) and was primarily attributed to an increased volume of muscle fibres (Friden et al., 1988). When the muscle is situated in a compartment, this may result in a compartmental syndrome (Fridén et al., 1986).

\section{Decreased muscle strength}

After different types of exercise in humans a decrease in muscle strength has been described (Newham et al., 1983c). Various authors have speculated that the reduction in strength may be attributed to damage of the contractile apparatus, because the decrease in strength has been found to be greater after eccentric than after other types of exercise (Davies and White, 1981; Komi and Vitasalio, 1977; Newham etal, 1983c). This suggestion is supported by a study of Friden et al. (1983b) who showed that the decrease and subsequent slow recovery in isokinetic strength at high angular velocities $(300 \%$ s) after eccentric exercise was probably related to damage in type II fibres that were actively involved at these velocities. Newham et al. (1987) showed that the reduction in the muscle strength could be attributed to an alteration within the muscle itself and not to pain related inhibition, because additional stimulation of the previously exercised muscles by means of skin electrodes did not result in an increase in muscle strength. In addition, McCully and Faulkner (1986) found a significant correlation between histological muscle damage and decrease in force in mice muscles after lengthening contractions. In contrast to this study, a discrepancy between the maximum force and the amount of damage was found in the muscles that were exposed to forced lengthening (Brooks and Faullkner, 1990). 
Muscles exposed to lengthening contractions showed a ypical pattern of contractioninjury and recovery during the first three days (Faulkner et al $\mathrm{l}_{\mathrm{*}, 1} 1989$; McCully and Faulkner, 1985). The recovery in maximal isometric force from $1 \mathrm{~h}$ to $1 \mathrm{day}$ reflected an apparent recovery from fatigue, whereas the decrease in isometric force between 1 and 3 days suggests a secondary, more severe damage following the initial injury (Faukner et al., 1989).

Several studies showed a changed force-frequency relationship after eccentric exercise (Faulkner et al.,1989; Davies and White, 1981, 1982; McCully and Faulkner; 1986; Newham et al. , 1983c, 1987; Sargeant and Dolan, 1987). Stimula tion of the muscles at different frequencies showed that the decrease in muscle. strength was particularly found at low stimulation frequencies $(10-20 \mathrm{~Hz})$. At high frequencies $(50-100 \mathrm{~Hz})$ no or a slight decrease in muscle strength was found. The so-called low frequency fatigue is considered to be due to damaged sarcoplasmic reticulum and is therefore attributed to an insufficient release of calcium for force generation (Newham et al., 1983c)

\section{Decreased range of motion and muscle length}

After eccentric exercise in humans a decrease in the relaxed elbow joint angle is shown, indicating spontaneous shortening of the forearm flexor muscle (Clarkson and Tremblay, 1988). The reduction was most pronounced 2 days post-exercise. This phenomenon was initially attributed to increased EMG activity and swelling. However, Bobbert et al. (1986), Howell et al. (1985) and Jones et al. (1987) did not support this, because the sore muscles were electrically sillent. In addition, a dissimilar time course of swelling and muscle shortening was found. Jones et al. (1987) suggested that shortening of the connective tissue was the basis for decreased range of motion. Another explanation that has been suggested is the existence of high intracellular calcium levels or low intracellular ATP levels. High intracellular calcium levels will result in contraction or decreased relaxation of the exercised muscles (Brody, 1969). However, the mechanism for the decreased range of motion is still unclear.

\section{Metabolic changes}

In biopsy samples of isolated hearts that were reperfused after minimally 30 min of lischemia, it was shown that myocardial metabolism was seriously disturbed: a decrease in ATP content and energy charge and a shift to ADP and AMP (van Bilsen, 1988). In addition, increases of degradation products of nucleotides, like xanthine and hypoxanthine were found. Metabolic changes in skeletal muscles have aiso been demonstrated in gracilis muscles that suffered ischemia for $7 \mathrm{~h}$. The profoundly damaged muscle was unable to restore ATP and creatinephosphate (CP) to pre-ischemic levels after reperfusion (Harris et al., 1986). In a 31P-NMR study Aldridge et al. (1986) found an increased inorganic phosphate (Pi) content in resting forearm muscle approximately $24 \mathrm{~h}$ after stretching exercise. With the same technique McCully et al. (1988) studied metabolism in situ during and post-exercise in skeletal muscles that performed eccentric exercise resulting in pain and de- 
creased muscle strength. They found an increased Pi/CP ratio. Increases in Pi/CP were similar to those seen in patients with various destructive neuromuscular diseases. Therefore, elevated Pi/CP levels have been proposed to be a marker of non-specific muscle damage (McCully et al., 1988). In addition, it thas been noted that post exercise muscle glycogen repletion is delayed after eccentric exercise (Costill et al., 1990; Kuipers ef al., 1985; O'Reilly et al., 1987). O'Reilly et al. (1987) found that 10 days after eccentric exercise muscle glycogen was still depleted, in both type 1 and type 11 fibres. The finding that 10 days post-exercise myofibrillar necrosis and inflammatory cell infiltration was found, suggests that the changes in glycogen level were related to degenerative changes. It is hypothesized by these authors that ultrastructural damage to the sarcolemma may impair glucose transport into the cell. According to Costill et al. (1990) the most likely explanation for the lower glycogen levels is that the traumatic muscle is infiltrated with inflammatory cells, which have a large affinity for glucose oxidation. However, another study suggests that changes in glycogen metabolism are not necessarily associated with structural changes (Kuipers et al., 1985).

\section{Increased activity of muscle enzymes in plasma}

Probably the first to document the phenomenon of exercise-induced increased muscle enzyme activities in plasma were Loll and Hilscher (1958). They showed that serum activities of aldolase, lactate dehydrogenase (LD) and aspartate aminotransferase (AST) were increased in subjects who had walked on a treadmill for only 5 minutes. In 1965, Vejjajiva and Teasdale were the first to study specifically the effect of exercise on plasma creatine kinase (CK) activities. Nowadays it is generally accepted that exercise may lead to leakage of muscle enzymes and other proteins that will enter the blood via the lymph. However, it remains unclear whether enzyme release is solely attributable to an increased permeability of the sarcolemma, to structural damage, or both. With the radioisotope technetium pyrophosphate (TcPYP) injected into the blood it was shown that the time course and magnitude of TcPYP uptake into damaged muscle was the same as that of CK release into the circulation (Newham et al., 1986b), but it does not throw any light on the nature of changes, since little is known about the mechanism by which Tc-PYP is taken up by damaged tissue.

Different cellular mechanisms have been proposed to explain the rise in plasma enzyme activities with exercise. Firstly, a non adequate maintenance of normal cell function caused by metabolic disturbances such as hypoxia or cellular energy deficit may lead to an impairment of sarcolemmal function (Gardner et al., 1964). Secondly, an elevated rate of oxygen consumption may lead to the production of various potentially toxic free radical intermediates, resulting in the activation of lipid peroxidation which compromises the barrier function of membrane structures (Palmer et al., 1963). Thirdly. phospholipase A2 might damage the sarcolemma (Jenkins, 1988). Lastly, exercise with high tension or high forces has been shown to give rise to an additional increased plasma enzyme activities suggesting a mechanical disruption of the sarcolemma (Clarkson et al., 1986). 
The pattern of muscle enzyme activity in plasma is not only determined by intracellular concentration, localization, molecular weight and degradation rate, but also by the type of exercise. A delayed appearance of muscle enzymes in the plasma has been found after eccentric exercise, in rats (Armstrong et al., 1983) as well as in humans (Clarkson et al. 1986; Newham et al, 1983a, 1986a). One possible reason for the dellay between exercise and change in membrane permeability is that the initial exercise causes minor damage to the muscle whilch is sufficient to initiate a chain of reactions which lead to the death of the fibres and release of soluble proteins (Aldridge et al, 1986). Therefore, Armstrong et al. (1983) speculated that the enzyme release immediately post-exercise and the delayed peaks could be attributed to structural damage and to an inflammatory response, respectively.

The peak values of plasma enzyme activities are assumed to be primarily determined by the amount of damage. It is assumed that the amount of damage is determined by the exercise intensity and duration (Tidius and lanuzzo, 1983). Also the type of exercise is a determining factor. Comparing different exercise regimens the greatest increases in plasma enzyme activities were found after eccentric exercise (Armstrong et al., 1983; Byrnes et al., 1985; Clarkson et al., 1986; Graves et al., 1984; Newham et al., 1983a, 1986a, b, 1987). There is no unanimity whother duration or intensity is most impontant for increases of plasma enzyme activities postexercise (for refs., see Hortobágyi and Denahan, 1989 and Noakes, 1987).

Plasma enzyme activity is not only determined by the type and amount of exercise but also by other factors. In animals as well as in human studies more enzyme release is found in males than in females (Amelink et al., 1988, 1990; Berg and Keul, 1981; Rogers et al., 1985; Shumate et al., 1979). Studies indicate that the difference is caused by sex hormones. Amelink and Bär (1986) and Bär et al. (1988) have shown that estrogens have a protective role on the sarcolemmal permeability, while androgens potentilate muscle enzyme release (Häkkinen and Alén, 1989). The exact mechanism, however, is yet unclear.

Not only gender but also raciall and environmental factors influence plasma enzyme activity. More enzyme release was found in black than in white people, at higher than at colder environmental temperature, and at higher altitudes compared with llower altitudes (Hortobági and Denahan, 1989; Noakes, 1987).

\section{The use of plasma enzyme activity for estimating the amount ol damage}

Analogous to the estimation of myocardial infarction size (Shell of al, 1973; Sobel et al., 1976, 1979; Willems et al, 1985), the amount of enzymes released in the plasma has been used to estimate the amount of exercise-induced muscle damage (Apple and Ahodes, 1988; Janssen et al., 1989). CK is considered to be a sensitive and reliable marker and is therefore frequently used. In addition, also carbonic anhydrase III (Väänänen et al., 1988) and myoglobin (Kagen et al.,1980; Driessen-Kletter et al., 1990) are considered to be reliable markers for muscle damage. A disadvantage of $\mathrm{CK}$ is that it is also present in other tissules, such as brain and heart (Jockers-Wretou and Pfleiderer, 1975; Tsung, 1976). After an extremely severe physical exercise there may be CK release from the skeletal muscullature as 
well as from the heart (Apple et al., 1984). However, CK can be subdivided into 3 different isoenzymes (Nanji, 1983). CK-MM, CK-BB and CK-MB were lound in skelletal muscle, brain and heart tissue, respectively. Because of specific localization in skeletal muscle CK-MM is proposed to be a better marker than total CK. Amelink et al. (1988) used the differentiation into the three isoenzymes to make clear that the sex related differences in CK release in rats after running on a treadmill could completely be attributed to CK-MM. Furthermore, CK-MM has been shown to exist in the plasma in three isoforms (Morelli et al., 1983; Perryman et al., 1984; Yasminen et al., 1981). CK-MM1 is the unmodified isoform that is released from the muscle tissue into the circulation. In the plasma CK-MM1 is converted via CK-MM2 (transition stage) in CK-MM3 (the modified isoform). Analysis of CK isoforms in serum following isometric exercise showed that CK-MM1 was an earlier indicator of skeletal muscle damage than total CK (Apple ot al., 1988; Clarkson et al., 1987a). However, based on a number of studies, it is suggested that discrepancies between the amount of exercise-induced muscle damage and enzyme release may occur (Garbus ot al., 1964; Highman and Altland, 1963; Papadopoulos et al., 1967). In addition, later studies suggest that the lower $C K$ release in females after a marathon is not associated with a lower amount of muscle damage (Janssen et al., 1989). Although CK measurements are used on large scale, little is known about the relationship between muscle damage and enzyme release.

\subsection{AIMS AND OUTLINE OF THE PRESENT STUDY}

From the previous overview it becomes clear that many questions about exercise-induced muscle damage remain to be solved. The purpose of the present study is to increase the knowledge of exercise-induced muscle damage and to obtain insight in the time course of initial damage and secondary changes with related features such as enzyme release, metabolic changes, force and stiffness. The specific objectives of the present study are:

- To develop an experimental animal model enabling muscle damage to be elicited in the rat tibialis anterior (TA) muscle in a controlled manner in situ. Muscle damagie was elicited with forced lengthening contractions (Chapter 2).

- To study the relationship between the initial TA muscle length, the range over which the muscle was lengthened and amount of primary damage (A-band and $Z$-line) and secondary changes (inllammation and infiltration). In addition, the type of primary damage was assessed (Chapter 3).

- To develop a method enabling muscle compliance to be measured in the rat TA muscle. In addition, to study the relationship between compliance, force and damage in TA muscles after forced lengthening and isometric exercise (Chapter 4).

- To study whether one bout of forced lengthening contractions compared with isometric exercise in the rat TA muscle has a protective effect against damage elicited by a second bout of forced lengthening contractions 3 weeks later and to investigate whether this effect, if any, is attributable to a peripheral or a central adjustment (Chapter 5). 
- To study the relationship between muscle damage and adenine and guanine nucleotides-, glycogen-, IMP contents and related compounds in rat TA muscle after forced lengthening and isometric exercise (Chapter 6).

- To study the relationship between exercise-induced secondary muscle changes and $C K, A S T$ and LD release in male and female rats that run uphill on a treadmill. In addition, to study gender related differences in secondary changes and enzyme release (Chapter 7).

- To study the effect of exercise duration on the amount of muscle damage, number of damaged fibres, length over which the muscle fibres are damaged and the spatial distribution of secondary changes in the soleus muscle in male and in female rats that run uphill on a treadmill (Chapter 8 ). 



\section{A forced lengthening exercise model for eliciting muscle damage in the rat tibialis anterior muscle}

\subsection{SUMMARY}

A description of an exercise apparatus is given by which it was possible to emplay forced lengthening contractions of the rat tibialis anterior (TA) muscle for eliciting muscle damage. In addition, a method to measure force of the TA muscle in situ is described. The TA muscle was tetanized via stimulation of the common peroneal nerve and at the same time forcibly lengthened by plantar flexion of the foot. Histological examination was done immediately and $48 \mathrm{~h}$ post-exercise. Isometric torque measurements were performed pre-, and $10 \mathrm{~min}$ and $48 \mathrm{~h}$ post-exercise. Forced lengthening resulted in primary damage and secondary changes in the TA muscle, which were absent in control experiments consisting of passive stretch, concentric exercise and non-exercise. In isometrically exercised muscles only minor primary damage and no secondary changes were found. Mainly type llA fibres were glycogen depleted immediately post-exercise and also showed secondary changes $48 \mathrm{~h}$ after forced lengthening. Isometric torque measurements of the foot showed that force of the TA muscle can be measured in a reproducible manner. A poor relationship between amount of primary damage and decrease in force was found. The same is true for the relationship between amount of secondary changes and decrease in force.

\subsection{INTRODUCTION}

To study factors that contribute to the elicilation of primary muscle damage, consisting of damage to the contractile elements, and secondary changes such as fibre degeneration and inflammation, a suitable model is required. It is well known that eccentric contractions are very potent to elicit muscle damage (for review, see Stauber, 1989). Several studies that focussed on studying exercise-induced muscle damage, employed eccentric exercise. For humans this included running downhill or stepping down (Newham et al., 1983a, 1986a, b), performing eccentric work on a cycle ergometer (Fridén et al.,1983a, b, 1984), or eccentric contractions with the arm- or leg muscles (Fridén et al., 1988, 1989; Newham et al., 1987).

Because of the risks involved, such as rhabdomyolysis (Milne, 1988) and because of the limitations on invasive and extensive experiments in humans, several investigators used animal models. A frequently used model in rodents is uphill or downhill running on a treadmill (Armstrong et al., 1983; Kasparek and Snider, 1985a, b: Kuipers et al., 1983; Ogilvie et al., 1988; Snyder et al., 1984), or running on wheels (Irintchev and Wernig, 1987). Some investigators developed an apparatus or a special tool to perform eccentric contractions in single muscles (Lieber and Fridén, 1988; McCully and Faulkner, 1985, 1986; Stauber et al., 1988). An advantage of 
these models is that one muscle can be exposed to an eccentric exercise protocol, while the contralateral muscle can serve as control. A possible disadvantage of these models is that often the muscle cannot be left in situ or the muscle has to be exposed to surgical interventions.

Faulkner and Jones (1985) developed a model in mice in which the foot was plantar flexed while activating the dorsiflexor muscles. This resulted in muscle damage in the tibialis anterior and extensor digitorum longus muscles (Faulkner et al., 1989). An important advantage of this model is that the muscles can be left in situ, enabling examination several days after forced lengthening contractions without surgical interventions. However, this model, as used by Faulkner and co-workers was developed for the use in mice. Application of this model is however limited because of the size of this species, making interventions like blood sampling and using single muscles for multiple purposes difficult. It was our intention to develop a modification of this model for the use in rats. In addition, it was our aim to include the possibility of applying not only forced lengthening, but also isometric or concentric contractions in the rat tibialis anterior (TA) muscle. Basically, the dorsiflexor muscles of the foot were tetanized via electrical stimulation of the common peroneal nerve, during which the foot was either plantar flexed, dorsi flexed, or fixed, resulting in lengthening, shortening or isometric contractions, respectively. The model should meet the following requirements:

- a minimum of surgical techniques should be involved

- the muscle should be left in situ without surgical manipulations, enabling changes, if any, to be studied at any time after stimulation

- the morphological and functional changes should be similar to those as reported in the literature

. the possibility to measure muscle force in situ

A description of the model and the results in connection with the above listed requirements are presented.

\subsection{EXERCISE APPARATUS AND EXERCISE PROTOCOLS}

\section{Exercise apparatus}

A schematic description of the exercise apparatus is given in Figure 2.1. The exercise apparatus consists of a footplate, in which the foot can be fixed. The size and shape of the foot plate can be adapted to the size of the foot. The footplate can freely move and allows flexion and extension of the ankle joint. The common peroneal nerve is stimulated electrically, activating the dorsiflexor muscles of the foot. When no external force is applied to the footplate, stimulation of the common peroneal nerve will result in a concentric contraction of the dorsiflexor muscles. Hence, fixating the footplate results in an isometric contraction, while applying external force inducing plantar flexion of the foot results in a forced lengthening contraction of the dorsiflexor muscles.

The force necessary for inducing forced lengthening contractions, is supplied by an electromagnet that is triggered to pull the footplate during activation of the 
dorsiffexor muscles. This evokes an average rotational velocity in the ankle joint of $450^{\circ} \cdot \mathrm{s}^{-1}$. Based on separate determinations of the sarcomere length at different angles of the ankle joint (Chapter 3 ), the lengthening per sarcomere was calculated to be on the average of $2 \mu \mathrm{m} . \mathrm{s}^{-1}$. A spring balance pulls the foot in the original position, before starting a new forced lengthening contraction.

During the experiment the anaesthetized animal is laying on the back. Two blocks placed at either side of the body inhibit lateral movement. The knee of the experimental leg is fixed by two adjustable pins and the foot is strapped and fixed in the foot plate.

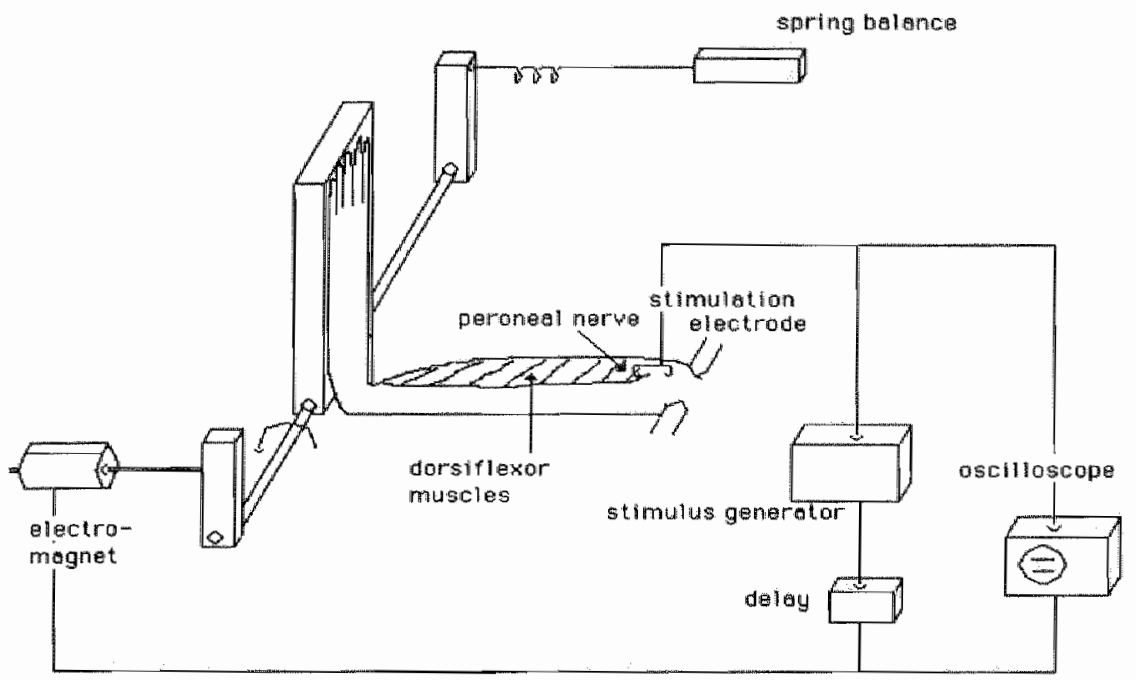

Figure 2.1. Schematic description of the exercise apparatus and electric equipment. For details, seo text.

\section{Electrical equipment and stimulation electrode}

With a stimulus generator (Grass SD 9, Grass Instruments, Quiney, MA) an electrical current can be applied to the common peroneal nerve via the electrode. Length, duration and frequency of the electrical pulses can be adjusted. The stimulus generator also activates the electromagnet via a microswitch. Delay and duration of activation of the electromagnet can also be adjusted. Both signals, the pulse train going to the stimulation electrode and the pulse train going to the electromagnet were displayed on an oscilloscope (Philips, Figure 2.1). 
The stimulation electrode consists of two coated wires (stainless steel, diameter $0.3 \mathrm{~mm}$. Al both tips of the electrode the coating is removed betore use. The tip with the negative charge is hooked to the exposed peroneal nerve, while the positive electrode is fixed to the overlying skin.

\section{Animals}

For the present study 66 male Wistar rats (weight 350-380 g) were used. Before the experiments they were housed in groups of up to 4 rats in a temperature controlled environment $\left(23-26^{\circ} \mathrm{C}\right)$. After the experiments the rats were housed separately, unless they were sacrificed immediately post-exercise. The animals had tree access to standard lab food (type 1210, Hope Farms, The Netherlands) and water. The light was on between $7.30 \mathrm{a} . \mathrm{m}$. and $7: 30 \mathrm{p} . \mathrm{m}$. The experiments were done between 9:00 a.m. and 17:00 p.m. The right hindlimb muscle of each animal was randomly assigned to one of the experimental groups: forced lengthening $(n=12)$, passive stretch ( $n=12)$, concentric exercise $(n=12)$, isometric exercise $(n=12)$ or nonexercise $(n=12)$. The contralateral muscles served as non-exercised control. Half of the animals of each group was used for studying primary damage, the other half was used for studying secondary changes. In a separate experiment the right hindlimb muscles $(n=6)$ were subjected to isometric contractions after which the TA muscles were processed for fibre lyping combined with glycogen depletion. The contralateral muscles served as non-exercised control.

\section{Surgical procedure and exercise protocols}

The animals were anaesthetized with ether. Via a $1.5 \mathrm{~cm}$ incision in the skin just beneath the knee the common peroneal nerve was exposed, using an operating microscope (Zeiss). Special care was taken to prevent damage to the peroneal nerve. Next, the uncoated tip of one wire of the electrode was hooked to the peroneal nerve, while the other tip was fixed to the skin. Subsequently, the animals were placed in the exercise apparatus.

The muscles were stimulated at $90 \mathrm{~Hz}$ for a duration of $400 \mathrm{~ms}$ once every 3 s. When forcibly lengthened no external force was applied to the footplate during the first 200 ms of stimulation enabling adequate contraction of the muscles. Thereafter the muscles were lengthened. Each contraction stanted at an angle of the ankle joint at $80^{\circ}$ and ended at $130^{\circ}$. Based on studies of McCully and Faulkner $(1985,1986)$ a standard protocol of 300 forced lengthening contractions was chosen in which five 3 minutes stimulation sessions were separated by 5 minutes recovery intervals. After the exercise protocol the animals were taken out of the apparatus. Bothelectrodetips were carefully removed. The subcutaneous connective tissue and the skin were sutured (Medicon).

In separate control axperiments the dorsiflexor muscles were either passively stretched, concentrically exercised, isometrically exercised or non-exercised. To exclude primary damage as the result of the dissection-, fixation w or cutting procedures, also non-stimulated muscles were investigated. 


\section{Histology and histochemistry}

To study the primary muscle damage immediately post-exercise the TA muscles were dissected out. Therefore, a catheter was inserted into the aorta and the limbs were maintained in a fixed position with a standard angle of the ankle joint of $100^{\circ}$. The limbs were flushed with $20 \mathrm{ml}$ saline and subsequently fixed with $30 \mathrm{ml}$ buffered formaldehyde $(100 \mathrm{ml}$ formaldehyde $(37-40 \%)$ in $900 \mathrm{ml}$ aqua bidest, $4 \mathrm{~g}$ sodium dihydrogen orthophosphate, $6.5 \mathrm{~g}$ di-sodium hydrogen orthophosphate, $\mathrm{pH}=7$ ) and completely dissected out. Twenty-four hours later the TA muscles were dehydrated and embedded in technovit 7100 (Kulzer). Three $\mu \mathrm{m}$ thick longitudinal sections were cut (Anglia Scientific) and stained according to Gomori (Gomori, 1950).

To study the secondary changes, TA and extensor digitorum longus muscles were dissected out $48 \mathrm{~h}$ post-exercise (except non-exercised muscles) and divided into 2 parts and subsequently frozen in isopentane that was cooled to melting point in liquid $\mathrm{N}_{2}$. Ten $\mu \mathrm{m}$ thick cross sections were cut (Anglia Scientific) and stained with haematoxylin-eosin (Romeis, 1968). For studying the fibre types that were affected cross sections were ATP-ase stained (Padykula and Herman, 1955) and compared with subsequent haematoxylin-eosin stained cross sections. For studying the glycogen depletion immediately after electrical stimulation cross sections of dorsiflexar muscles were taken and stained with PAS (Dubowitz and Broake, 1973).

\section{Force measurements}

To study the effect of exercise on the contractile properties in the dorsiflexor muscles the isometric torque of the foot was measured by a force transducer. This was done pre-, and $10 \mathrm{~min}$ and $48 \mathrm{~h}$ after forced lengthening as well as after isometric exercise in duplicate. After disconnecting the electromagnet, a force transducer (Grass FTO3C, Grass Instruments, Quiney, MA) was connected between the foot plate and a recording apparatus (Schwarzer DME 47). The angle of the ankle joint was maintained at $90^{\circ}$. The dorsiflexor muscles were stimulated via the peroneal nerve at $90 \mathrm{~Hz}$ for a duration of $400 \mathrm{~ms}$. Because of leakage of current to the posteriorly located muscles in the hindlimb at higher voltages, which did resuit in activation of antagonistic muscles, isometric torque was always measured submaximal at $3 \mathrm{~V}$. In a separate experiment in which the agonistic contribution of the extensor digitorum longus and peroneal muscles was excluded by cutting the distal ligaments of both muscles, the contribution of the TA muscle to the torque measurements was assessed.

\subsection{RESULTS AND DISCUSSION}

\section{Histological changes}

With the present model it was possible to have the dorsiflexor muscles of the foot contract by forced lengthening, concentrically or isometrically and the procedure involved a minimum of surgical interventions. Within a few hours post-exercise the rats moved normally in their cages indicating that the procedure did not interfere with normal locomotion. 

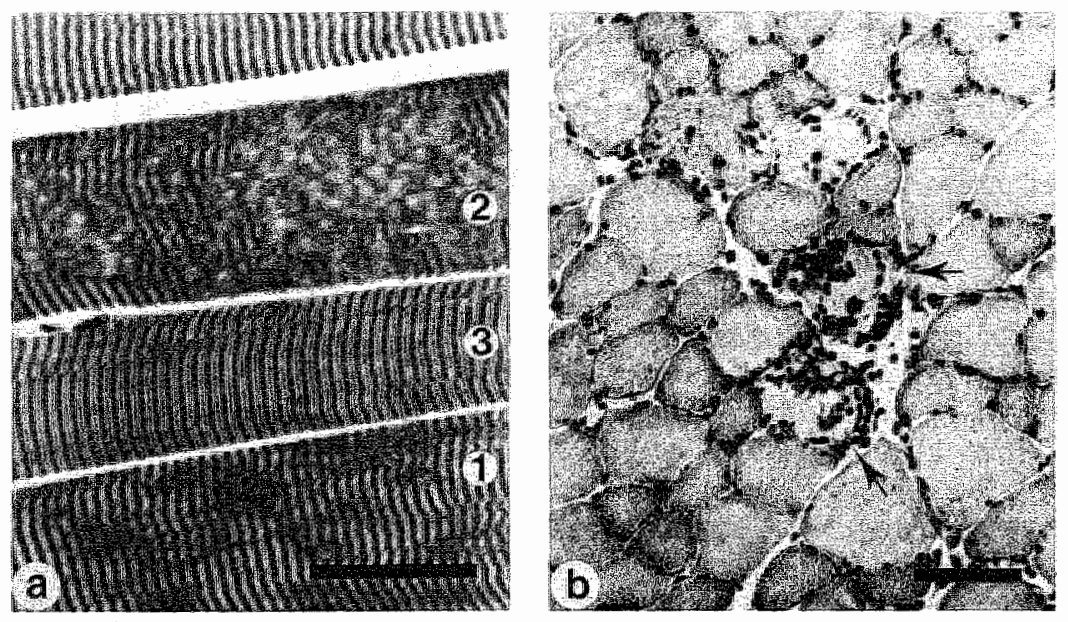

FIGUAE 2.2. a) Longitudinal section stained according to Gomori (bar $=25 \mu \mathrm{m}$ ); (1) fibre showing focal A-band and Z-line damage, (2) fibre showing extensive disturbances of A-bands and Z-lines, (3) fibre with wirtually no damage; b) Haematoxylin-eosin stained cross section of TA muscle (bar $=50 \mu \mathrm{m}$ ); fibres infiltrated by macrophages (arrows) surrounded by normal muscle fibres.

Microscopical examination showed that histological damage consisting of both primary damage and secondary changes were present in the TA muscles immediately and $48 \mathrm{~h}$ after forced lengthening of the dorsiflexor muscles, respectively. In the extensor digitorum longus musicles secondary changes were seldom found and it was therefore excluded from further analysis.

Primary damage as well as secondary changes were distributed throughout the whole TA muscle. The primary damage consisted of streaming, broadening and extension of A-bands and Z-lines, as described by Fridén et al. (1983b) and Ogilvie et al. (1988). See Figure 2.2a. The secondary changes consisted mainly of muscle fibres infiltrated by lymphocyles and leukocyles, and muscle fibres with wacuoles, hyaline aspect and central nuclei (Armstrong ot al., 1983; Kuipers at al., 1983). See Figure 2.2b. Primary damage and secondary changes were absent in non-exercised control muscles. In muscles that were isometrically exercised some occasional spots with signs of minor primary damage, but no secondary changes were found. Passive stretch and concentric contractions did not result in any primary damage or secondary changes. Therefore, it is concluded that the TA muscles had to be forcibly lengthened for eliciting both types of muscle damage. In addition, primary damage is not elicited by dissection, fixation or cutting procedures. The observation that not all, but a smaller group of muscle fibres was affected is probably determined by the current that was used to stimulate the TA muscles. 


\section{Characteristics of the TA muscle}

The architecture of the TAmuscle is unipennate (Garrett et al., 1988). ATP-ase staining of cross sections in TA muscles $(n=2)$ showed that the muscle consisted mainly of type $\| \mathrm{A}(28.4 \pm 0.8 \%$, mean $\pm \mathrm{SD})$ and type $\| \mathrm{B}(70.7 \pm 0.4 \%)$ fibres, which is in agreement with the findings of Armstrong and Phelps (1984). Type I fibres formed the minority $(1.75 \pm 0.2 \%)$. Therefore, the TA muscle can be characterized as a fast-twitch muscle. The anterior part of the muscles consisted mainly of type IIB fibres, the mid and posterior part consisted both of type llA and IIB fibres. Type I fibres were only found in the posterior part of the muscle.

\section{Fibre type, muscle damage and glycogen depletion in TA muscles}

The combination of haematoxylin-eosin and ATP-ase staining in subsequent cross sections in TA muscles $(n=2)$ revealed that it were primarily the type llA fibres that showed secondary changes. Of all fibres that were affected, $74.9 \pm 4.7 \%$ (mean $\pm S D$ ) belonged to type IIA and $25.0 \pm 4.7 \%$ belonged to type IIB. Damaged type I fibres were not found. This is not in agreement with the report of Lieber and Friden (1988), who showed that the type IIB fibres were selectively damaged in rabbit TA muscles after forced lengthening.

It is unknown whether primary damage was specifically restricted to type llA fibres, or that it is also found in type IIB and type I tibres. In contrast with secondary changes that can easily be seen by histological examination in frozen cross sections, primary damage cannot reliabily be assessed in frozen sections. Unfortunately, it is technically impossible to assess both primary damage by histological methods and fibre typing by histochemistry in longitudinal sections of fibres that are fixed with formaldehyde.

PAS staining of cross sections revealed that type ilA fibres were selectively glycogen depleted. Therefore, it is suggested that mainly type ilA fibres were recruited in the exercise protocol, as used in the present study. It is this fibre type that also showed secondary changes most extensively.

\section{Force measurements}

Repeatedisometric torque measurements of non-exercised dorsiflexor muscles of the foot revealed that it was possible to measure muscle force in a reproducible way. The covariance between repeated measurements within the same animals was $3.73 \%$. Separate experiments in which the contribution of the extensor digitorum longus and peroneal muscles to dorsi flexion was excluded showed that the isometric torque of the foot, when the angle of the ankle joint was maintained at $90^{\circ}$ could almost completely be attributed to the TA muscles (Figure 2.3).

A correlation coefficient of $0.54(p \leq 0.005)$ between amount of primary damage in the TA muscles and decrease of isometric torque of the dorsillexor muscles was found. The correlation coefficient between amount of secondary changes and decrease in isometric torque was $0.32(p \leq 0.0018)$. It suggests that the amount of primary damage and secondary changes is not clearly reflected in a decrease in muscle force. 


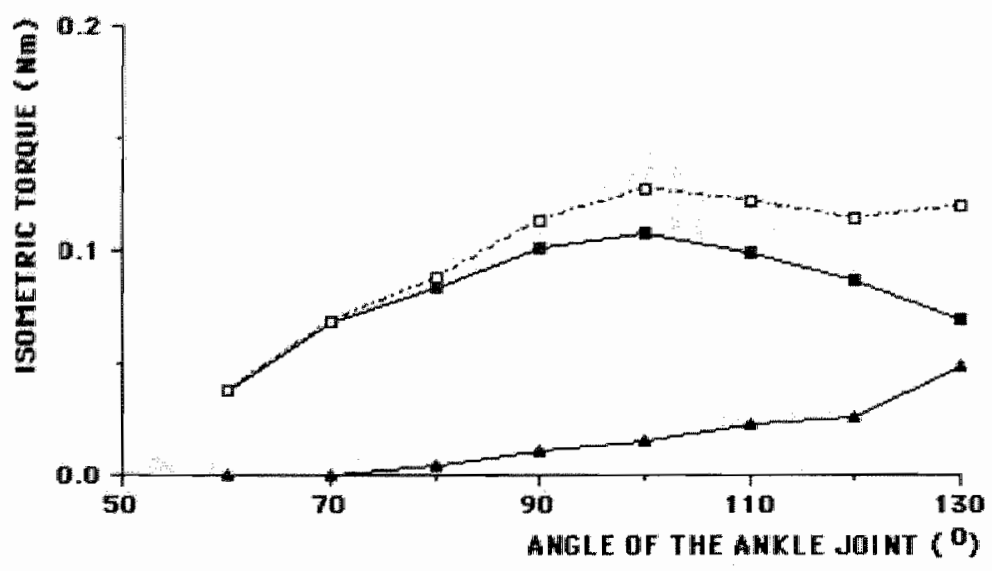

Figure 2.3. Isometric torque of tibialis anterior muscle ( $\mathbf{D}$ ), extensor digirum longus and peroneal muscles ( $\mathbf{A}$ ) and all three dorsiffexor muscles together ( $\square$ ) at different angles of the ankle joint.

\subsection{CONCLUSIONS}

1. It was possible to elicit primary damage and secondary changes in the TA muscles by forced lengthening. In experiments consisting of passive stretch and concentric contractions no damage was found. In isometrically exercised muscles only a minimal amount of primary damage was found. Dissection-, fixation- and cutting procedures did not cause any primary damage, neither was it seen in nonexercised muscles. Therefore, isometric exercise, concentric exercise and passive stretch can be used as control experiments.

In addition, the following requirements are fulfilled:

- a minimum of surgical techniques are involved

- the muscles are left in situ without surgical manipulations

- histological changes can be studied over a longer period of time

2. Isometric torque measurements of the dorsiflexor muscles of the toot showed that the muscle force can be measured in a reproducible way. With an ankle joint of $90^{\circ}$ only the muscle force of the TA muscle is measured. The results indicate a poor relationship between amount of primary damage and secondary changes on one hand and a decrease in muscle force on the other hand. 


\section{Relationship between muscle length and muscle dam- age with forced lengthening contractions in the rat tibialis anterior muscle}

\section{1 SUMMARY}

The aim of the present study was to investigate the type and amount of primary muscle damage ( $Z$-line and A-band lesions) and secondary changes (inflammation and degeneration) after forced lengthening of the rat tibialis anterior (TA) muscle at different lengths. Therefore, the relationship between muscle length, isometric force of the dorsiflexor muscle and angle of the ankle joint was studied. TA muscles in inale Wistar rats were lengthened while tetanizing the muscle via the common peroneal nerve. The initial angle of the ankle joint and the range of dorsi flexion was varied between 4 groups of rats: $50-80^{\circ}, 70-115^{\circ}, 90-145^{\circ}$ and $120-150^{\circ}$. Control experiments consisted of isometric exercise, passive stretch and non-exercise. To quantify primary damage in longitudinal sections and secondary changes in cross sections the muscles were dissected out immediately after and $48 \mathrm{~h}$ post-exercise, respectively. Muscle damage was quantified by means of point counting with a grid. Forced lengthening elicited primary damage consisting of both Z-line and A-band lesions, which was most extensive in the $70-115^{\circ}, 90-145^{\circ}$ and $120-150^{\circ}$ ranges. Secondary changes were only observed after forced lengthening, most extensively in muscles that were forcibly lengthened in the ranges of $70-115^{\circ}$ and $90-145^{\circ}$. In isometrically exercised muscles only a minor amount of primary damage and no secondary changes were found. No relation was found between sarcomere lengths during forced lengthening and type of primary damage.

\subsection{INTRODUCTION}

It is well recognized that eccentric muscle contractions are a potent way to elicit muscle damage (Armstrong et al., 1983; Fridén et al.. 1981, 1983b; McCully and Faulkner, 1985; Ogilvie et al., 1988). Since it has been demonstrated that with eccentric contractions a lower number of motor units is recruited (Stauber, 1989), it is assumed that the damage is of mechanical origin. This is supported by the work of McCully and Faulkner (1986) who demonstrated that during lengthening contractions the farce generated as well as the velocity of lengthening are related to the exient of structural damage. Another finding in favour of the importance of mechanical overload is that the primary exercise-induced damage consists of damage to the contractile elements (Fridén et al., 1981, 1983b).

Fridén and co-workers $(1981,1983 \mathrm{~b})$ studied the ultrastructure of human skeletal muscle after eccentric exercise and found that the structural damage 
between $8.5-12 \mathrm{~mm}^{2}$ was scanned. The damage was expressed as number of lesions per $\mathrm{mm}^{2}$. To assess the type of lesions, in each square the type of damage was determined, according to Ogilvie et al. (1988).

Along the longitudinal plane individual damaged muscle fibres were further investigated by electron microscopy. Large semi-thin (1 $\mu \mathrm{m})$ sections with muscle fibres cut longitudinally were stained with $1 \%$ toluidine blue for pre-screening with a light microscope. Affected areas were selected for ultrastructural analysis on thin sections. These sections were obtained with a glass knife using a microtome (Ultracut, Reichert-Jung, Austria). Sections showing a sillver gray interference color were collected on a 75 mesh copper grid with formvar supporting fillm and subsequently stained with uranyl acetate ( $7 \%$ w/v in aq dest; $10 \mathrm{~min})$ and basic lead citrate (5 min). Micrographs were taken with a Philips EM400 electron microscope.

\section{Assessing secondary changes}

For this purpose, the TA muscles were dissected out $48 \mathrm{~h}$ post-exercise and divided into two parts. Both parts were frozen in isopentane cooled to melting point in liquid $\mathrm{N}_{2}$. From both parts $10 \mu \mathrm{m}$ thick sections were cut in a cryostat (Anglia Sclientific) at $-20^{\circ} \mathrm{C}$. Each 20th section was mounted on glass and stained with haematoxylin-eosin. Muscle fibres were considered to be affected when one of the following features was observed: fibres infiltrated by inflammatory cells, vacuoles in the cyloplasm, hyaline aspect and fibres with multiple central nuclei.

The extent of muscle changes was assessed microscopically (Zeiss) at a magnification of $100 \mathrm{x}$ in four representative cross sections: two cross sections in the proximal part and two cross sections in the distal part of the muscle. In each part of the muscle the total number of mounted cross sections was counted. For example, in case 30 cross sections were mounted, the numbers 10 and 20 were taken as representative for that part of the muscle.

The quantification was done by one person who was ignorant of the exercise protocol and was based on a method as described by Weibel (1979). By point counting each individual changed muscle fibre was scored in a grid that was moved through the selected cross sections. Care was taken that after counting, the grid was moved far enough to prevent overlap between consecutive areas. Since the grid represented a constant area $\left(0.86 \mathrm{~mm}^{2}\right)$ the total number of changed muscle fibres was divided by the number of grids that could be placed in the four sections. Of each muscle that was siudied the mean number of muscle fibres per grid was counted. The $\%$ of affected fibres was calculated by dividing the number of affected fibres by the total number of tibres.

\section{Force measurements}

Before-, during-and 10 minpost-exercise the isometric torque of the dorsiflexor muscles was measured to be able to compare iorce generation in muscles subjected to forced lengthening in the ranges of $50-80^{\circ}, 90-145^{\circ}, 120-150^{\circ}$ as well as in the isometrically exercised muscles. For a detailed description, see Chapter 2. 


\section{Statistics}

The Kruskal-Wallis test was used to compare primary damage and secondary changes between muscles which were forcibly lengthened over different ranges, respectively. The analysis of variance (Anova) was used to compare isometric torque measurements between different exercise protocols. The level of significance was set at $p<0.05$.

\subsection{RESULTS}

In Figure 3.1 the relationship between sarcomere length, isometric torque of the TA muscle and the angle of the ankle joint is given. With an increase of the angle the sarcomere length increased, although the relationship is not linear. The isometric torque as a function of ankle joint angle and sarcomere length shows a curvilinear relationship with an optimum force occurring at an ankle joint angle of approximately $100^{\circ}$.

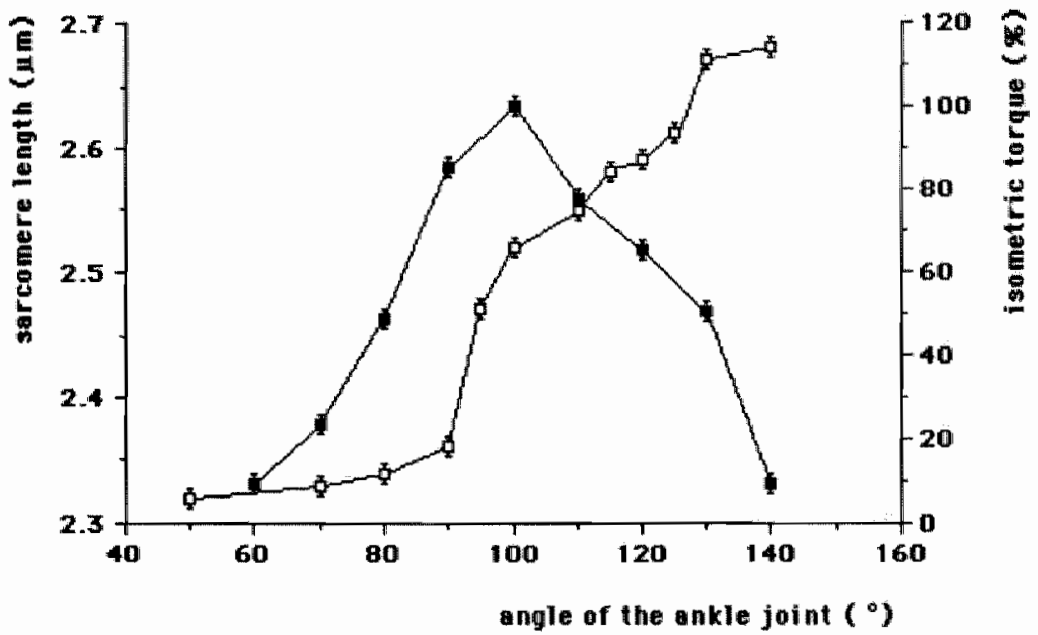

FIGURE 3.1. The relationship between the sarcomere length ( $\square$ ), the isometric torque ( ) and the angle of the ankle joint. The maximal isometric torque as found at $100^{\circ}$ of the ankle joint was set at $100 \%$ (mean $\pm S D$ ), all other values are related to this value.

Table 3.1 shows the amount of primary damage after different exercise regimens. Compared with the passivelly stretched TA muscles and non-exercised control muscles in which no primary damage was found, a significant amount of primary damage was found in the forcibly lengthened TA muscles as well as in the isometrically exercised muscles. In muscles that were forcibly lengthened over the ranges of $70-115^{\circ}, 90-145^{\circ}$, and $120-150^{\circ}$ the amount of primary muscle damage was significantly higher than in isometrically exercised muscles and in muscles that were forcibly lengthened in the range of $50-80^{\circ}$. Microscopical analysis showed that 
TABLE 3.1. The amount of primary damage (mean I SEM) in longitudinal sections of TA muscles that were subjected to different exercise regimens (including non-exercise). Damage is expressed as number of lesions per mm2 (for further details, see Material and Methods).

$p<0.05$ compared with passively stretched and control TA muscles; $t p<0.05$ compared with forced lengthening in the range of $50-80^{\circ}$ and isometric exercise.

\begin{tabular}{|c|c|c|}
\hline $\begin{array}{l}\text { range of plantar } \\
\text { llexion ( ) }\end{array}$ & $\begin{array}{l}\text { number of } \\
\text { TA muscies }\end{array}$ & $\begin{array}{l}\text { primary muscle } \\
\text { damage }\end{array}$ \\
\hline $50-80$ & $n=6$ & $1.19+0.46^{*}$ \\
\hline $70-115$ & $n=6$ & $7.28 \pm 1.75^{\circ}+$ \\
\hline $90-145$ & $n=8$ & $9.55 \pm 2.12^{*}+$ \\
\hline $120-150$ & $m=6$ & $8.28+1.85 *$ \\
\hline 90 & & \\
\hline (isometric) & $n=7$ & $1.21 \pm 0.37$ \\
\hline $90-145$ & & \\
\hline (passively stretched) & $n=6$ & 0 \\
\hline control & $n=6$ & 0 \\
\hline
\end{tabular}

TABLE 3.2. Characteristics of primary damage in TA muscles in relation to different exercise regimens and in non-exercised controls. Values are expressed as mean \pm SEM.

\begin{tabular}{llll}
$\begin{array}{l}\text { range of plantar } \\
\text { flexion ( })\end{array}$ & $\begin{array}{l}\text { A-band } \\
\text { damage } \\
(\%)\end{array}$ & $\begin{array}{l}\text { Z-line } \\
\text { damage } \\
(\%)\end{array}$ & $\begin{array}{l}\text { A-band and } \\
\text { Z-line damage } \\
(\%)\end{array}$ \\
\hline $\begin{array}{l}50.80 \\
n=6\end{array}$ & $0.2 \pm 0.5$ & $0.2 \pm 0.5$ & $99.5 \pm 1.0$ \\
$\begin{array}{l}60-115 \\
n=6\end{array}$ & $0.2 \pm 0.3$ & $31.3 \pm 17.1$ & $68.3 \pm 17.0$ \\
$\begin{array}{l}90-145 \\
n=8\end{array}$ & $0.3 \pm 0.2$ & $1.6 \pm 0.4$ & $98.1 \pm 0.5$ \\
$\begin{array}{l}120-150 \\
n=6\end{array}$ & $0.5 \pm 1.5$ & $15.7 \pm 13.7$ & $83.7 \pm 14.9$ \\
$\begin{array}{l}90 \text { (isometric) } \\
n=7 \\
\text { control muscles }\end{array}$ & 0 & $0.3 \pm 0.3$ & $99.6 \pm 0.3$ \\
$n=6$ & 0 & 0 & 0
\end{tabular}



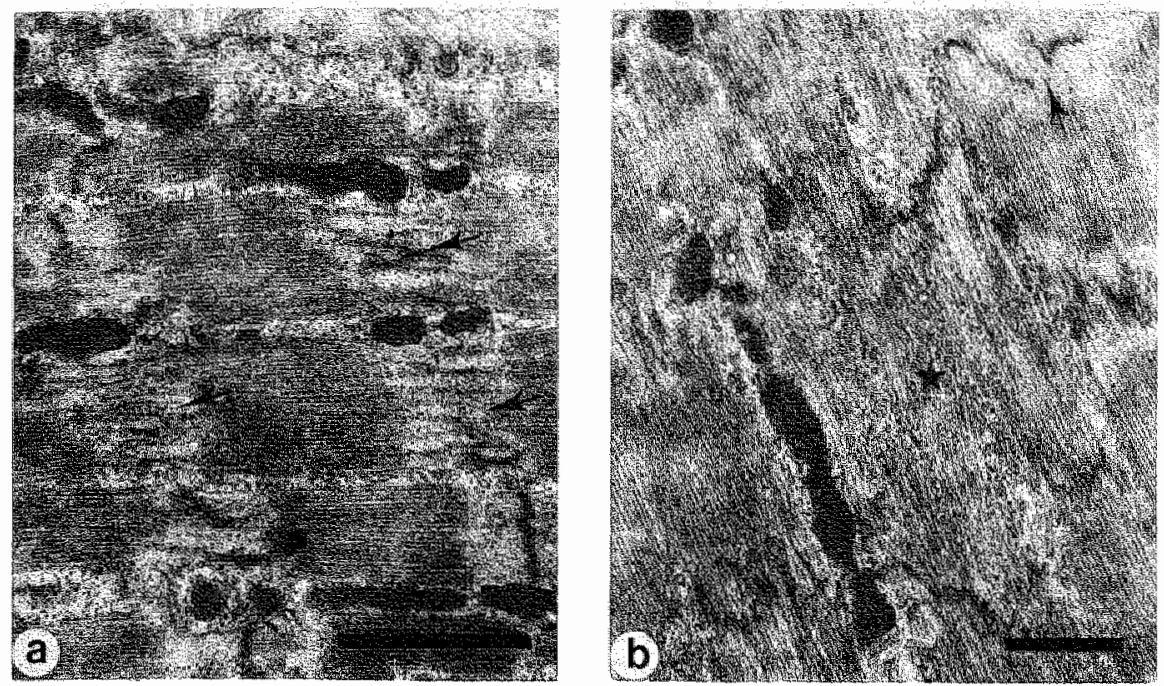

FIGURE 3.2. Electron micrographs of the TA muscle. (a) Z-line streaming (arrows),

(b) A-band extension ( $\star$ ) and Z-line disuption (arrow). Bar=1 $\mu \mathrm{m}$.

in $68-99 \%$ no differentiation betweren A-band and Z-line lesions could be made (Table 3.2). Not all muscle fibres showed primary lesions. Fibres with primary damage could be found adjacent to fibres without any damage. In Figure 3.2 two examples of a micrograph are given, demonstrating A-band and Z-line damage in TA muscle that was forcibly lengthened.

Table 3.3 shows the amount of secondary changes after different exercise regimens. Irrespective of the range over which lengthening took place, forced lengthening resulted in a significant increase in secondary changes compared with passively stretched, isometrically exercised and non-exercised control muscles. A significant increase in secondary changes was found when the TA muscles were forcibly lengthened in the range of $70-115^{\circ}, 90-145^{\circ}$, and $120-150^{\circ}$, compared with $50-80^{\circ}$. The amount of secondary changes was significantly increased when the muscles were forcibly lengthened between $70-115^{\circ}$ and $90-145^{\circ}$ compared with 120 . $150^{\circ}$. The changes consisted of muscle fibres infiltrated by inflammatory cells. Changes were found over the entire muscle length and not specifically in proximal or distal part parts of the muscle. In the cross sectional plane the affected fibres were primarily located in the anterior and in the centre regions of the muscles.

Figure 3.3 shows the isometric torque of dorsiflexor muscles of the foot during different exercise regimens. TA muscles that were forcibly lengthened in the ranges of $90-145^{\circ}$ and $120-150^{\circ}$ showed a significant decrease in isometric torque compared with pre-exercise values. In the TA muscles that were forcibly lengthened in the range of $50-80^{\circ}$, and in muscles that were isometrically exercised, no significant decrease in isometric torque was found. The decrease in isometric torque in muscles 
TABLE 3.3. The amount of secondary muscle damage (mean $\pm S E M$ ) in cross sections of TA muscles that were subjected to different exercise regimens (including non-exercise). Damage is expressed as \% muscle fibres that is damaged (for further details, see Material and Methods): " $p<0.05$ compared with isometric, passively stretched and control TA muscles; $t p<0.05$ compared with forced lengthening in the range of 50 $80^{\circ}$ and $120-150^{\circ}$.

\begin{tabular}{lll}
$\begin{array}{l}\text { range of plantar } \\
\text { flexion }\left({ }^{\circ}\right)\end{array}$ & $\begin{array}{l}\text { number of } \\
\text { TA muscles }\end{array}$ & $\begin{array}{l}\text { secondary muscle } \\
\text { changes }\end{array}$ \\
\hline
\end{tabular}

$\begin{array}{lll}50-80 & n=6 & 0.05 \pm 0.02 * \\ 70-115 & n=7 & 4.92 \pm 1.54 \cdots \dagger \\ 90-145 & n=10 & 3.68 \pm 1.32 * \dagger \\ 120-150 & n=6 & 0.87 \pm 0.17 * \\ 90 \text { (isometric) } & n=6 & 0 \\ 90-145 \text { (passively stretched) } & n=6 & 0 \\ \text { control } & n=6 & 0\end{array}$

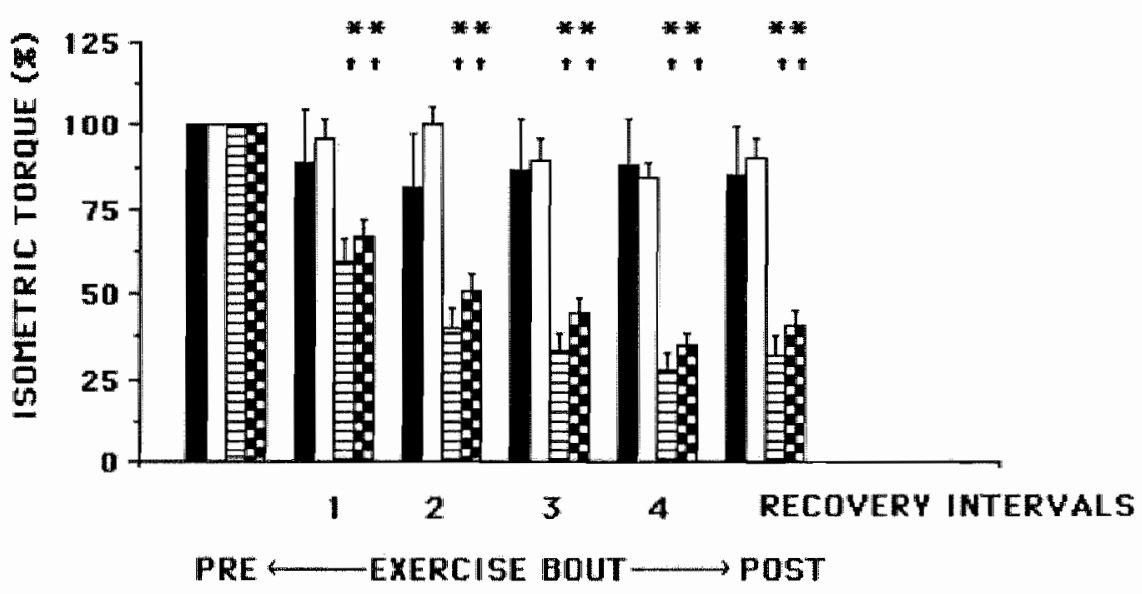

FIGURE 3.3. Isometric torque (mean \pm SEM) of dorsiflexor muscles of the foot before and during forced lengthening at different muscle lengths and in isometrically exercised muscles. Pre-exercise values are set at 100\%.

isometric exercise

$\square$ forced lengthening between $50-80^{\circ}$ or the ankle joint

- forced lengthening between $90-145^{\circ}$ of the ankle joint

a forced lengthening between $120-150^{\circ}$ of the ankle joint

" $p<0.05$ compared with pre-exercise values; $t p<0.05$ forced lengthening between $90-145^{\circ}$ and $120-150^{\circ}$ compared with forced lengthening between 50 $80^{\circ}$ and isometric exercise. 
that were forcibly lengthened in the ranges of $90-145^{\circ}$ and $120-150^{\circ}$ was significantly greater than in muscles that were either forcibly lengthened between $50-80^{\circ}$ or isometrically exercised.

\subsection{DISCUSSION}

The main aim of the present study was to investigate the type and amount of primary damage and secondary changes atter forced lengthening of the rat tibialis anterior (TA) muscle at different muscle lengths. The sarcomere length was not determined directly, but was measured in muscles that were fixed in situ with different angles of the ankle joint. The non-linear increase in sarcomere length as a function of the angle of the ankle joint can be explained by its anatomy. The tendon of the TA muscle makes a curve and attaches into the metatarsal area. Because the momentum changes with smaller angles of the ankle joint, the shortening of the TA muscle is not linearly related with changes in ankle joint. The sarcomere lengths as found in the present study are greater than usually found (Podlolsky and Schoenberg, 1983). It should be realized, however, that the sarcomere length was assessed in inactive muscies that were fixed in situ. Usually the relationship between sarcomere length and force is assessed in active muscles. However, for technical reasons this was not possible in the present study. Based on the general relationship between force and sarcomere length maximal force is expected at sarcomere lengths between 2.0 and $2.25 \mu \mathrm{m}$ (Podolsky and Schoenberg, 1983). In Figure 3.1 the sarcomere length at maximal force is approximately $2.6 \mu \mathrm{m}$. Subtracting approximately $0.4 \mu \mathrm{m}$ from all values as presented in Figure 3.1 would yield sarcomere lengths that are close to these as expected during activation. The variability of the sarcomere length throughout the whole TA muscle was negligible and was within $0.05 \mu \mathrm{m}$. This suggests that the relationship between sarcomere length and angle of the ankle joint is similar in all muscle fibres.

Forced lengthening over different ranges of motion of the ankle joint was effective in eliciting primary muscle damage. In non-exercised and passively stretched muscles no damage was lound, which demonstrates the necessity to activate the muscle when lengthening. Although primary muscle dlamage was anticipated after forced lengthening (Fridén et al., 1981, 1983b; Ogilvie et al., 1988), the present study also revealed a minor amount of primary damage in isometrically exercised muscles. This suggests that the strain put on the contractile elements, with only a small shortening of the sarcomeres, is able to elicit some minar primary damage. McCully and Faulkner (1985) showed in a similar modell that high tension levels were elicited during isometric exercise as well, although not as high as during forced lengthening. This may explain why in the isometrically exercised muscles of the present study some primary damage was found. This is in agreement with a number of studies of Clarkson et al. $(1985,1986,1987 \mathrm{a})$, in which enzyme release after isometric exercise was suggestive of muscle damage.

Forced lengthening contractions, performed in the range where maximal force can be generated revealed significantly more primary damage than in TA muscles 
that were isometrically exercised or forcibly lengthened at a short length. Based on the relationship between sarcomere length and angle of the ankle joint (Figure 3.1). the change in sarcomere length was smaller in the range of $50-80^{\circ}$, compared with the other ranges. McCully and Faulkner (1986) reported data emphasizing also the importance of the velocity of forced lengthening for eliciting damage. They hypothesized that the damage in eccentric exercise is related to cross-bridge cycling. It is assumed that at low lengthening speeds no damage occurs since the cross-bridge cycling can keep pace with the change in length.

The primary damage consisted mainly of both A-band and Z-line damage, and only in a minority of cases a distinction between A-band and Z-line lesions could be made. In addition, a relationship between the type of primary damage and the sarcomere length was absent. The findings of Fridén et al. (1981, 1983b) and Ogilvie ot al. (1988) that one specific part of the contractile element, i.e., Z-line and A-band, respectively, is damaged could not be confirmed in the present study. From the data of this study it was not possible to indicate one specitic spot of the sarcomere as the origin of damage and hence as the weakest link. Another difference was that in this study fibres were affected over the entire length or over a substantial length of the fibre, while the damage that Friden et al. (1981; 1983b) and Ogilvie et al. (1988) observed was more focal, i.e., damage was restricted to a few Z-lines or A-bands. Possibly the intensity of exercise is responsible for this difference.

Studying the effect of exercise on the amount of secondary changes, it was found that all forced lengthening protocols elicited secondary changes. In isometrically exercised and in passively stretched muscles no secondary changes were found which confirms a finding of McCully and Faulkner (1985). In generall, it is assumed that a relationship exists between the amount of primary damage and the subsequent extent of secondary changes. However, sometimes a discrepancy is found between the amount of primary damage and the amount of secondary changes. In isometrically exercised muscles only a minor amount of primary damage was found immediately post-exercise, while no secondary changes were found 48 h past-exercise in any muscle fibre. A greater difference between the amount of primary damage and secondary changes was found in muscles that were forcibly longthonod at long muscle longth (Table 3. 1 aind 3.31. A significant amoum of primary damage was not followed by an increase in secondary changes. Possibly the muscle fibre is able to repair a minor amount of primary damage and it is assumed that a certain limit in amount has to be exceeded before secondary changes will occur.

Force generation can be related to the histological findings, i.e., in isometrically exercised and in forcibly lengthened muscles at short lengths no decrease in muscle force was found, the amount of damage being also minimal. Muscles that were forcibly lengthened between $90^{\circ}$ and $145^{\circ}$ or between $120^{\circ}$ and $150^{\circ}$ showed a higher amount of histological damage accompanied with a stronger decrease in muscle force. The finding that more primary damage and a greater decrease of muscle force was found at greater compared with shorter muscle lengths, corroborates studies of Jones et al. (1989) and Newham et al. (1988). They reported that more damage, as indicated by a greater loss of muscle force, did also occur at long muscle 
lengths compared with short muscle lengths.

In summary, forced lengthening contractions using different muscle lengths do elicit primary damage, which is most extensive when the muscle is forcibly lengthened at longer sarcomere lengths. Also in isometric exercise, a minor amount of primary damage was found. No relationship was found between sarcomere lengths during forced lengthening and type of primary damage. This suggests that no specific part of the sarcomere can be identified as the weakest spot. Secondary changes, such as inflammation and a sustained decline in force generation were only observed after forced lengthening. The decline in force was related to the extent of primary damage. 



\section{Muscle compliance in relation with forced lengthen- ing-induced damage in the rat tibialis anterior muscle}

\subsection{SUMMARY}

A method was developed which made it possible to measure changes in compliance in situ in the rattibialis anterior (TA) muscle. Compliance (ratio between change in length and external force) was measured as a function of time after subjecting the right TA muscle to forced lengthening, and related to force and histological damage. The non-exercised left TA muscle served as control. Compliance, force and damage were determined $6 \mathrm{~h}$, and 1,3 and 10 days post-exercise. The same parameters were assessed 24 h after either isometric exercise or passive stretch of the right TA muscle, while the left TA muscie served as control. Forced lengthening resulted in damage to the contractile elements 1 day, and hyaline and inflammatory changes 3 days post-exercise. Ten days days post-exercise a great number of satellite cellls and occuasionally a thickening of connective tissue were present without any degenerative changes. At all time points forced lengthening resulted in a decreased compliance and a decreased force. After isometric exercise some minor damage was found with a decreased compliance, however, this was less than after forced lengthening. In passively stretched muscles no damage and no change in compliance was found. It is concluded that forced lengthening resulted in an increased passive stiffness that is attributable to degenerative changes during the first days and to thickening of the connective tissue thereafter.

\subsection{INTRODUCTION}

Intensive, unaccustomed or eccentric exercise may lead to muscle damage as reflected in delayed onset muscle soreness, enzyme release, swelling and shortening of the affected muscles (Clarkson, 1990). Human studies conducted by Cllarkson and Tremblay (1988), Ebbeling and Clarkson (1990) and Jones et al. (1987) reported muscle shortening in eccentrically exercised biceps muscles as reflected in a reduced range of motion (ROM) of the elbow joint. The decreased ROM may persist for several days and is accompanied by soreness and muscle weakness. Although no direct evidence is available, it has been assumed by some authors that factors such as muscle damage and muscle swelling contribute to the muscle shortening (Fridén et al., 1986, 1988). Clarkson and Tremblay (1988) have suggested that the musclle damage they observed was associated with accumullation of calcium into the sarcoplasm which may have lead to a decreased relaxation and consequently an increased stiffness. Jones et al. (1987) suggested that 
shortening of connective tissue is a causative factor of increased muscle stiffness. Taking all these studies logether, it is clear that the phenomenon of muscle shortening is well known in humans, but that its cause is still unexplained. In animals no studies have been conducted in which the passive muscle stiffness in relation with muscle damage has been investigated.

Therefore, the first aim of the present study was to develop a method which made it possible to measure changes in passive muscle stiffness in situ in the rat tibialis anterior (TA) muscle. Muscle stiffness was measured as compliance, defined as the ratio between change in length and external force applied to the muscle. The second aim was to measure changes in compliance in TA muscles that were subjected to forced lengthening, while the contralateral muscles served as control. The compliance was measured at different time points after exercise and the changes, if any, were related to changes in muscle force generation and the occurrence and amount of histological muscle damage.

\subsection{MATERIAL AND METHODS}

\section{Animals}

In this study 37 ( 3 months old) male Wistar rats were used. For housing and experimental conditions, see Chapter 2 . The rats were randomly assigned to one of 7 groups:

group 1. non-exercised control animals $(n=5)$ in which compliance was measured in the right and left TA muscles in order to assess the intraindividual variability,

groups $2,3,4$, and 5: animals ( $n=6$ for each group) in which each right TA muscle was forcibly lengthened; the compliance was measured $6 \mathrm{~h}$, and 1,3 and 10 days post-exercise, respectively, in both muscles,

group 6: animals $(n=6)$ in which the right TA muscle was isometrically exercised; the compliance was only measured 1 day post-exercise in both muscles, and

group 7: animals $(n=2)$ in which the right TA muscle was passively stretched; the compliance was only measured 1 day post-exercise in both muscles.

\section{Exercise protocol}

Under ether anaesthesia an electrode was hooked to the peroneal nerve. Thereafter, the animals were placed in the exercise apparatus and subjected to forced lengthening, isometric contractions or passive stretch. For a detailed description, see Chapter 2.

The TA muscles were stimulated for six $3 \mathrm{~min}$ sessions separated by 5 min recovery intervals. The muscles were stimulated once every $3 \mathrm{~s}$. For detalled information about the electrical stimulation protocol, see Chapter 2 . 
For forced lengthening contractions, the extension of the ankle joint was started at $85^{\circ}$ and ended at $130^{\circ}$. For isometric contractions the muscles were electrically stimulated in the same way as the foreibly lengthened muscles, but the angle of the ankle joint was maintained at $90^{\circ}$. The passively stretched muscles were exercised under the same condition as the forcibly lengthened muscles, but without stimulation of the peroneal nerve.

\section{Measurement of muscle compliance}

The animals were anaesthetized with narcovet (Apharmo, Arnhem, The Netherlands). To avoid any activity of the TA muscles via the central nervous system the peroneal nerves of both legs were cut. A wire (length 50 $\mathrm{cm}$, diameter $0.01 \mathrm{~mm}$, Medicon) was tightly connected to the tendon of one of the TA muscles. Subsequently the tendon was cut distally from the attachment of the wire and the muscle was carefully dissected free from the underlying extensor digitorum longus muscle and its surrounding tissue. Special care was taken not to damage the nourishing blood vessel of the muscle. To avoid any influence of the fascila, the connective tissue on the anterior surface of the muscles was removed. Thus, the TA muscle was only attached to the tibia. To prevent dehydration the muscles were constantly moisturized with physiological saline. The same procedure was repeated for the opposite leg.

To measure the compliance of the TA muscles the animals were laying down on their back. Both the knee and the foot were fixed to avoid any lateral and longitudinal movements of the leg. The wire that was connected to the tendon was hung over a pulley and was distally connected with a basket in which different weights could be placed. With $4.5 \mathrm{~g}$ in the basket the initial resting length was measured using a nonius. The length of the muscle was measured with increasing weights to $27,49.5,72$ and $94.5 \mathrm{~g}$, respectively. Such a series of measurements was done 6 times in each animal. To bring the muscle back to its initial length before starting a new series, the muscle was tetanized three times with $10 \mathrm{~V}$ for $400 \mathrm{~ms}$ at $90 \mathrm{~Hz}$ via an electrode that was placed on the surface of the muscle. The same protocol was used for the contralateral TA muscle that served as control.

The muscle compliance was calculated as the ratio between change in muscle length and the weight that was applied to strelch the muscle.

\section{Force measurements}

The isometric torque of the right foot of each animal belonging to group $2,3,4,5,6$, or 7 was measured pre-exercise and again before determining the compliance. For a detailed description, see Chapter 2 .

\section{Histalogy}

Immediately after measuring the compliance both the right (exercised, unless belonging to group 1) and left (control) TA muscles were completely dissected out for assessing primary damage and secondary changes in 
longitudinal sections. The procedure for flushing, fixation, cutting and staining is described in Chapter 2. A description of the method used for quantifying both types of damage in longitudinal sections is given in Chapter 3.

\section{Statistics}

The analysis of variance (Anova) was used to test differences in compliance, isometric torque and muscle damage after forced lengthening at different time points post-exercise and to test differences in compliance, isometric torque and muscle damage after difterent exercise regimens. Regression analysis was used to test differences in compliance between left and right non-exercised muscles and to test interrelationships between

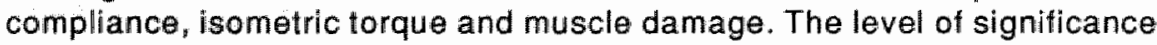
was set at $p<0.05$.

\subsection{RESULTS}

In Figure 4.1 it can be seen that in non-exercised control muscles no difference in compliance was found between left and right TA muscles. The correlation coefficient was $0.92(P \leq 0.0001)$.

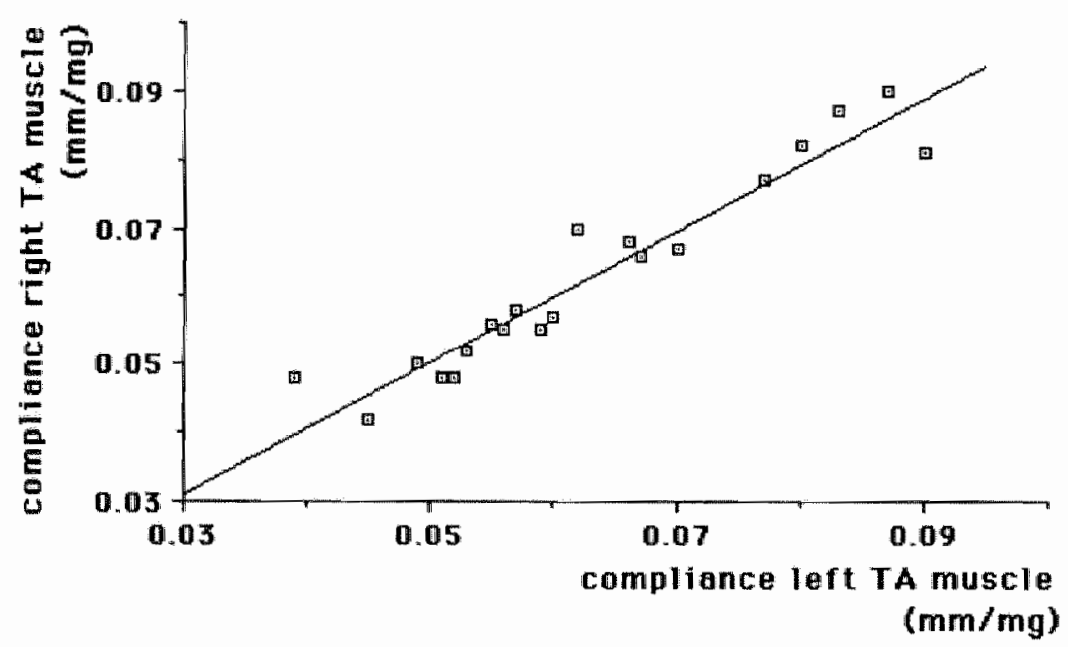

FIGURE 4.1. Comparison between compliance in non-exercised left and right TA muscles in the same animals $(n=5)$; for details, see text. 
Table 4.1 shows that 1 day post-exercise the compliance decreased compared with the control values of the contralateral muscles following both isometric exercise and forced lengthening. The decrease in compliance in isometrically exercised muscles was significantly less than the decrease in the forcibly lengthened muscles. In the forcibly lengthened muscles the compliance remained reduced until at least 10 days post-exercise compared with the non-exercised contralateral muscles. Except for 10 days postexercise, changes in compliance between control and exercised muscles were most pronounced at the lower weights of 27 and $49.5 \mathrm{~g}$. The compliance measurements conducted 10 days post-exercise showed that heavier weights also demonstrated significant differences in stiffness. In passively stretched muscles no decrease in compliance was found. Differences in compliance between control muscles of some exercise groups can be attributed to interindividual differences. Intra-individual differences were neglible (Figure 4.1).

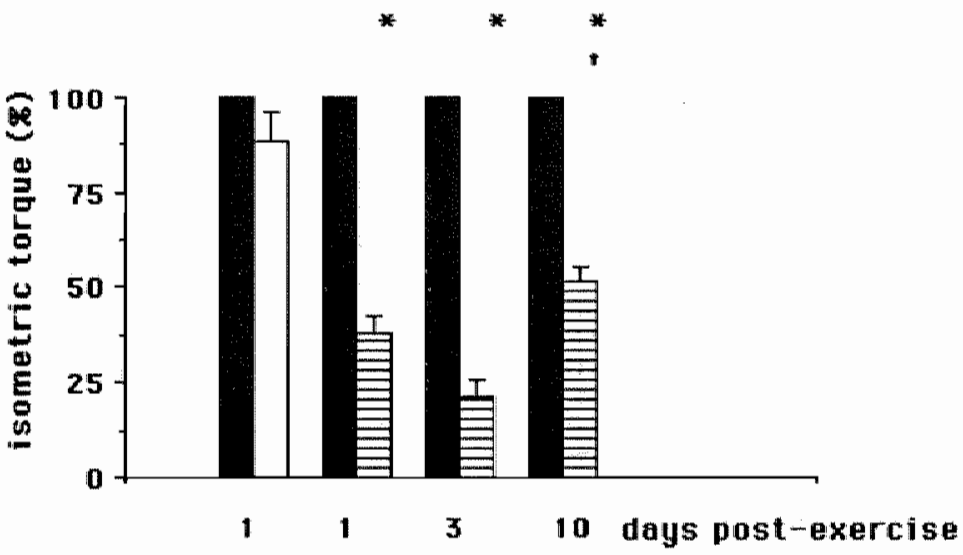

FIGURE 4.2. Isometric torque (mean \pm SEM) of dorsiflexor muscles of the foot before ( $\square$ ), and after isometric exercise ( $\square, n=6$ ) or forced lengthening ( 目， $n=6$ ); pre-exercise values are set at 100\%; all subsequent values are expressed as \% or the first measurements. " $p<$ 0.05 compared with pre-exercise values" $t p<0.05$ between forced lengthening 10 days post-exercise with forced lengthening 3 days postexercise.

The isometric torque measurements are depicted in Figure 4.2. After isometric exercise the isometric torque had almost returned to pre-exercise values in one day. In the forcibly lengthened muscles the isometric torque remained reduced compared with pre-exercise values until at least 10 days post-exercise, although at 10 days it had significantly increased from the levels seen at 3 days post-exercise. In the passively stretched muscles $(n=2)$ no decrease in isometric torque was found. 

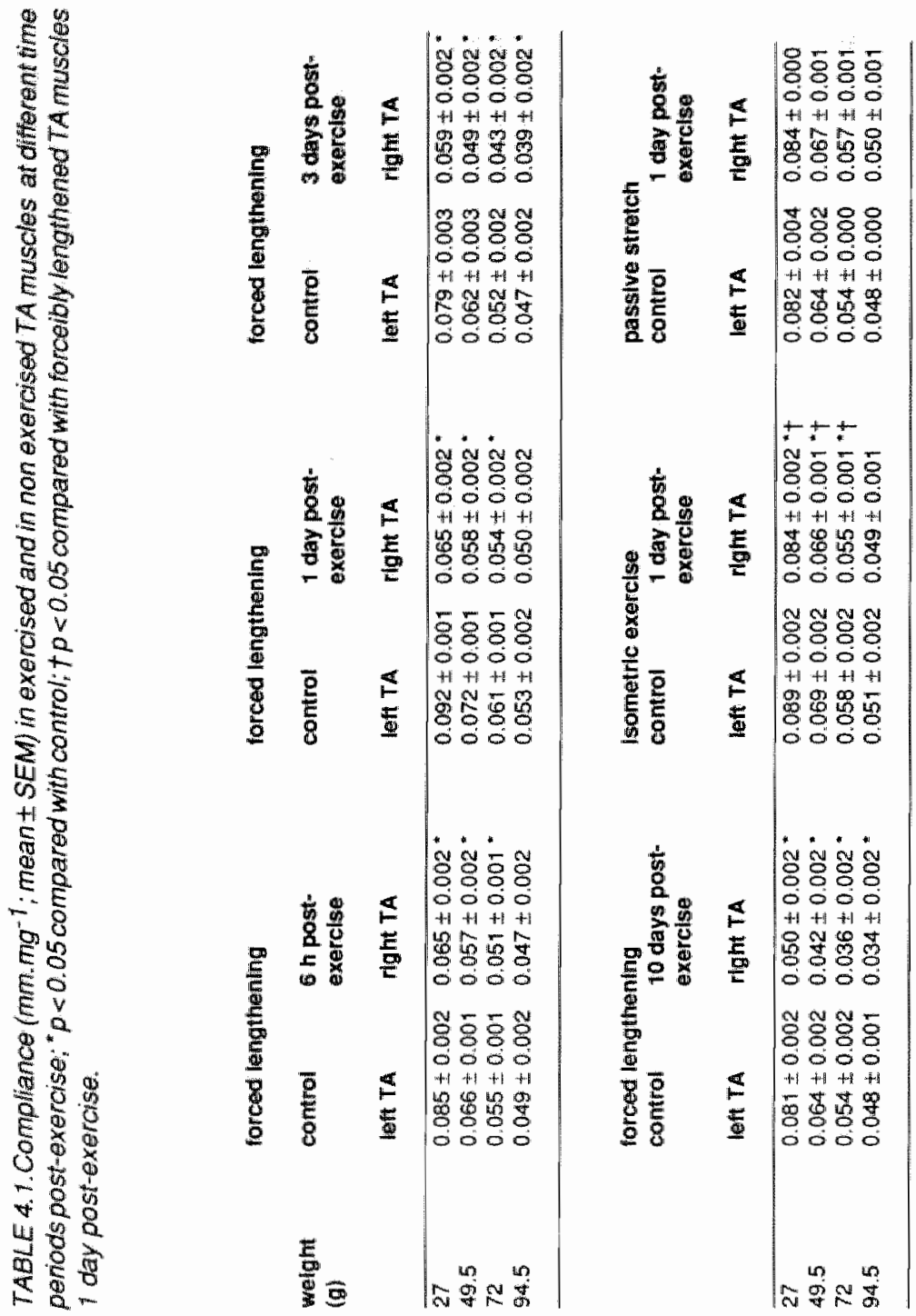
Table 4.2 shows that $6 \mathrm{~h}_{y}$ and 1 and 3 days after forced lengthening histological damage was found in the TA muscles, that was significantly greater than the damage found in the isometrically exercised muscles in which only minor damage was observed 1 day post-exercise. In passively stretched muscles no sign of any damage was found. Six $h$ after forced lengthening and $24 \mathrm{~h}$ after isometric exercise the damage consisted of primary damage, i.e., damage to the contractile elements. Twenty-four $h$ after forced lengthening the affected fibres contained primary damage and secondary changes, i.e., hyaline degeneration, vacuoles, and infiltration of leukocytes. Three days after forced lengthening only secondary changes consisting of inflammatory changes were found. Ten days after forced lengthening no remnants of inflammation, but marked signs of regeneration indicated by numerous satellite cells were found. Occasionally a thickening of endomysium and epimysium was observed. In all non-exercised muscles no damage was found.

TABLE 4.2. The amount of muscle damage (mean \pm SEM) in longitudinal sections of TA muscles that were subjected to different exercise regimens and dissected out at different time periods post-exercise. Damage is expressed as number of lesions permm ${ }^{2}$. $p<0.05$ compared with non-exercised TA muscles; $t p<0.05$ compared with isometric exercise.

\begin{tabular}{|c|c|c|}
\hline type of exercise & $\begin{array}{l}\text { time } \\
\text { post-exercise }\end{array}$ & $\begin{array}{l}\text { amount of } \\
\text { histological } \\
\text { changes }\end{array}$ \\
\hline forced lengthening, $n=6$ & $6 \mathrm{~h}$ & $\begin{array}{l}14.25 \pm 1.28 " \dagger \\
\text { (primary damage) }\end{array}$ \\
\hline forced lengthening, $n=6$ & 1 day & $\begin{array}{l}15.07 \pm 1.97 \text { "t } \\
\text { (primary damage and } \\
\text { secondary changes) }\end{array}$ \\
\hline forced lengthening, $n=6$ & 3 days & $\begin{array}{l}14.42 \pm 2.35 \text { " } \\
\text { (secondary changes) }\end{array}$ \\
\hline forced lengthening, $n=6$ & 10 days & $\begin{array}{l}\text { numerouss satellite } \\
\text { cells }\end{array}$ \\
\hline isometric, $n=6$ & 1 day & $\begin{array}{l}1.00 \pm 0.20^{\circ} \\
\text { (primary damage) }\end{array}$ \\
\hline passive stretch, $n=2$ & 1 day & 0 \\
\hline
\end{tabular}

In Figure 4.3 a view is given of the 3 stages: primary damage, secondary changes and regeneration. No significant correlations between changes in compliance, isometric torque and muscle damage were found. 

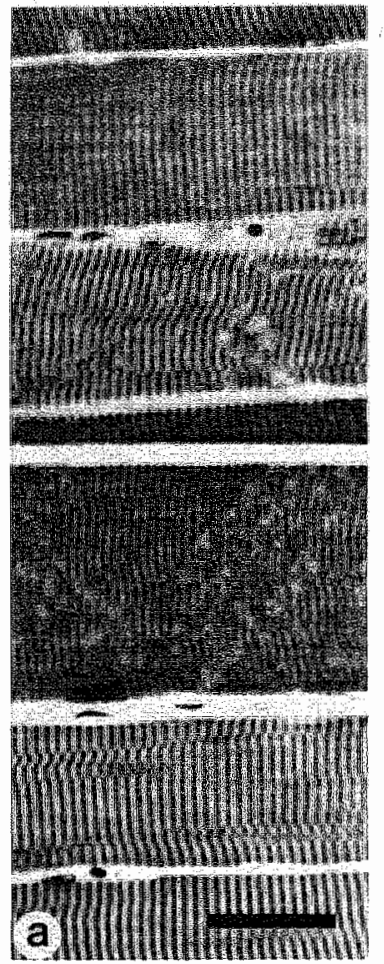
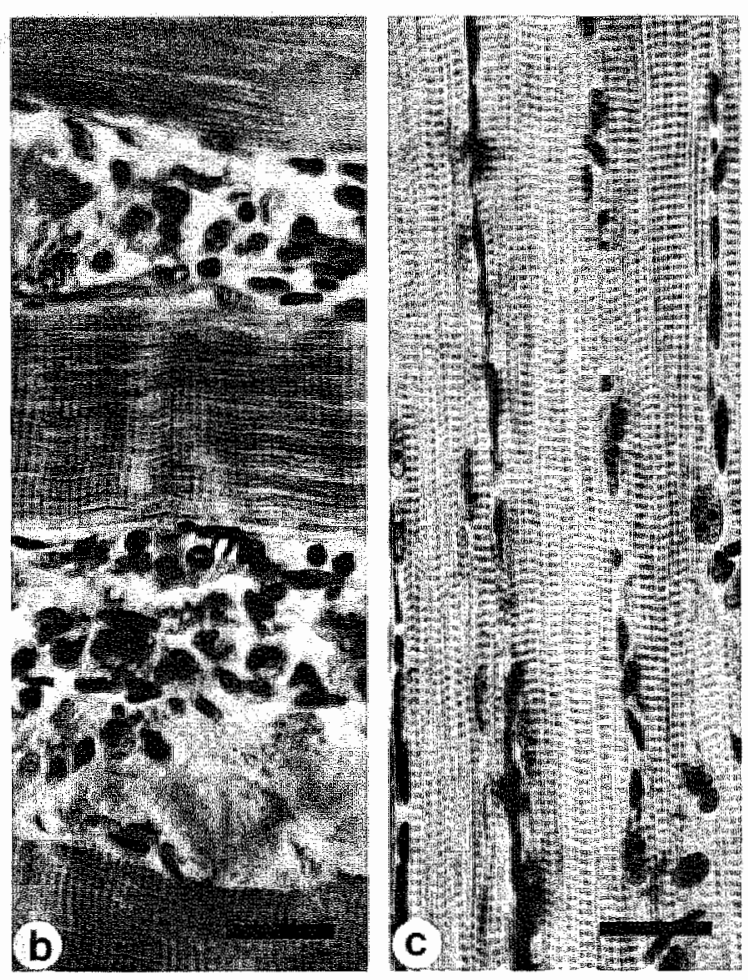

FIGURE 4.3. Longitudinal sections of muscle fibres, stained according to Gomori (bar $=25 \mu \mathrm{m}$ ). Six hours after forced lengthening muscle fibres showed A-band and Z-line irregularities (a), 3 days after forced lengthening muscle fibres were infiltrated by inilammatory cells and showed degeneration (b), and 10 days after forced lengthening an accumulation of satellite cells was found (c).

\subsection{DISCUSSION}

The first aim of the present study was to develop a method which made it possible to measure changles in passive stiffness in the rat tibialis anterior (TA) muscle in situ. As can be seen in Figure 4.1 the compliance between the left and right muscles in the same animals is highly correlated. In addition, repeated measurements in the same muscle within a relatively short time span (15 $\mathrm{min}$ ) yield reproducible results. The covariance was $3.27 \%$. Therefore, this method was used to measure changes in passive muscle stiffness in the exercised muscle by comparing it with the opposite non-exercised 
muscle in the same animal. The compliance was measured by using different weights. The results show that the changes in compliance were most marked using low weights (27 and $49.5 \mathrm{~g}$ ). This suggests that the measurements with low weights detect changes in passive stiffness that are not attributed to the connective tissue. This is supported by the findings in the muscles that were studied 10 days post-exercise. The histological features included increases in connective tissue, while the passive stiffness was also clearly demonstrated using the heavier weights.

The second aim was to investigate the effect of forced lengthening contractions on changes in compliance of the TA muscle, if any, over a longer period of time, and to relate these changes to force generation and the amount of muscle damage. Compared with isometrically exercised and passively stretched muscles, the greater decrease in compliance in the forcibly lengthened muscles can probably be attributed to differences in amount of muscle damage. Microscopical analysis 1 day post-exercise showed that in the isometrically exercised muscles only some minor changes. were found and in passively stretched muscles muscle damage was even absent. In the forcibly lengthened muscles it was shown that $6 \mathrm{~h}$, and 1 and 3 days post-exercise a significant amount of primary damage and secondary changes were found. The amount of damage in forcibly lengthened muscles is reflected in a reduced ability to generate force 1 and 3 days post-exercise, while in isometrically exercised muscles no decrease in force generation was found.

An explanation that is proposed for the decreased compliance is calcium accumulation in the damaged muscle fibres, resulting in decreased relaxation (Brody, 1969). There is some evidence that calcium plays a crucial role in eliciting exercise-induced muscle damage (Armstrong, 1990). Changes in calcium homeostasis are assumed to be associated with watershifts and a number of secondary changes (Duan et al., 1990). Another possibility that has been suggested is that changes in the connective tissue, i.e., endomysium and epimysium do contribute to the decreased compliance (Fritz and Stauber, 1988; Jones et al., 1987; Peeze Binkhorst et al., 1990; Stauber et al., 1990) The presence of monocytes in endomysium and epimysium suggest that changes do occur in connective tissue, which is supported by some studies in which the release of hydroxyproline was demonstrated after intense muscle exercise (Abraham, 1977). Muscle swelling has also been suggested as causing increases in stiffness (Fridén et al., 1986;1988; Howell et al., 1985). Supportive for this is that several muscle fibres showed swelling during the first hours after exercise. However, these changes do not last. Taking the long time course of increased muscle stiffness into account, it is unlikely that muscle swelling plays a major role for the changes in compliance that last for 10 days.

A major difference between the present and other studies (Clarkson and Tremblay, 1988; Ebbeling and Clarkson, 1990) is the time course of the decreased compliance. The decreased compliance in the present study is 
observed until at least 10 days after forced lengthening, while in both other studies the stifness was observed until at least 5 days posi-exercise, after which recovery takes place. This difference may primarily be attributed to a different extent of damage. Based on the measurements of the present study it is assumed that the changes in passive stiffness during the first days postexercise are attributable to extensive damage related changes. The increased stiffness 10 days post-exercise can probably be attributed to increases in connective tissue. Thickening of the intramuscular connective tissue most probably increases the passive stiffness of the muscle. Furthermore, it may be attributable to a different experimental approach to measure stiffness. In humans the range of motion has been measured which reflects the inability to stretch the affected muscles in extreme positions, rather than true compliance.

In summary, a major contribution of the present study is the development of a method to measure compliance and changes in it in the rat TA muscle in situ. Forced lengthening resulted in a decreased compliance that lasted for at least 10 days. Extensive damage was found after forced lengthening and the changes consisted of damage to the myofibrils immediately after exercise, and inflammation and regeneration thereafter. The initial change in compliance could be explained by degeneration associated factors, while the decreased compliance 10 days post-exercise may be attributable to an increase in connective tissue. 


\section{Peripheral adaptation after one bout of forced lengthening in the rat tibialis anterior muscle}

\subsection{SUMMARY}

It has been demonstrated that, based on reduced enzyme release, one bout of eccentric work protects against damage from a second bout. The aim of the present study was to investigate whether one bout of forced lengthening or isometric contractions of the rat tibialis anterior (TA) muscle has a protective effect on histological muscle damage from a second bout of forced lengthening. In addition, isometric torque before, during and after exercise bouts was measured. The left (TA) muscles of male Wistar rats $(n=9)$ were subjected to forced lengthening twice (FL-FL), while the right TA muscles were isometrically exercised followed by forced lengthening (1SO-FL). An interval of 3 weeks separates the first and second bout of exercise. Two dlays after the second bout of exercise both left (FL-FL) and right (ISO-FL) muscles were dissected out and the amount of histological damage was quantified morphometrically. The results show a significantly reduced amount of damage in the FL-FL muscles compared with the ISO-FL muscles. Muscles that were forcibly lengthened for the second time (FL-FL) demonstrated a smaller decline in isometric torque than muscles that were isometrically exercised before (ISO-FL). Based on the amount of damage and the torque measurements, it is concluded that in contrast with isometric exercise one bout of forced lengthening limits the amount of damage induced by a second bout of forced lengthening.

\subsection{INTRODUCTION}

Unaccustomed and eccentric exercise can elicit muscle damage as reflected in muscle enzyme release, soreness, swelling, stiffnesis and a decrease of force (Clarkson et al., 1986; Davies and White, 1982; Fridén, 1984a; Fridén et al., 1988; Newham ot al., 1983a). Systematic training has been shown to reduce the amount of exercise-induced damage as suggested by a reduction of the damage related symptoms (Evans ef al., 1986; Friden et al., 1983a; Howell et al., 1985; Hunter and Critz, 1971; Knuttgen, 1986; Komi and Buskirk, 1972; Nutall and Jones, 1968). Recent studies suggest that not only regular training, but also one single bout of eccentric exercise has a prophylactic effect against eccentric exercise-induced muscle damage from a second bout (Byrnes et al., 1985; Clarkson et al., 1985, 1987b; Irintchev and Wernig. 1987; Kirwan et al., 1986; Pierrynowski et al., 1987; Schwane 
and Armstrong, 1983; Triffletti et al., 1988). This prophylactic effect after one single bout of eccentric exercise has been demonstrated to last for several weeks (Clarkson and Tremblay, 1988; Jones et al., 1987; Kuipers et al., 1985). The adaptation can theoretically be attributed to adaptations within the muscle itself or to adjustments in the central nervous system leading to a changed recruitment, as proposed by Knuttgen (1986). Armstrong et al. (1983) suggested that during the first bout of exercise the most vulnerable fibres are damaged and removed, while the less susceptible fibres will survive.

A number of studies that reported adaptation after a single bout of exercise base their conclusion on indirect indicators of muscle damage such as enzyme release, decreased muscle strength, muscle stiffness and muscle soreness (Byrnes et al., 1985; Clarkson et al.., 1985, 1987a, b; Triffletti et al., 1988). It is unknown whether the amount of histological muscle damage is indeed decreased after a second bout of eccentric exercise given three weeks after a first bout of exercise. In addition, it is unknown in how far the protective effect of one bout of eccentric exercise can be attributed to structural adjustment of the muscle or to changes in the central nervous system. In the exercise model as described in Chapter 2 , it was possible to subject the rat tibialis anterior (TA) muscle in situ repeatedly to forced lengthening, thereby eliciting muscle damage. To perform forced lengthening contractions the peroneal nerve was electrically stimulated, hence the central nervous system was by-passed. If a second bout of forced lengthening would elicit less or no damage, this could only be attributed to a peripheral adaptation.

Thus, the aim of the present study was to investigate whether one bout of forced lengthening contractions compared with isometric exercise in the rat TA muscle had a protective effect against damage elicited by a second bout of forced lengthening contractions 3 weeks later.

\subsection{MATERIAL AND METHODS}

\section{Animals}

In this study 9 male Wistar rats (3 months old) were used. For housing and experimental conditions, see Chapter 2 .

\section{Surgicall and experimental procedure}

The rats were anaesthetized with narcovet (Apharmo, Arnhem, The Netherlands, $1 \mathrm{ml}$ per $100 \mathrm{~g}$ body weight) after which an electrode was hooked to the common peroneal nerve. Thereafter, the animals were placed in the exercise apparatus and subjected to forced lengthening or isometric exercise (see Chapter 2). For forced lengthening the ankle joint was subjected to plantar flexion, each contraction starting at an angle of $80^{\circ}$ and ending at $135^{\circ}$. For isometric exercise the lootplate was fixed so that the ankle joint was at $90^{\circ}$. 


\section{Protocoll}

To study the influence of a previous bout of either forced lengthening or isometric exercise, the TA muscle of the left limb was exercised by forced lengthening, while the TA muscle of the right limb was isometrically exercised. Electrical stimulation and duration of the protocol in both types of exercise were identical. After a period of 3 weeks, both muscles were subjected to a second bout of exercise consisting of forced lengthening. A three week interval between the two exercise protocols was based on studies that showed that the prophylactic effect of eccentric exercise may last for 3-6 weeks (Clarkson and Tremblay, 1988; Kuipers et al., 1985)

In the first bout of exercise both muscles were stimulated for three 4 min sessions separated by $5 \mathrm{~min}$ recovery intervals. In the second exercise bout the muscles were stimulated for six $4 \mathrm{~min}$ sessions separated by $5 \mathrm{~min}$ recovery intervals. During the stimulation sessions the muscles were stimulated once every $4 \mathrm{~s}$. For further details about the electrical stimulation protocol, see Chapter 2 .

\section{Histology}

To study exercise-induced secondary changes in cross sections the TA muscles were dissected out $48 \mathrm{~h}$ after the second bout of exercise. The fixation, cutting and staining procedures are described in Chapter 2. Muscle fibres were considered to be affected when one of the following features was seen: fibres infiltrated by inflammatory cells, vacuoles in the cytoplasm, hyaline aspect and fibres with multiple central nuclei.

The extent of secondary changes in cross sections was assessed according to the quantification procedure as described in Chapter 3 .

\section{Force measurements}

To study the influence of exercise on force generation of TA muscles, the isometric torque of the dorsiflexor muscles of the foot was measured immediately before, and $10 \mathrm{~min}$ after all exercise bouts. In addition, the isometric torque was also measured in the recovery periods between the exercise sessions. This was done at the 4 th min of each recovery period. The method to measure isometric torque is described in Chapter 2.

\section{Statistics}

The amount of secondary changes in both TA muscles was compared using the Wilcoxon rank-sign test. The effect of different exercise regimens on isomelric torque measurements was tested by the analysis of variance (Anova). The level of significance was set at $p<0.05$. 


\subsection{RESULTS}

Table 5.1 shows that after the second bout of exercise consisting of forced lengthening, the amount of secondary changes in the TA muscles that were isometrically exercised during the first bout ( $(S O-F L)$ was significantly higher compared with the TA muscles that were forcibly lengthened for the second time (FL-FL). Affected fibres were usually infiltrated by inflammatory cells.

TABLE 5.1. Amount of secondary changes (\% of affected fibres in cross sections; mean \pm SEM) after 2 different exercise schedules. " $p<0.05$ between left and right TA muscles.

amount of histological muscle clamage

right TA muscies ( $n=9$ )

(isometric exercise followed by forced lengthening.

Figure 5.1 depicts isometric torque measurements of the dorsiflexior muscles of the foot during the first bout of exercise. Pre-exercise values were not significantly different between the isometrically exercised and forcibly lengthened muscles. Compared with the pre-exercise values, isometric torque during the first bout was significantly lower, both in the isometrically exercised and in forcibly lengthened muscles. However, except for the first recovery period the decline in isometric torque in the forcibly lengthened TA. muscles was significantly greater than in the isometrically exercised muscles.

Figure 5.2 depicts isometric torque measurements during the second bout of exercise. The values before the second bout of exercise were not significantly different between left and right muscles, but they were significantly higher compared with the values before the first bout. During and after the second exercise bout the isometric torque in both forcibly lengthened TA muscles was significantly lower compared with the pre-exercise values. However, the isometric torque in the right TA muscles that were forcibly lengthened for the second time, demonstrated a smaller decline. This difference was only significant between the second and fourth exercise session. 


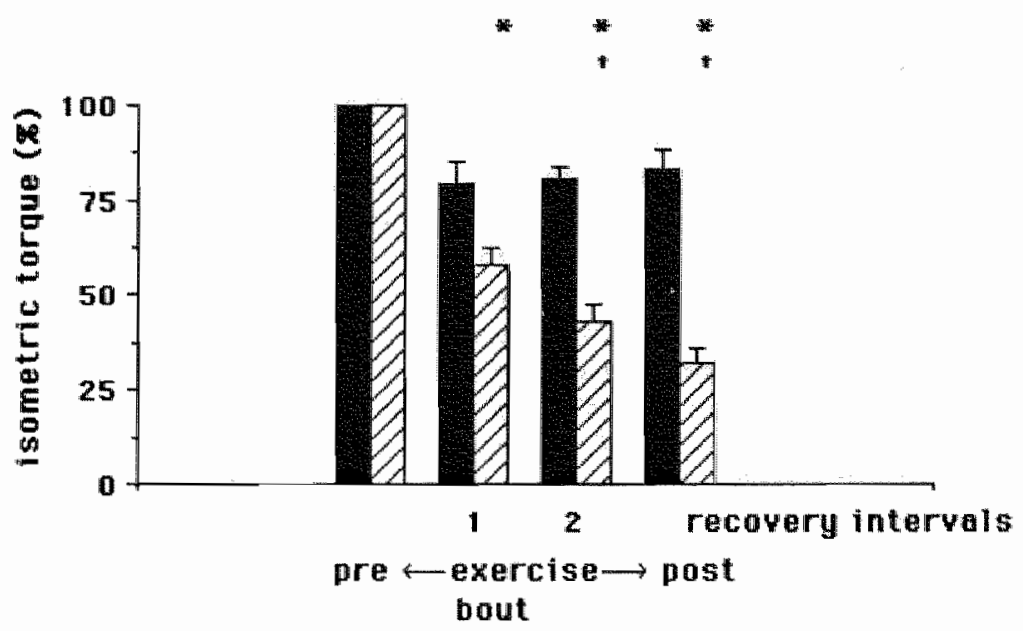

FIGURE 5.1. Isometric torque (mean \pm SEM) of dorsiflexor muscles of the foot, measured before, during (recovery periods $y$ and 2) and after iso. metric exercise (,$n=9)$ and forced lengthening $(n, n=9)$, respectively; pre-exercise values are set at $100 \%$. $p<0.05$ compared with pre-exercise values; $t p<0.05$ compared with forced lengthening.
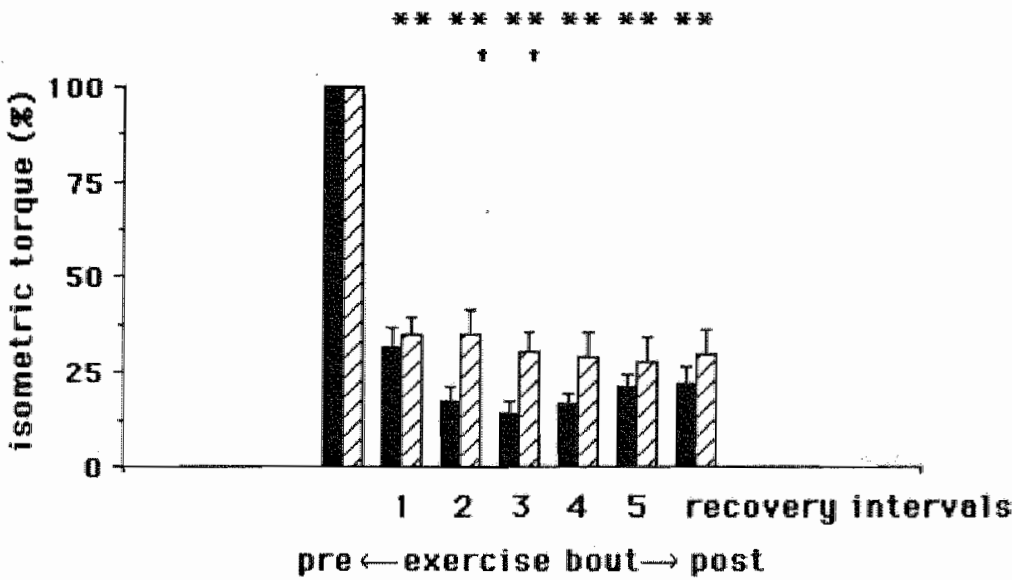

FIGURE 5.2. Isometric torque (mean \pm SEM) of dorsiflexor muscles of the foot that were subjected for the first ( $\mathrm{Q}, n=9$ ) or the second time ( $n=9$ ) to forced lengthening; isometric torque was measured before, during (recovery period's 1-5) and after exercise; pre-exercise values are set at $100 \%$. $p<0.05$ compared with pre-exercise values; $t p<0.05$ between both forcibly lengthened muscles in the same recovery period. 


\subsection{DISCUSSION}

The aim of the present study was to investigate whether a previous bout of forced lengthening contractions has a protective effect against muscle damage from a second bout of forced lengthening 3 weeks later. This study shows that TA muscles which were forcibly lengthened for the second time demonstrated less muscle damage compared with muscles that were forcibly lengthened for the first time. This finding is in agreement with the conclusions of other studies (Bymes et al., 1985; Clarkson et al., 1985, 1987a, b; Ebbeling and Clarkson, 1990; Jones et al., 1987; Schwane and Armstrong, 1983; Triffletti et al., 1988). However, in these studies the conclusions were based on indirect markers of muscle damage, such as enzyme release, muscle strength, muscle stiffness and muscle soreness, while the present study provides ditect evidence. Since the central nervous system was bypassed, the decreased susceptibility to exercise-induced muscle damage after one bout of forced lengthening as found in the present study, has to be attributed to structural changes in the muscle.

The histological findings are supported by force measurements. In the recovery intervals during isometric exercise the isometric torque was reduced, but was virtually restored $10 \mathrm{~min}$ post-exercise to pre-exercise values. In the forcibly lengthened TA muscles a reduction in isometric torque was also measured, but this reduction was larger and was maintained until at least 10 min post-exercise. The reduction in isometric torque in isometrically exercised muscles is assumed to be mainly caused by fatigue. A previous study (Chapter 3) demonstrated that the faillure of recovery in forcibly lengthened muscles can primarily be attributed to structural damage. In isometrically exercised muscles which show only a very small amount of muscle damage a quick recovery is possible.

The isometric torque in the recovery intervals during the second bout of forced lengthening was decreased in both TA muscles. However, it was remarkable that in the recovery intervals between the 2nd and 4th exercise session the decline in isometric torque of the left muscles was less compared with that of the right muscles. This suggests that the left muscles, that were forclbly lengthened for the second time were better able to sustain forced lengthening contractions. McCully and Faulkner (1986) also indicated that the first sessions of forced lengthening were most important for eliciting muscle damage (i.e. the "sensitive period"), while later sessions contributed less. A greater tensile strength during the first exercise sessions in muscles that were forcibly lengthened for the second time indicates that in this "sensitive period" the muscles withstand forced lengthening contractions better, possibly resulting in less damaged muscle tissue.

In spite of the ability of the FL-FL muscles to sustain forced lengthening contractions better during the second exercise bout, the relative decrease in force during the second bout of exercise was larger than during the first bout 
(Fig. 5.1 vs 5.2 ). This seems contradictionary. The force generation in absolute terms during the recovery intervals, however, was similar during both bouts. This can be attributed to the fact that the pre-exercise torque values before the second bout of exercise were thigher compared with preexercise values before the first bout $(0.125 \pm 0.035 \mathrm{Nm}$ vs $0.101 \pm 0.023 \mathrm{Nm}$; mean \pm SD), indicating an increase in muscle strength. This is not necessarily caused by adaptation after the first bout of exercise. The experiments were done in animals that were still growing, thus the increase in strength can also be attributed to an increase in muscle mass.

In 3 rats isometric torque measurements were done $48 \mathrm{~h}$ after the second exercise bout. The values in the FL-FL muscles were $70.3 \%$ and in the ISO-FL muscles $43.0 \%$ of the pre-exercise values. This suggests a relation between amount of secondary changes and decrease in force generation after a second bout of forced lengthening. This is not in agreement with a finding of Newham et al. (1987), who reported a dissociation between maximum voluntary contraction force and muscle damage after repetitive eccentric exercise. However, this discrepancy must be attributed to the fact that in the present study muscle damage was determined microscopically, whille in the study by Newham et al. (1987) the conclusion about muscle damage was based on plasma CK activities.

Different mechanisms have been proposed to explain the lower amount of damage after a second bout of forced lengthening. Armstrong et al. (1983) suggested that after the first bout of eccentric exercise the stress susceptible fibres are removed while the more resistant fibres do survive. This is contradicted by studies of Schwane and Armstrong (1983) and Clarkson and Tremblay (1988), where adaptation took place after one bout of eccentric exercise, without eliciting muscle damage. It can also be proposed that an increase in tensile strength of the connective tissue occurs after the first bout of exercise, making the muscle more stretch resistant. No indications for connective tissue damage or increase in connective tissue were found at histological examination, although Clarkson and Tremblay (1988) and Newham et al. (1987) found indications for a strengthening of endomysial and perimysial connective tissue. A third possibility is that an adjustment occurred in the contractile elements. The present study does not allow conclusions about the mechanism of adjustment, so its origin has yet to be elucidated.

In summary, it is concluded that muscles that have been subjected to forced lengthening for the second time do demonstrate less histologicall damage and decline in force compared with muscles that are either forcibly lengthened for the first time or that were isometrically exercised before. Since the central nervous system was by-passed, the adaptation has been attributed to changes within the muscle. 



\section{High energy phosphates, IMP and glycogen in the rat tibialis anterior muscle after forced lengthening and isometric contractions}

\subsection{SUMMARY}

Eccentric exercise may elicit damage to the contractile elements. The primary damage is followed by degeneration and inflammation, and changes in glycogen and energy metabolism. The mechanism underlying changes in glycogen homeostasis and energy metabolism is not yet well established. Therefore, the aim of the present study was to investigate the effect of forced lengthening and isometric exercise on adenine and guanine nucleotides, IMP, creatine phosphate, and glycogen content in the rat tibialis anterior (TA) muscle. Forced lengthening was used to elicit secondary changes, while secondary changes were absent in isometrically exercised muscles. The right muscles were either forcibly lengthened or isometrically exercised, while the contralateral muscles served as non-exercised control. TA muscles were dissected out 0,6 and $24 \mathrm{~h}$ post-exercise for biochemistry.

Immediately after both types of exercise an increase in IMP lissue levels was found. Irrespective of the type of exercise, gllycogen content was decreased immediately post-exercise, while it was restored $6 \mathrm{~h}$ later. Twentyfour h post-exercise a second decline in glycogen content was found after both types of exercise. In forcibly lengthened muscles ATP content was decreased $0,6(p>0.05)$ and $24 \mathrm{~h}$ post-exercise. In isometrically exercised muscles no ATP decrease was found at any time point. It is concluded that forced lengthening results in decreased ATP levels. Changes in glycogen homeostasis were found both after forced lengthening and isometric contractions. Assuming that only forced lengthening eliclted secondary changes, these changes in glycogen content are not strictly related to secondary muscle changes.

\subsection{INTRODUCTION}

The initial changes after muscular overload consist of structural damage to the contractile ellements. The primary damage is followed by secondary changes consisting of degeneration, an inflammatory response and eventually regeneration (Armstrong et al., 1983). Although the precise mechanism for inducing secondary changes is unknown, it is suggested that an increase in the cytoplasmic calcium concentration plays a major role (Armstrong. 1990). A disturbed calcium homeostasis may affect various metabolic processes. 
Calcium may activate proteolytic enzymes and phospholipase $A_{2}$ activity which in turn may affect the integrity of cellular membranes, as is shown in heart muscle (van der Vusse et al., 1989b) and in skeletal muscle (Duncan and Jackson, 1987; Jackson et al., 1984). An excess of calcium in the cytoplasm may stimulate the sequestration of calcium in mitochondria, which may compromise oxidative phosphorylation and result in a decreased ATP generation, as found in ischemic heart (van Bilsen, 1988) and in certain muscle diseases (Wrogemann and Pena, 1976). A decreased ATP generation may affect energy metabolism. This is supported by NMR studies of Aldridge et al. (1986) and McCully et al. (1988) that indicate changes in creatine phosphate (CP) and ATP values in skeletal muscle until 1 day after eccentric exercise-induced muscle damage.

Data from studies that employed eccentric exercise demonstrated that muscle glycogen levels were lower $24 \mathrm{~h}$ after (Costill et al., 1990; Kuipers et al., 1985) and up until 10 days after eccentric exercise compared with immediately post-exercise (O'Reilly et al., 1987). Although the mechanism underlying the transient post-exercise decrease in tissue glycogen stores has yet to be elucidated, it has been suggested that the observed changes in glycogen content are associated with inflammatory changes (Costill et al., 1990). It is also possible that glycogen turnover is affected by other metabolic changes, such as the energy state of the muscle. Thus, little and fragmentary information is available about metabolic changes in muscle, if any, that may occur specifically in relation to exercise-induced muscle damage.

Therefore, the aim of the present study was to investigate the effect of forced lengthening and isometric exercise on adenine and guanine nucleotides-, creatine phosphate-, IMP- and glycogen content in the rat tibialis anterior (TA) muscle over a time period of $24 \mathrm{~h}$.

\subsection{MATERIAL AND METHODS}

\section{Animals}

In the present study 36 male Wistar rats (weight $300-350 \mathrm{~g}$ ) were used. The housing and experimental conditions are described in Chapter 2. The animals were randomly assigned to either group $A$ or group $B$. In group A (18 rats) the TA muscle in the right leg was forcibly lengthened, while the TA muscle in the left leg served as non-exercised control. In group B (18 rats) the TA muscle in the right leg was exercised isometrically, while the TA muscle in the left leg served as non-exercised control.

\section{Experimental procedure}

Under ether anaesthesia an electrode was hooked to the common peroneal nerwe. Thereafter, the animals were placed in the exercise apparatus and the dorsiflexor muscles of the foot were subjected to either forced lengthening or isometric contractions. For details see Chapter 2. For forced lengthening contractions, extension of the ankle joint was started at $85^{\circ}$ and 
ended at $130^{\circ}$; for isometric contractions the angle of the ankle joint was maintained at $90^{\circ}$.

The muscles were stimulated at $90 \mathrm{~Hz}$ for $400 \mathrm{~ms}$ once every $4 \mathrm{~s}$. When forced lengthening contractions were performed during the first $200 \mathrm{~ms}$ of stimulation no external force was applied to the footplate enabling adequate contraction of the muscles. The exercise bouts consisted of six $4 \mathrm{~min}$ stimulation sessions separated by 5 min recovery intervals. After the exercise bouts the animals were placed back in their cages unless they were sacrificed immediately post-exercise.

\section{Tissue sampling}

Immediately after, $6 \mathrm{~h}$ or $24 \mathrm{~h}$ after termination of the exercise bout, tissue samples were taken from the proximal part of the TA muscle with the use of a surgicial blade. The time delay between cutting a piece of muscle and freezing in liquid nitrogen was approximately $3 \mathrm{~s}$. The frozen tissue was stored at $-80^{\circ} \mathrm{C}$ until analysis. Prior to biochemical analysis tissue samples were freeze-dried overnight at $-30^{\circ} \mathrm{C}$.

\section{Assay of metabolites in muscle tissue}

Freeze-dried tissue was weighed and divided into at least two parts. One part (weighing about $10 \mathrm{mg}$ dry weight) was used for determination of adenine nucleotides and related compounds, creatine phosphate, lactate, and glucose. To this end, the tissue sample was extracted at $-15^{\circ} \mathrm{C}$ in a mixture of perchloric acid $\left(3 \mathrm{~mol} . \mathrm{I}^{-1}\right)$ and dithiothreitol $\left(5 \mathrm{mmol} . \mathrm{I}^{-1}\right)$. The extraction volume was adjusted to the dry weight of the tissue sample (about $25 \mathrm{ul} . \mathrm{mg}^{-1}$ dry weight of tissue). The tissue was ground with a glass rod in the extraction fluid and subsequently rapidlly frozen in liquid nitrogen and thawed to a temperature of $4^{\circ} \mathrm{C}$. The mixture was centrifuged at $4^{\circ} \mathrm{C}$ with $1200 \mathrm{~g}$ for $5 \mathrm{~min}$. An aliquot of the supernatant was removed and neutralized with $\mathrm{KHCO}_{3}$. The neutralized supernatant was stored at $-80^{\circ} \mathrm{C}$ until further analysis (van der Vusse et al., 1989a). The second part of the freeze-dried tissue (about $5 \mathrm{mg}$ dry weight) was used for glycogen determination. The tissue specimen were kept at $100^{\circ} \mathrm{C}$ for $3 \mathrm{~h}$ after addition of $1.0 \mathrm{ml}$ of $11 \mathrm{~mol} . \mathrm{I}^{\circ}$ $1 \mathrm{HCL}$ to hydrolyze glycogen. Thereafter, the samples were neutralized with Tris $(0.12 \mathrm{M}) / \mathrm{KOH}(2.1 \mathrm{M})$ saturated with $\mathrm{KCL}$. The glucose residues were measured fluorometrically as described elsewhere (van der Vusse et al., 1984). The values obtained were corrected for the amount of free glucose already present at the time of tissue sampling (see below).

The tissue contents of adenine nucleotides and related compounds were determined by high-performance liquid chromatography (hplc) with the use of a modified method after Wynants and van Belle (1985). Briefly, a small sample of the neutralized extract ( $10 \mu \mathrm{l})$ was applied to a reversed phase column (Lichrosorb RP-18, Merck, FRG). Stepwise gradient elution, using two solvents was applied to separate the compounds of interest. Flow rate amounted to $0.8 \mathrm{ml} / \mathrm{min}$. Solvent $\mathrm{A}$ was an aqueous buffer of $\mathrm{NH}_{4}\left(\mathrm{H}_{2} \mathrm{PO}_{4}\right)(150$ 

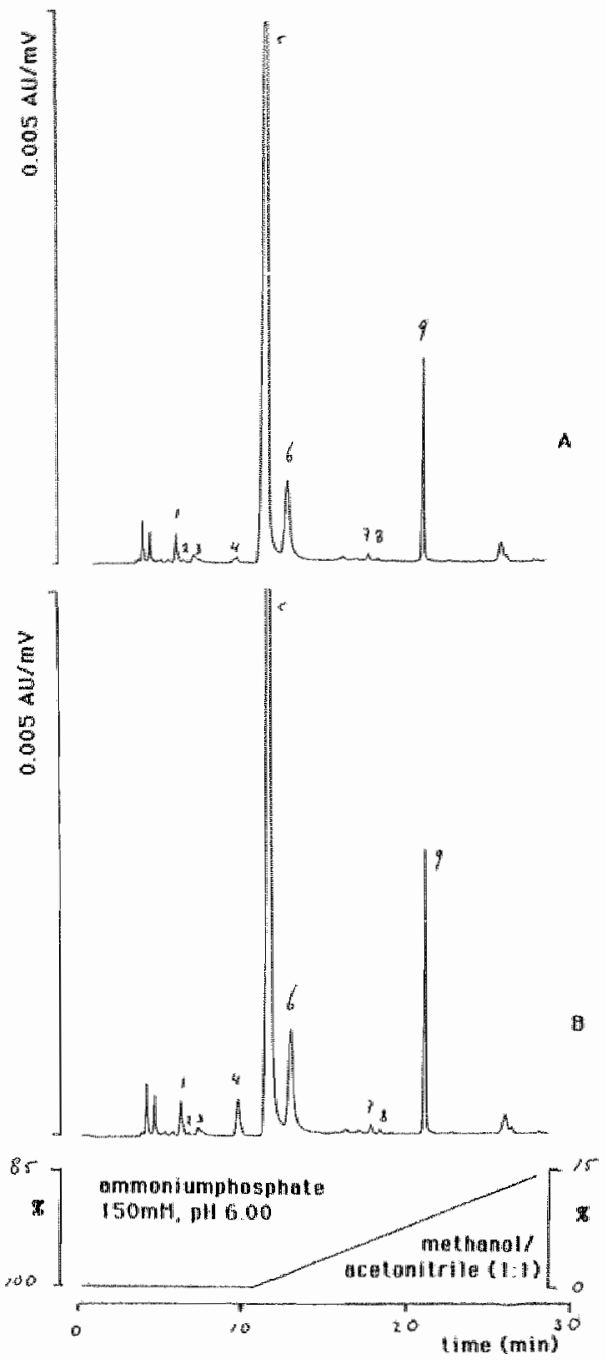

FIGURE 6.1. Typical HPLC chromatograms of extracts of TA mUscle. Chromatogram $A$ and $B$ reflect the content of adenine nucleotides and related compounds in tissue taken immediately after the exercise bout (forced lengthening, B) and in contralateral control tissue (A). Peak identification: 1, GTP; 2, GDP: 3, GMP+ unic acid; 4, IMP; 5 , ATP; 6 , ADP; 7, AMP; 8, NADP; 9, NAD. Total run time was 30 min. The gradient of the elution fluid's is shown at the lower panel. 
mmol. $1^{-1}, \mathrm{pH}=6.0$ ), solvent $\mathrm{B}$ consisted of a $1: 1$ (by volume) mixture of acetonitrile and methanol. Peaks were detected at $254 \mathrm{~nm}$ and identified by comparing retention times with known standards. LiChroCART 4-4 (Merck, FRG) was used as guard column (see Figure 6.1, showing typical examples of chromatograms of muscle extracts). Creatine phosphate was measured fluorometrically as described earlier (van der Vusse et al., 1984). Lactate was assayed according to Passoneau (1974). Free glucose was assayed as described before (van der Vusse et al., 1984).

\section{Statistics}

The biochemical data belween the experimental and control muscles within the same animals, and between different animals were tested by the paired and unpaired Student t-test, respectively. For comparison of biochemical data at different time points analysis of variance (Anova) was employed. The level of significance was set at $p<0.05$.

\subsection{RESULTS}

The data of adenine nucleotides content are listed in Table 6.1. It shows that a significant decrease in adenine nucleotides content postexercise was only found in the forcibly lengthened muscles, although the difference $6 \mathrm{~h}$ post-exercise did not reach the level of significance. The decrease in adenine nucleotides content in the forcibly lengthened muscles was significantly greater than in the isometrically exercised muscles.

The data of IMP and glycogen contents are listed in Table 6.2. Immediately post-exercise the content of IMP was significantly increased, both in forcibly lengthened and in iscmetrically exercised muscles. Comparing the post-exercise values in IMP between forced lengthening and isometric exercise no statistical difference was found. Both forced lengthening and isometric exercise failed to affect contents of guanine nucleotides, NAD, CoA, xanthine, hypoxanthine, creatine phosphate and lactate at any time point.

As can be seen also in Table 6.2, immediately post-exercise the glycogen content was significantly lower compared with pre-exercise levels in both types of exercise. The decline after both types of exercise was similar. Six $h$ after exercise the glycogen levels were virtually restored to levels as found in the control muscles. However, $24 \mathrm{~h}$ post-exercise both in the forcibly lengthened and in isometrically exercised muscles glycogen was significantly lower compared with non-exercised control muscles. 


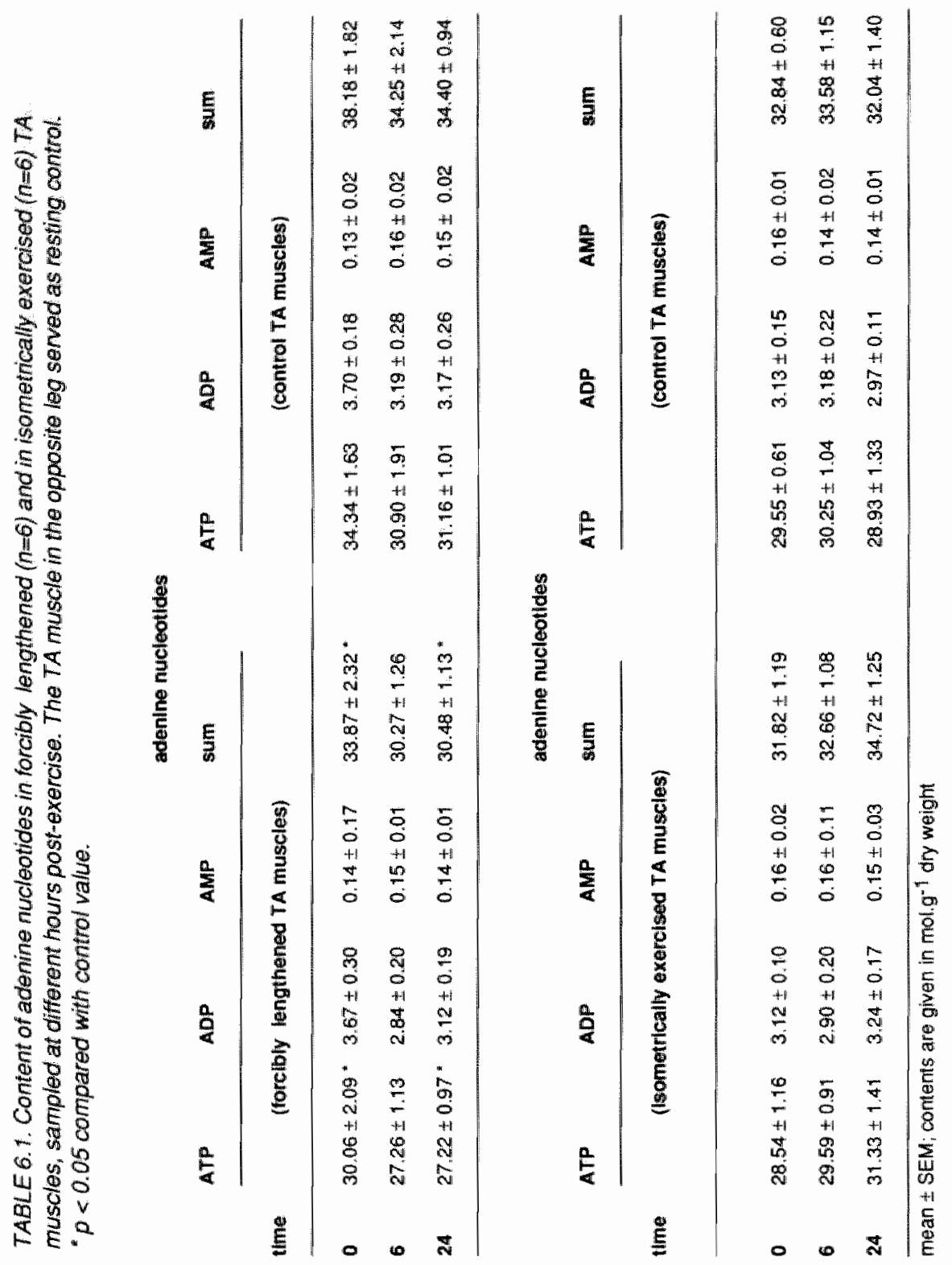



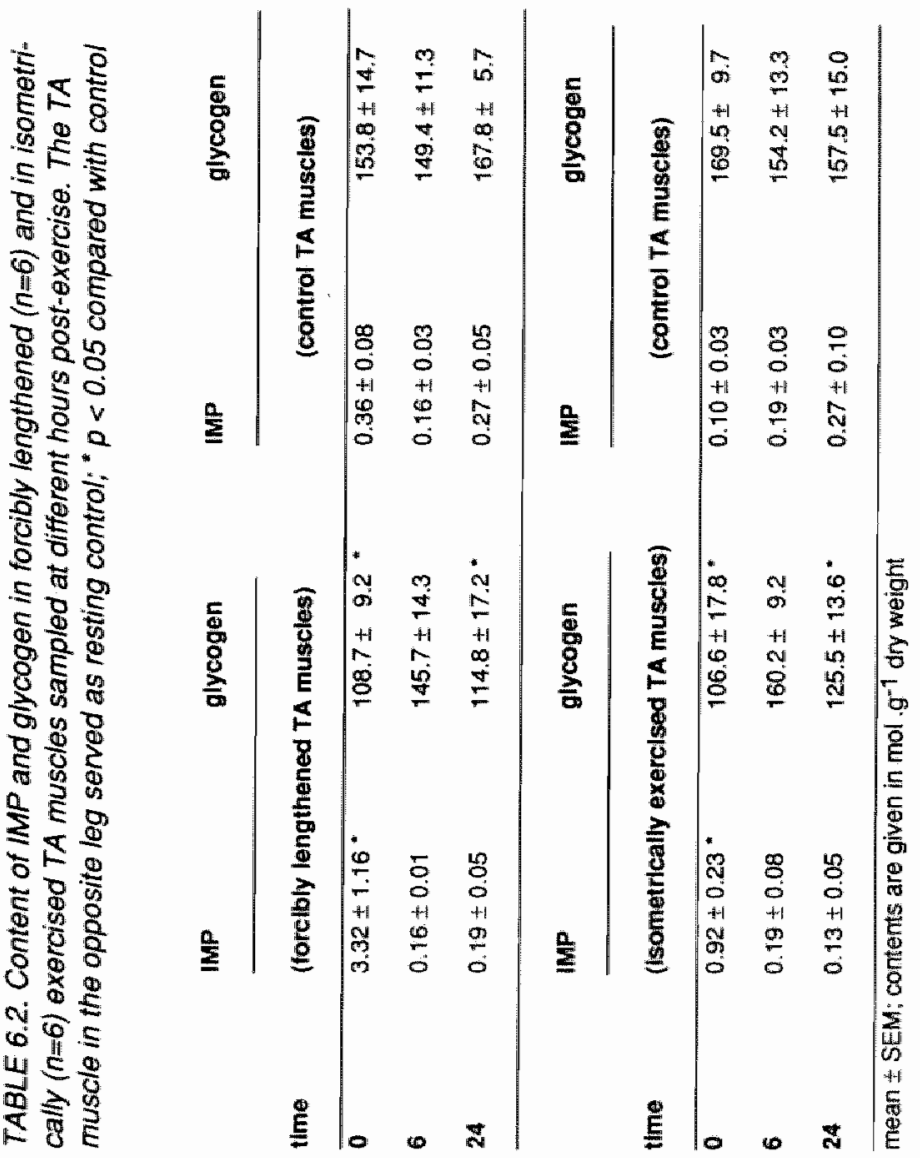


\subsection{DISCUSSION}

The aim of the present study was to investigate the effect of forced lengthening and isometric exercise on adenine and guanine nucleotides-, creatine phosphate-, IMP-and glycogen content in the rat TA muscle.

In the TA muscles that were forcibly lengthened a decrease in adenine nucleotide content was found immediately post-exercise, while also 6 and 24 $\mathrm{h}$ later adenine nucleotides content was lower than in non-exercised control muscles. In the isometrically exercised muscles the values were nat different from the contralateral non-exercised control muscles. Comparing the data from the present study with findings as reported by others, it can be noticed that the decrease in adenine nucleotides as found in the forcibly lengthened exercise was not as large as found by others who tetanized muscles isometrically in situ (Meyer and Terjung, 1979). A possible explanation for this difference is that the stimulation protocol as used in the present study was less severe, i.e., fewer contractions per unit of time and interrupted by recovery intervals.

The lower ATP levels after forced lengthening compared with isometric exercise remain unexplained. The increased IMP levels after both types of exercise indicate that the rate of ATP hydrolysis exceeded the rate of ATP resynsthesis, resulting in increased levels of ADP and AMP. However, an increase of ADP and AMP after both types of exercise was absent. It remains obscure why the IMP formation was particularly present in the forcibly lengthened muscles, since the activation procedure and the exercise protocol were identical in both types of exercise. Since Dudley and Terjung $(1985 a, b)$ found that a more anaerobic state of the muscle with acidosis will contribute to a greater IMP increase, it could be argued that forced lengthening may cause a disturbed microcirculation with tissue acidosis. However, since tissue lactate levels were not different from control values at any time point, it is unlikely that severe tissue acidosis did occur.

It was remarkable that $24 \mathrm{~h}$ later in the forcibly lengthened TA muscles ATP content was still decreased. This may be caused by the impaired capacity to regenerate ATP after exercise that caused muscle damage. It is assumed that in damaged muscle fibres calcium will accumulate in the sarcoplasm and in mitochondria, resulting in a decreased capacity of oxidative phosphorylation (Armstrong, 1990). Although no calcium was measured in the present study, other investigations suggest that eccentric exercise may lead to an accumulation of calcium in the mitochondria (Duan ef al., 1990). Also after ischemia followed by reperfusion ischemia-induced muscle damage was found that was accompanied with a decrease in ATP content (Harris et al., 1986).

The increased tissue IMP levels without changes in CP. AMP, and lactate seems contradictory. It is possible that the metabolic changes occurred primarily during the first session of the exercise bout. The recovery intervals and the lower force generation because of fatigue may have resulted in 
diffusion of lactate on the one hand and restoration of CP levels on the other. Thus, the metabolic parameters assessed immediately after the last bout may reflect changes that occurred during the previous exercise sessions.

It should be realized that ATP and IMP data represent average values, measured in approximately $10 \mathrm{mg}$ of muscle tissue. Hence it cannot be ruled out that the biochemical changes in single fibres have been larger. The samples were taken from a region of the muscle consisting of approximately $28 \%$ type IIA and $72 \%$ type IIB fibres. A previous study in which glycogen depletion pattern was studied showed that with the present model type IIA fibres showed the greatest glycogen depletion (Chapter 2). Therefore, it is assumed that type llA fibres were most heavily involved and mainly contributed to the accumulation of IMP. Based on the assumption that $28 \%$ of the muscle sample consisted of type IIA fibres and that IMP is mainly formed in these fibres, the IMP content in type IIA fibres would have been higher than the average values presented.

Inosine and hypoxanthine, degradation products of IMP were not found to be increased in any of the TA muscles studied. This is in contrast with findings as reported in damaged heart tissue (van Bilsen, 1988). Possibly the extent of damage in the present study was not sufficient to show this increase. Another explanation is that type II fibres, compared with type I fibres, contain low $5^{\prime}$-nucleotidase activities, as is reported by Tullson and Terjung (1990), which results in low capacity of type llA fibres to convert AMP and IMP into adenosine and inosine, respectively.

Both exercise protocols showed a decrease in glycogen content, immediately post-exercise, followed by a restoration of the glycogen content $6 \mathrm{~h}$ thereafter. Twenty-four $\mathrm{h}$ later again a decline was found. Other studies in which eccentric exercise was used also showed a decreased glycogen content level until at least one day (Costill et al., 1990) or until at least 10 days post-exercise (O'Reilly et al., 1987). It was remarkable, however, that in the present study also in the isometrically exercised muscles $24 \mathrm{~h}$ postexercise a decrease in glycogen content was found and that $6 \mathrm{~h}$ postexercise the glycogen content was restored at pre-exercise levels, after which a second decline in glycogen content was found. This indicates that the muscle has the capability to restore the exercise-induced glycogen depletion within $6 \mathrm{~h}$, but thereafter it is suggested that the mechanism failed to maintain the pre-exercise values. The decrease $24 \mathrm{~h}$ post-exercise may result from a decreased synthesis, or an increased glycogen use, or both. Because a decrease in glycogen content $24 \mathrm{~h}$ post-exercise was also found in isometrically exercised muscles it is suggested that changes in tissue glycogen content do not directly relate to the induction of muscle damage as suggested by Costill and co-workers (1990). This is supported by the findings of Kuipers et al. (1985), in which $24 \mathrm{~h}$ after eccentric cycling decreased glycogen levels were found in the absence of structural damage. Neither does the decline in glycogen content $24 \mathrm{~h}$ post-exercise in the forcibly lengthened muscles seem to be related to decreased ATP levels, because 
lower glycogen levels were also found in isometrically exercised muscles. The data from the present study do not allow conclusions as to the underlying mechanisms of decreased post-exercise glycogen levels.

In summary, the present study demonstrates that the IMP content was increased immediately after both types of exercise. In contrast with isometric exercise, forced lengthening resulted in a decrease in ATP, which cannot be completely explained and which persisted for at least $24 \mathrm{~h}$. It is assumed that the changes are attributable to exercise-induced changes in the restoration of energy rich phosphates. Glycogen levels were decreased both after isometric exercise and forced lengthening, while $6 \mathrm{~h}$ post-exercise preexercise levels were reached. An unexplained decrease was seen $24 \mathrm{~h}$ after both types of exercise. 


\section{Relationship between exercised-induced muscle damage and enzyme release in male and female rats}

\subsection{SUMMARY}

The relationship between the amount of exercise-induced muscle damage and the release of CK, AST and LD was studied. Gender differences in enzyme release and histological damage were also studied. Serial preand post-exercise blood samples were drawn from untrained male and untrained female catheterized Wistar rats which ran 1.5 or $2.5 \mathrm{~h}$ uphill on a treadmill (incline $+10^{\circ}$ ). Three days post-exercise muscle damage was quantified morphometrically in five different hindlimb and in five different forearm muscles. The 1.5 and $2.5 \mathrm{~h}$ exercise elicited histological damage only in the soleus muscle. Significant plasma CK, AST and LD elevations were found immediately post-exercise both in male and female rats. However, the enzyme release was significantly greater in males than in females. Part of this could be explained by differences in clearance rates between males and females. No gender difference in the amount of histological damage was found. The actual volume of histological muscle damage was significantly less than the calculated muscle damage based upon enzyme release. An increase in the exercise duration from 1.5 to $2.5 \mathrm{~h}$ resulted in a disproportionate increase in both histological muscle damage and muscle enzyme release. From the present study it is concluded that muscle enzyme release is not clearly reflected by histological muscle damage.

\subsection{INTRODUCTION}

The plasma activities of specific muscle enzymes such as creatine kinase (CK), aspartate aminotransferase (AST) and lactate dehydrogenase (LD) are used as markers for muscle tissue damage (Jones et al., 1986; Lijnen et al., 1988; Lott, 1984). CK release from the myocardium is used for diagnostic purposes in patients who are suspected of a myocardial infarction (Lee and Goldman, 1986). Based on the myocardial CK content, the total amount of enzyme released into the vascular compartment may yield information of the infarction size (Roe, 1977; Sobel et al., 1979).

In patients with skeletal muscle disorders, plasma CK activity is used to indicate the status of the disease (Jackson et al., 1987), or to gain information concerning the integrity of the sarcolemma (Jones et al. 1986; Mokri and Engel, 1975). The release of muscle enzymes in athletes is used to estimate the amount of muscle damage after severe exercise, based on the assumption that release is related to the muscle enzyme content as well as to the amount of exercise-induced muscle damage (Apple and Rhodes, 
1988; Fridén et al., 1989; Janssen et al., 1989).

CK release is also used to estimate muscle damage in animals. Schwane and Armstrong (1983) used changes in CK activity as a marker for muscle injury to study training effects in rats. Their results contirm the results of Garbus and co-workers (1964) who reported that untrained rats that were subjected to strenuous exercise demonstrated a higher muscle enzyme release than trained animals. A number of other studies from the early sixties that were conducted to investigate the relationship between exercise-induced muscle damage and enzyme release, suggested that discrepancies between the amount of exercise-induced damage and enzyme release may occur (Garbus et al., 1964; Highman and Altland, 1963; Papadopoulos et al., 1967). However, these investigators used only one plasma sample for enzyme delermination, while the total amount of enzyme release and the amount of histological damage were not quantified. More recently, a gender difference in post-exercise enzyme release has been demonstrated i.e., females were observed to have a lower plasma enzyme release than males (Apple and Rogers, 1986; Rogers et al., 1985; Shumate et al., 1979). This gender difierence has also been reported in rats (Amelink and Bär, 1986; Amelink et al., 1988). It has not been established yet whether the lower enzyme release in females is associated with less histological damage.

Therefore, the aim of the present study was fourfold:

a) to study the relationship between exercise-induced histological muscle damage and muscle enzyme release,

b) to study whether an increase in exercise duration results in proportionate increases in the amount of histological damage and plasma enzyme activities,

c) to study whether gender differences in plasma enzyme activities are associated with differences in the amount of histological damage,

d) to study factors that may account for gender differences in plasma enzyme activity (muscle enzyme content and enzyme clearance rate).

\subsection{MATERIALS AND METHODS}

\section{Animals and Instrumentation}

In the present study untrained male and female 8-10 weeks old Wistar rats were used. The rats were housed individually in a temperature controlled environment $\left(23-26^{\circ} \mathrm{C}\right)$. They had tree access to food (type 1210. Hope Farms) and water. The light was on between 7:30 a.m. and 7:30 p.m.

In the first part of this study 43 rats were randomly assigned to one of 3 groups:

- group A: 15 rats that ran for $1.5 \mathrm{~h}$ ( 8 males and 7 females)

- group B: 16 rats that ran for $2.5 \mathrm{~h}$ (7 males and 9 females)

- group $C: 12$ rats that served as resting controls (6 males and 6 females). 
For assessing the influence of exercise duration and gender, in group $B, 3$ rats from the original 16 ( 1 male and 2 females) were excluded from analysis, since they were not able to complete the 2.5 h of exercise. However; they were used for studying the relationship between histological muscle damage and muscle damage based on enzyme release.

A flexible catheter (I.D. $0.64 \mathrm{~mm}, 0 . D .1 .19 \mathrm{~mm}$ ) was inserted into the jugular vein one week before the exercise bout allowing repeated blood sampling in the conscious animals (Steffens, 1969).

In separate experiments, for which 6 male and 6 female rats were used, clearance rates in the resting state and also following a bout of exercise, were studied. The rats were cannulated as described above for measuring the clearance rates after a bolus injection with enzyme preparations. In addition, the soleus muscle enzyme content was determined in 6 male and 6 female rats.

\section{Exercilse protocol, blood sampling and enzyme analyses}

To induce muscle damage the rats ran uphill on a rodent treadmill (Quinton). The exercise took place between 8:45 and 12:00 a.m. After a 15 min adaptation phase the workload was fixed at $1810 \mathrm{~m} / \mathrm{h}$ with a $10^{\circ}$ incline for $1.5 \mathrm{~h}$ (group A) or $2.5 \mathrm{~h}$ (group B). The rats were stimulated to keep running by a mild electric current, which was set on the grid for $0.1 \mathrm{~s}$ every $5 \mathrm{~s}$. The animals ran uphill according to a study of Kuipers et al. (1983) in which it was shown that muscle damage was restricted to type 1 fibres of the soleus muscle and could vary between animals from very mild to severe.

In group A (1.5 h running) blood was sampled repeatedly $(0.4 \mathrm{ml}$ per sample): pre-exercise and $0,3,6,9,12,24,48$ and $72 \mathrm{~h}$ post-exercise. Based on the results of plasma enzyme activities in group $A$, more emphasis was put on the first hours post-exercise in group $B$ ( $2.5 \mathrm{~h}$ running) and consequently the sampling schedule was as follows: pre-exercise and $0,1,3,5,9,21$ and $45 \mathrm{~h}$ post- exercise. After sampling, $0.4 \mathrm{ml}$ of donor blood obtained from rats. of the same strain, was substituted.

After centrifugation the plasma was stored at $-25^{\circ} \mathrm{C}$ until analysis. The activities of creatine kinase (CK; EC 2.7.3.2.), aspartate aminotransferase (AST; EC 2.6.1.1.) and lactate dehydrogenase (LD; EC 1.1.1.27) in plasma were measured at $25^{\circ} \mathrm{C}$, using a standard bioassay (Boehringer) and expressed as units per liter. The plasma enzyme activities were corrected for plasma volume changes, using the plasma protein concentration as a reference.

\section{Histology}

To study the relationship between muscle enzyme release and histo. logical damage a number of muscles were dissected and processed for microscopical analysis. The muscles were dissected 3 days after the exercise bout, since other studies demonstrated that histological changes were 
most pronounced and extensive 24-72 h after exercise (Armstrong et al., 1983, Kulpers et al, 1983). The following muscles were used for the assessment of histological damage: $m$. soleus, $m$. plantaris, $m$. gastrocnemius, $m$. tibialis anterior and $\mathrm{m}$. extensor digitorum longus (EDL). The muscles of each animal were dissected from the right and left hindlimb and both were used for analyses. In addition, in 4 male rats that ran for $2.5 \mathrm{~h}$ the left and right $\mathrm{m}$. triceps longum, $m$. triceps lateralis, $m$. triceps medialis, $m$. extensor digiti and $m$. flexor carpi ul naris from the forelimb were dissected. After dissection. the muscles were weighed on a microbalance (Sartorius) and cooled in isopentane with liquid nitrogen. The frozen muscles were stored at $-80^{\circ} \mathrm{C}$.

From all muscies $10 \mu \mathrm{m}$ thick serial cross sections were cut in a cryostat (Anglia Selentitic) at $-20^{\circ} \mathrm{C}$. Each 15 th section was mounted on glass and used for microscopical examination. The sections were stained with haematoxylin-eosin. The following criteria were used to consider a fibre as damaged: multiple central nuclei, hyaline aspect, multiple vacuoles and infiltration by inflammatory cells.

Since it has been shown that with the present exercise protocol the length over which a fibre is damaged always exceeded $150 \mu \mathrm{m}$ (Kuipers et al., 1983) the sections were taken at $150 \mu \mathrm{m}$ intervals. Individual fibres could be followed over the entire length by examining serial sections. With a microscope (Zeiss, magnification 100x), prisma and measuring tablet with a grid (MOP-Videoplan, Kontron) the total volume of damaged muscle tissue was compared with the total muscle volume. The weight of damage $(\mathrm{mg})$ was calculated from the percentage of volume damaged. The measurements were done by one person in duplicate and the coefficient of variation was $2 \%$.

\section{Estimating muscle damage from enzyme release}

Based on the principle of calculating the amount of cardiac damage from enzyme content in cardiac tissue, cumulative enzyme release, fractional catabolic rate and plasma volume (Willems et al., 1979, 1985) skeletal muscle damage was also estimated in exercised animals. The amount of enzyme release from the damaged muscle tissue into the plasma (A) is equal to $A=F C R . V p$. JEtdt, in which FCR is the fractional catabolic rate (slope of the activity plotted versus time on a logarithmical scale after an enzyme bolus injection). Vp plasma volume (assumed to be $0.0321 . \mathrm{kg}^{-1}$ body weight; Yale and Terhorst, 1972) and Et the plasma enzyme activity (U.1-1). Hence we calculated the weight of damaged muscle tissue from $A . E c^{-1}$, in which $E c$ is the tissue enzyme concentration in soleus muscle tissue (U.g- ${ }^{-1}$ wet weight), since histological muscle damage was restricted to the soleus muscle. In separate experiments it was found that the difference between administered amount of enzyme via the heart catheter and the recovered amount of enzymo was less than $10 \%$.

Since gender differences in muscle enzyme release were found, a comparison was made between soleus muscle enzyme contents and enzyme clearance rates after an enzyme bolus injection in male and female rats. The 
enzyme content of CK, AST and LD in the soleus muscles ( $U . g^{-1}$ wet weight) was measured at $25^{\circ} \mathrm{C}$ by means of a bioassay (Boehringer) in $100 \mathrm{mg}$ homogenized muscle tissue in 6 male and 6 female rats. Clearance rates of $C K, A S T$ and LD from the vascular compartment in males versus females were compared in separate experiments. For that purpose $100 \mathrm{mg}$ soleus muscle was homogenized in $2 \mathrm{ml} 0.9 \% \mathrm{NaCl}$. After centrifugating, 100-150 $\mu$ supernatant was given via the heart catheter to 6 male and 6 female rats. For measuring plasma enzyme activities blood was sampled before the enzyme administration and $0,5,10,20,30,60$ and 120 minutes thereafter. The clearance rates ( $k d$-values) of CK, AST and LD were calculated from the slope of the natural log scale of enzyme activity versus time.

To study eventual short term exercise-induced changes in clearance rates the $\mathrm{kd}$-values were also determined immediately after $1.5 \mathrm{~h}$ exercise in the same 6 male and 6 female rats. CK clearance rates were calculated for 30 minutes after administration of an enzyme bolus, while for AST and LD the measuring period was $1 \mathrm{~h}$.

\section{Statistical analysis}

Since the data were not normally distributed, the Wilcoxon signed-rank test was used to compare pre- and post-exercise plasma CK, AST and LD levels within the groups. The Willcoxon rank-sum test was used to study the effect of exercise duration and gender, and to compare histological muscle damage between groups $A, B$ and $C$. The Student t-test was used to compare the clearance rates of CK, AST and LD. Differences were considered to be statistically significant at $p<0.05$.

\subsection{RESULTS}

\section{Histological muscle damage}

Signs of histological damage were only found in the soleus muscle. Degenerative changes could not be found in the extensor digitorum longus, tibialis anterior and gastrocnemius muscles and in any fibre of the nonexercised rats, the only exception being the plantaris muscle in group $B$ ( 2.5 h exercise), where in 2 out of 16 animals a total of 3-4 damaged fibres were found. No signs of histological damage were found in any of the studied forelimb muscles. The main feature of histological muscle damage consisted of myofibre infiltration with neutrophilic and eosinophilic granulocytes, while multiple central nuclei formed the minority. Accumulation of inflammatory cells was also observed in the interstitial space adjacent to affected fibres.

As can be seen in Table 7.1 running uphill for $2.5 \mathrm{~h}$ elicited a significant increase in the volume of muscle damage, compared with $1.5 \mathrm{~h}$ of running. This was true in both male and female animals. Neither in group A nor in group differences in the amount of histological damage were found between male and female animals. 
TABLE 7.1. Total (left plus night) soleus muscle weights (mean \pm $S E M)$ and percentage of soleus muscle volume with histological damage (mean \pm SEM) in the different groups of animals. "Significant increase in muscle damage compared with control group. $t$ Significant increase in muscle damage compared with $1.5 \mathrm{~h}$ exercise.

\begin{tabular}{|c|c|c|}
\hline & $\begin{array}{l}\text { soleus wet } \\
\text { welght (mg) }\end{array}$ & $\begin{array}{l}\text { damaged volume } \\
(\% \text { of total soleus musclle) }\end{array}$ \\
\hline \multicolumn{3}{|c|}{ group A ( $1.5 \mathrm{~h}$ exercise) } \\
\hline 8 males & $282.8 \div 8.3$ & $0.09 \pm 0.02$ \\
\hline 7 females & $192.3 \pm 2.4$ & $0.13 \pm 0.02^{\prime \prime}$ \\
\hline \multicolumn{3}{|c|}{ group B (2.5 h exercise) } \\
\hline 6 malles & $254.8+20.1$ & $1.31 \pm 0.49^{*}+$ \\
\hline 7 lemales & $235.0 \pm 10.7$ & $1.31 \pm 0.40^{\circ} t$ \\
\hline \multicolumn{3}{|c|}{ group C (control) } \\
\hline 6 mallos & $242.8 \pm 9.3$ & 0 \\
\hline 6 females & $187.9 \pm 8.2$ & 0 \\
\hline
\end{tabular}

Comparing the damage per animal in the right and left limb muscles yielded a correlation coefficient of $r=0.75(p<0.001)$.

\section{Plasma enzyme activities, exercise duration and gender}

The increases in CK and LD activity after $2.5 \mathrm{~h}$ of running were significantly higher immediately post-exercise compared with $1.5 \mathrm{~h}$ of running, in both male and female rats. The increase in AST activity after $2.5 \mathrm{~h}$ of running was significantly higher until $9 \mathrm{~h}$ post-exercise compared with 1.5 h of running, in both male and female rats (Fig. 7.1 and 7.2).

Increases in plasma AST and LD activity immediately after $1.5 \mathrm{~h}$ of running were significantly higher in male rats compared with female rats. The increase in plasma LD activity remained significantly higher in males until $3 \mathrm{~h}$ post-exercise. The increase in plasma $\mathrm{CK}$ activity after $2.5 \mathrm{~h}$ of running in the males remained significantly higher for $1 \mathrm{~h}$ post-exercise compared with the females. The male rats demonstrated a significantly higher increase in plasma AST activity than females until $9 \mathrm{~h}$ post-exercise.

Significant gender differences were found in the total number of units of CK, AST and LD released. The total number of units released (mean \pm SEM) of CK, AST and LD in males were $30.8 \pm 7.5,11.8 \pm 3.4$ and $46.7 \pm 15.8$ $\mathrm{U}$ and in females $11.6 \pm 2.2,4.5 \pm 1.0$ and $13.0 \pm 3.7 \mathrm{U}$. 

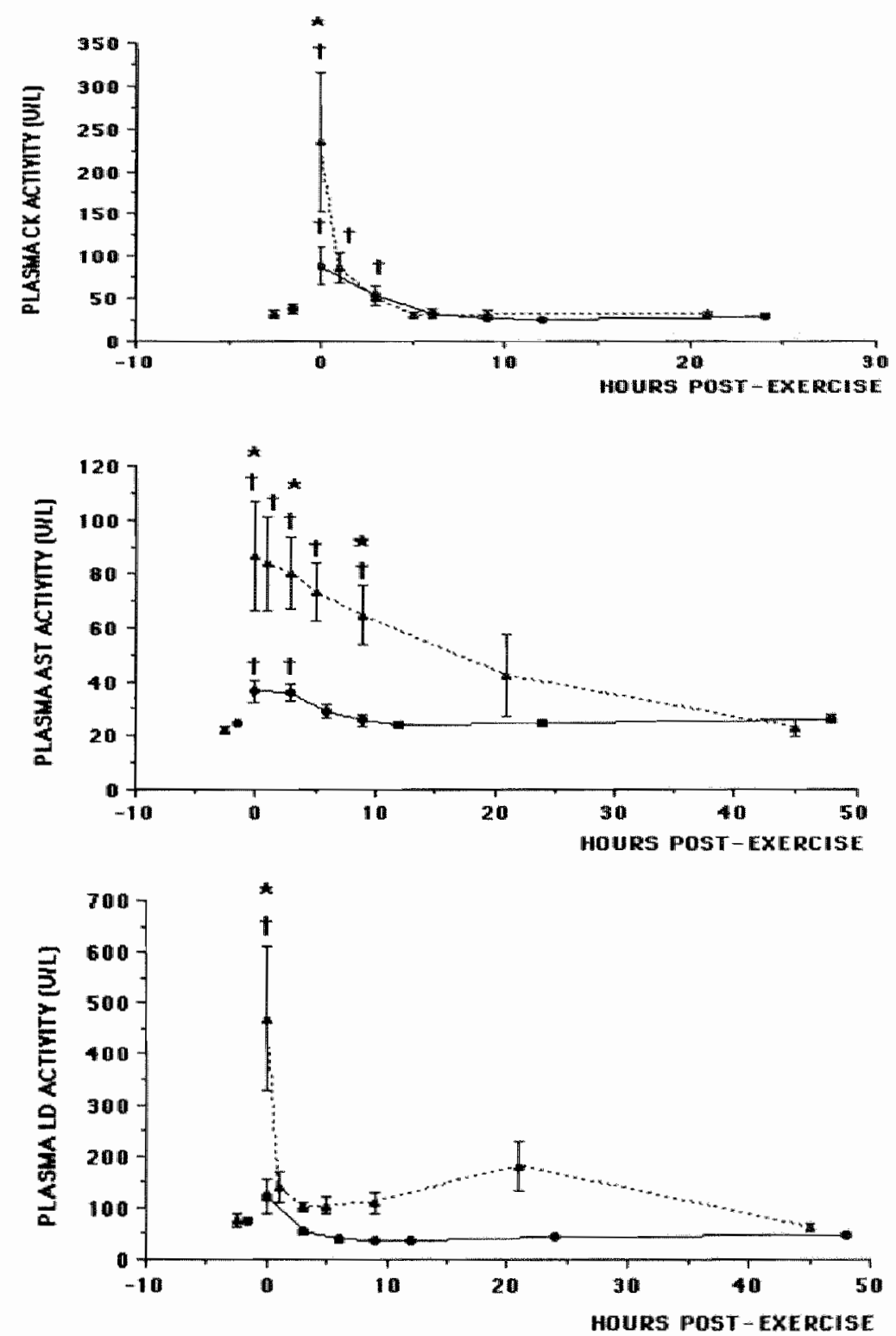

FIGURE 7.1. Plasma CK, AST and LD activities (mean \pm SEM) in male rats betore and after running for $1.5 \mathrm{~h}(\boldsymbol{\Theta}, n=8)$ or $2.5 \mathrm{~h}(\boldsymbol{\Lambda}, n=6)$. + Significant difference between pre-and post-exercise values. "Significant difference between the 1.5 and $2.5 \mathrm{~h}$ regimen. 

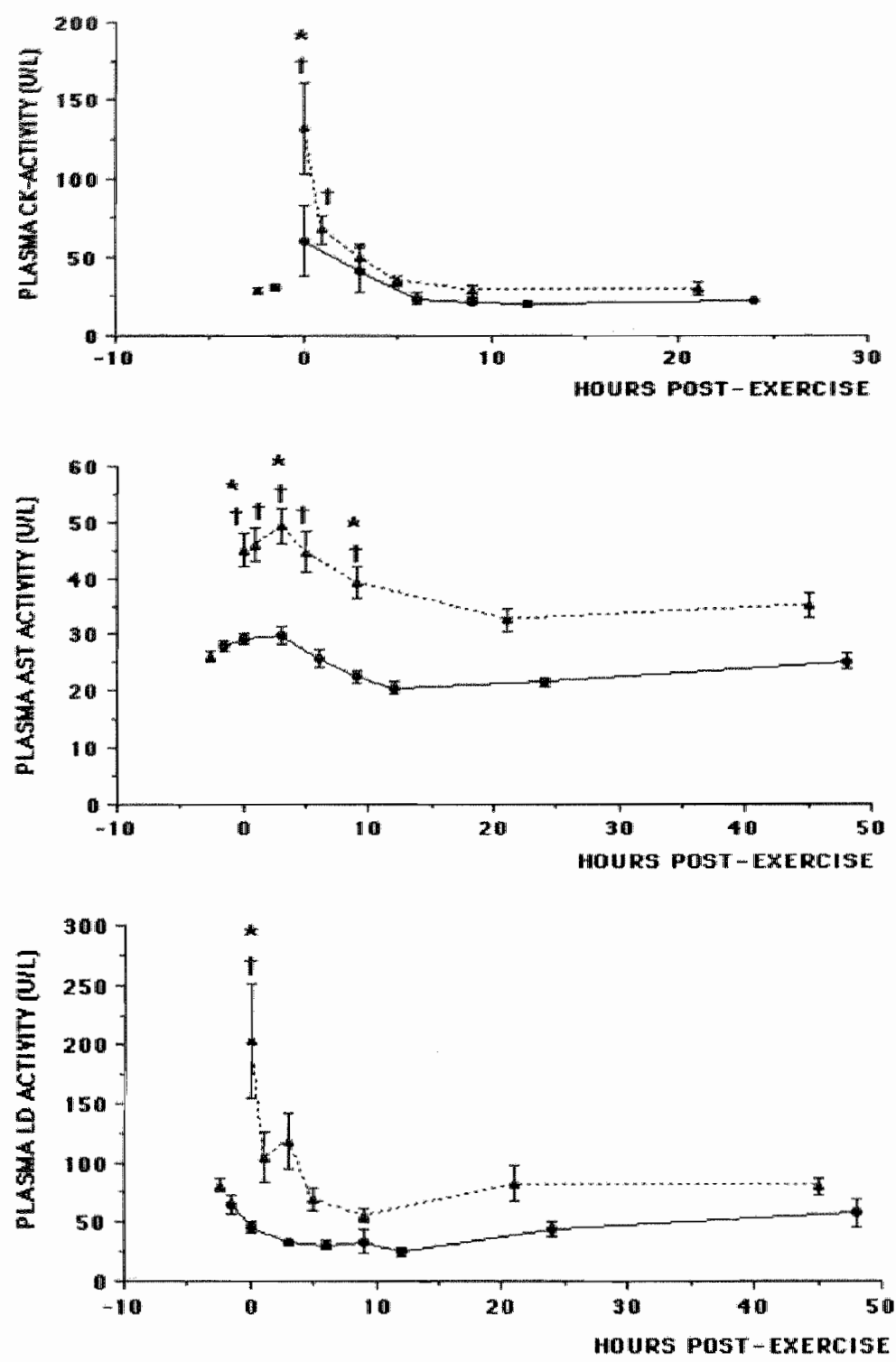

FIGURE 7.2. Plasma CK, AST and LD activities (mean \pm SEM) in fomale rats betore and after running for $1.5 \mathrm{~h}(0, n=7)$ or $2.5 \mathrm{~h}$ $(\mathbf{\Lambda}, n=7)$. + Significant difference between pre and post-exercise values. "Significant difference between the 1.5 and $2.5 \mathrm{~h}$ regimen. 


\section{Plasma enzyme activitles versus muscle damage}

Table 7.2 demonstrates that the muscle damage as calculated from enzyme release for the 3 enzymes studied was significantly greater than the actual histological muscle damage. In male rats the muscle damage calculated from CK, AST and LD release was significantly greater compared with female rats, while the actual histological damage in male rats was not significantly greater compared with fermale rats.

TABLE 7. 2. Comparison between actual histological muscle damage and estimated muscle damage, based on enzyme release of CK, AST and LD in male and female rats. "Significant difference between estimated muscle damage based on enzyme release and actual histological damage. + Significant difference in estimated muscle damage based on enzyme release between male and female rats.

actual damaged tissue weight (mg) estimated damage (mg)

\begin{tabular}{ll}
\hline $\mathrm{CK}$ & $\mathrm{AST}$
\end{tabular}

\begin{tabular}{llccc}
$\begin{array}{l}\text { malles } \\
(n=7)\end{array}$ & $3.1 \pm 0.9$ & $24.8 \pm 6.0^{*} \dagger$ & $156.0 \pm 45.7^{*} \dagger$ & $50.6 \pm 47.1^{*}+1$ \\
$\begin{array}{l}\text { females } \\
(n=9)\end{array}$ & $3.2 \pm 0.9$ & $11.3 \pm 2.1^{*}$ & $5.4 .7 \pm 12.5^{*}$ & $17.4 \pm 4.9^{*}$ \\
\hline
\end{tabular}

\section{Muscle enzyme content and clearance rates}

No significant differences were found in soleus enzyme content between male and female rats. The CK, AST and LD content (mean \pm SEM) in the soleus muscles of male rats $(n=6)$ was $1382 \pm 86,79 \pm 5$ and $157 \pm 18$ $\mathrm{U} . \mathrm{g}^{-1}$ wet weight, respectively. The CK,AST and LD content (mean \pm SEM) in the soleus muscles of female rats $(n=6)$ was $1196 \pm 39,79 \pm 4$ and $161 \pm$ $12 \mathrm{U} \cdot \mathrm{g}^{-1}$ wet weight, respectively. The clearance rates for CK and AST were only significantly higher post-exercise in temale rals compared with males 
TABLE 7.3. Clearance rates (kodvalues expressed as $h^{-1}$; mean $\pm S E M$ ) of CK, AST and LD in male ( $n=6$, except for $L D, n=4)$ and female rats $(n=6$, except for $L D, n=4)$.

"Significant difference between male and female rats. + Significant difference between at rest and immediately post-exercise.

\begin{tabular}{|c|c|c|}
\hline & malle rals & female rats \\
\hline $\begin{array}{l}\text { kd CK (at rast) } \\
k_{d} C K \text { (exercise) }\end{array}$ & $\begin{array}{l}6.42 \pm 0.56 \dagger \\
2.58 \pm 0.44^{2}\end{array}$ & $\begin{array}{l}4.7 .4 \pm 1.10 \\
4.32+0.49\end{array}$ \\
\hline $\begin{array}{l}k_{d} \text { AST (at rest) } \\
k_{d} \text { AST (exarclse) }\end{array}$ & $\begin{array}{l}1.02 \pm 0.12 t \\
0.42 \pm 0.12\end{array}$ & $\begin{array}{l}1.14 \pm 0.20 \\
0.78 \pm 0.05\end{array}$ \\
\hline $\begin{array}{l}k_{d} L D \text { (at rest) } \\
k_{d} L D \text { (exerclse) }\end{array}$ & $\begin{array}{l}5.09+1.45 \\
5.09+0.91\end{array}$ & $\begin{array}{l}5.09 \pm 0.18 \\
3.64 \pm 0.36\end{array}$ \\
\hline
\end{tabular}

(Table 7.3). In male rats, CK and AST clearance was significantly higher at rest than after exercise. In female rats, the clearance of LD was significantly greater at rest, compared with post-exercise.

\subsection{DISCUSSION}

\section{Histological muscle damage}

The present study demonstrated that running uphill elicited degenerative changes and release of muscle enzymes both in male and female rats. Histological damage was only found in the soleus muscle. The increase in muscle damage after running for $2.5 \mathrm{~h}$ was disproportionately greater compared with $1.5 \mathrm{~h}$ exercise (Table 7.1), which indicates that the exerciseinduced muscle damage does not linearly increase with exercise time. This also seems to be true in man, since compared with the first $30 \mathrm{~km}$, during the last $12 \mathrm{~km}$ of a marathon a disproportionate increase in muscle damage was lound in marathon runners (Janssen ot al., 1989). Although from the present data no explanation is available, others have suggested that this may be associated with glycogen depletion (Janssen et al., 1989).

In male and female rats, running for the same amount of time, an equal amount of histological muscle damage was found, which was to be expecled since the ratio between the soleus weight and the body weight was similar in both sexes. In both male and female rats that ran on the treadmill, a significant positive correlation $(r=0.75)$ between the histological muscle damage of the left and right soleus muscles was found. However, occasionally unexplained differences in the extent of muscle damage between left and right soleus muscles were observed, which should be taken into account when quantifying muscle damage in just one leg. 


\section{Muscle enzyme release}

In the present study, peaks in the muscle enzyme releases were abserved immediately post-exercise. This is in agreement with other investigators, who used level running (Amelink and Bär, 1986; Armstrong of al., 1983), uphill and downhill running (Armstrong ot al., 1983), and an in vitro preparation (Jones et al. "1983). However, after downhill running or stepping exercise a second peak was observed after approximately 24 hours (Armstrong et al., 1983; Newham et al., 1983a; Schwane et al., 1983). Although the precise mechanism of enzyme release has not yet been established, it is assumed that the peak immediately following exercise is associated with an acute and transient increased sarcolemmal permeability due to a decline in the pool of energy rich phosphates (Armstrong et al., 1983; Jones et al., 1983). A second peak is assumed to be related to an inflammatory response (Clarkson and Ebbeling, 1988, Hortobágyi and Denahan, 1989). The speed at which the enzyme values in the plasma return to basal levels is, amongst others, dependent upon the efflux rate, the total enzyme efflux, lymphatic transport and the clearance rate of the enzyme.

The enzyme release patterns demonstrated a gender difference which is in agreement with other studies (Amelink and Bär, 1986; Amelink et al., 1988). But, while we did find a significant exercise-induced increase in plasma CK activity in the female rats, Amelink and Bär (1986) falled to find an exercise-induced increase in mean plasma enzyme activities in female rats. This difference may be explained by a more vigorous protocol in the present study ( $2.5 \mathrm{~h}$ running uphill at $30 \mathrm{~m} / \mathrm{min}$ ) compared to the protocol used by Amelink and Bär (1986; 2 h level running at $19 \mathrm{~m} / \mathrm{min}$ ).

The gender differences in post-exercise elevations of plasma CK and AST activities can only partly be explained by greater clearance rates in the female rats during exercise (Table 7.3) and cannot be attributed to different amounts of necrotic muscle tissue (Table 7.1), different muscle enzyme contents, or differences in clearance rates determined at rest (Table 7.3). As suggested from the studies of Amelink and Bär (1986), Bär et al. (1988), Häkkinen and Alén (1989) and Thomson and Smilth (1980) sex hormones seem to modify membrane permeability, i.e. androgens enthance CK efflux, while estrogens inhibit CK efflux. However, the present study indicates that sex hormones fail to have a protective influence against histological muscle damage, because the same amount of damage was found in both sexes.

Irrespective of gender, an effect of exercilse duration was seen on enzyme efflux, i.e. $2.5 \mathrm{~h}$ running uphill resulted in a significantly elevated plasma CK, AST and LD activity compared with rats running for $1.5 \mathrm{~h}$. Both exercise intensity and duration are related to the exercise-induced plasma CK activity (for reviews, see Hortobágyi and Denahan, 1989; Noakes, 1987). However, with longer exercise duration these two factors cannot be clearly separated. With increasing fatigue the maximal running speed decreases. Therefore a fixed submaximal running speed will become a higher percentage of maximal speed with increasing exercise duration. 


\section{Histological muscle damage and muscle enzyme release}

Calculated muscle damage based on muscle enzyme release tumed out to be larger than the amount of histological damage in the soleus muscle (Table 7.2). Estimating muscle damage from the enzymes measured, plasma CK activity yields a result that comes closest to histollogical muscle damage. From the present data the discrepancy between histological damage and enzyme release cannot be explained satisfactorily. It cannot be ruled out that the sarcolemma becomes transiently more permeable during exercise. CK release has also been observed in rats after level running without signs of histological damage being observed (Armstrong et al., 1983). In addition, also in in vitro studies enzyme release can be observed without apparent histological damage (Jones et al., 1983). This suggests that an increased permeability is not necessarily associated with histological damage (Highman and Altland, 1963; Jones et al., 1983). Therefore, it cannot be excluded that normal soleus muscle fibres and also other muscles may have contributed to the enzyme release. Ogilvie et al. (1988) have shown that in soleus muscles of rats that were subjected to level or downhill running, A-band lesions were observed immediately after exercise. They speculated that tearing of filaments in the A-band regions could disturb the sarcolemma and subsequently could lead to enzyme release. However, the extent of the early lesions is only minor compared to the findings 24-48 h later (Kuipers et al., 1983). The early lesions may be associated with the enzyme release immediately after exercise. Comparing the extent of the early lesions with enzyme release, the discrepancy between damage and enzyme release would be greater. Another possibility which may contribute to the discrepancy between estimated and histological damage, is that organs like the liver and the heart may contribute to the plasma enzyme release. Determination of liver enzyme L-alanine aminotransferase (ALT) and the subfractions of the enzymes indicated that this contribution was negligible (unpublished observation). In addition, Amelink et al. (1988) showed that heart damage, indicated by increased CK-MB, was absent. Although we found that the contribution of CK-BB was negligible, Amelink ot al. (1988) observed that a contribution of CK-BB, probably released from blood platelets, may occur. They showed that, although the relative CK-BB change was small, approximately $25 \%$ of the totall enzyme activity could be attributed to CK-BB (Amelink, 1990).

In summary, the present study shows that exercise with longer duration elicits a disproportionate increase both in histological muscle damage and enzyme release. A novel finding is that the amount of structural damage was significantly lower than the estimated amount of damage, based on on the total amount of CK, AST, and LD released into the vascular compartment. In addition, the present study showed that gender differences in enzyme release after exercise do not reflect differences in the amount of histological damage. It is concluded that increases in plasma activity of muscle enzymes do not necessarily reflect structural damage, but changes in membrane 
permeability as well. Based on the results of the present study, the use of plasma enzyme activities for estimating the amount of muscle damage is unsuited. 



\section{Quantitative aspects of secondary changes in male and female rat soleus muscle after exercise of dif- ferent duration}

\subsection{SUMMARY}

The aim of the present study was to investigate the effect of exercise duration on the amount of secondary changes (inflammation and degeneration), the number of affected muscle fibres, the segment over which muscle fibres were affected and the spatial distribution of affected muscle fibres in the rat soleus muscle after submaximal uphill running. In addition, gender differences in secondary changes were studied. Wistar rats ran on a treadmill ( $10^{\circ}$ incline, $1840 \mathrm{~m} / \mathrm{h}$ ) for 1.5 or $2.5 \mathrm{~h}$. Three days post-exercise the left and right soleus muscles were dissected out. From the muscles serial cross sections were cut from proximal to distal, by which individual fibres could be followed over their entire length. Secondary changes were quantified morphologically. With increasing exercise duration a disproportionate increase in secondary changes was found. An increased number of affected fibres as well as an increase in mean length over which fibres were affected, was found. No differences in the amount of muscle damage between male and female rats were observed. Beside small occasional clustering, affected fibres were randomly distributed throughout the soleus muscle.

\subsection{INTRODUCTION}

Microscopical analysis has revealed that an acute bout of endurance running may result in muscle fibre degeneration in the muscles that are involved in exercise (for review, see Ebbeling and Clarkson, 1989). Whereas most studies focussed on the extent of damage (Armstrong ot al., 1983; Kuipers et al., 1983), type of damage (Kuipers et al., 1983; Ogilvie et al., 1988) or biochemical alterations in the muscles (Armstrong ot al., 1983; Snyder et al., 1984), few studies reported about the spatial distribution of damage throughout the muscle (Irintchev and Wernig, 1987; Newham ot al., 1986b; Ogilvie et al., 1988; Salminen, 1985). In one study the distribution of muscle necrosis was studied in inflammatory muscle disorders (Comola et al., 1987). Since the distribution of fibre damage was generally studied only for a limited segment of the muscle, it cannat be ruled out that the exercise-induced damage as found in a particular segment is not representative for the whole muscle. This may have consequences when extrapolating the damage as found in a small sample, to the whole muscle. Support for this is provided by studies that indicate that the damage may not equally be distributed throughout the 
muscle. Salminen (1985) reported that in mice more damage was found in the deep portions of some muscles. In addition, Ogilvie et al. (1988) showed that after exercise more damage was found in the proximal part of rat soleus muscles. In man there are also indications for uneven distribution of muscle damage, as shown by the $99 m_{\text {technetium pyrophosphate (Tc-PYP) uptake }}$ by skeletal muscle after exercise (Newham et al., 1986b). There are some indirect indications for uneven distribution of muscle damage, since Newham et al. (1983c) found uneven distribution of soreness after eccentric work. These findings may question the representativity of muscle biopsies.

The extent of muscle damage is also related to the duration of the exercise (Salminen, 1985). However, it is not known whether any increase in damage is restricted to certain areas or is equally distributed along the whole length of the muscle. Furthermore, it is unknown whether the increase in muscle damage is the result of an increase in number of damaged muscle fibres, an increase of length of the affected segments, or both. In addition, based on enzyme release, it has been shown that exercise-induced muscle damage differs between male and female rats (Amelink and Bär, 1986; Amelink ot al. 1988).

Therefore, the aim of the present study was to investigate the effect of exercise duration ( $1.5 \mathrm{~h}$ and $2.5 \mathrm{~h}$ ) on the total amount of secondary changes (inflammation and degeneration), the number of affected fibres, the length of the affected segments in muscle fibres and the spatial distribution of affected fibres in the soleus muscle in malle and female rats running uphill on a treadmill.

\subsection{MATERIAL AND METHODS}

\section{Animals and exercise protocols}

In the present study 18 malle and 18 female Wistar rats ( 3 months old) were used. The rats were housed in individual cages in a temperature controlled environment $\left(23-26^{\circ} \mathrm{C}\right)$. They had free access to water and food (type 1210, Hope Farms, The Netherlands). The light was on between 7:30 a.m. and 7:30 p.m. The animals were randomly assigned to either group $A$, $B$, or $C$.

Group A ( 6 males and 6 females) and group B ( 6 males and 6 females) ran uphill $\left(10^{\circ}\right.$ incline) on a rodent treadmill (Quinton) for 1.5 and $2.5 \mathrm{~h}$, respectively. Using this protocol it has been shown that secondary changes were elicited in the soleus muscles (Kuipers et al., 1983). Group C (6 males and 6 females) consisted of 12 sedentary control animals.

The animals were exercised between 9:00 a.m. and 12:00 a.m. The treadmill speed was gradually increased until after $15 \mathrm{~min} 1840 \mathrm{~m} / \mathrm{h}$ was reached. This speed was maintained throughout the exercise bout. If needed the rats were stimulated to run by a mild electrical current that was set on the resting grid for $0.1 \mathrm{~s}$ every $5 \mathrm{~s}$. 


\section{Histology}

To study secondary changes the soleus muscles were dissected out 72 $h$ post-exercise, since a previous study demonstrated that these changes were most pronounced and extensive 24-72 h after exercise (Kuipers et al., 1983). The dissection of the muscles was done under ether anaesthesia of the rats. The muscles were frozen in isopentane, cooled to melting point in liquid $\mathrm{N}_{2}$. From the soleus muscles $10 \mu \mathrm{m}$ thick sections were cut in a cryostat (Anglio Scientific) at $-20^{\circ} \mathrm{C}$. Each 15 th section was mounted on glass, stained with haematoxylin-eosin and used for microscopical examination. Muscle fibres were considered to be affected when one of the following features could be identified: fibres infiltrated by inflammatory cells, vacuoles in the cytoplasm, hyaline aspect and fibres with multiple central nuclei. By use of a microscope (Zeiss, magnification 100x), prisma and a transparant measuring tablet (MOP-videoplan, Kontron) fibre area of individual affected fibres as well as the total muscle area at $150 \mu \mathrm{m}$ intervals along the longitudinal axis were measured. By examining successive sections individual fibres could be followed over their entire length. In this way, it was possible to assess the length of the affected segments. Also the total number of affected fibres was counted.

\section{Distribution of affected muscle fibres along the longitudinal axis}

To be able to compare the secondary changes along the longitudinal axis in the different rats that might have different length of the soleus muscle, each muscle was divided into 15 segments. See Figure 8.1 (upper part). The segments were numbered 1 to 15 from proximal to distal, respectively. Although the length of all segments within one muscle were equal, because of possible differences in muscle length between animals, the length of corresponding segments of muscles from different animals could differ. Origin and insertion of the muscles were determined microscopically by looking at the transition of muscle to tendon. Since it was known that the distance between cross sections was $150 \mu \mathrm{m}$, the total length of the muscle was calculated from the total number of sections. Using the number of cross sections in each muscle it was possible to calculate the length of the 15 segments in each individual muscle.

The middle section of each segment was considered as representative for that particular segment. In the representative sections all affected muscle fibres were counted and the percentage of affected muscle area was calculated in each section. For comparison of secondary changes in corresponding segments between rats of the 3 groups $A, B$ and $C$ the total number of affected muscle fibres and the mean percentage of affected muscle area was established in the 15 corresponding segments.

\section{Distribution of affected fibres in the transverse plane}

For studying the distribution of secondary changes in the transverse plane only the centre part of the muscle was used. See Figure 8.1 (lower 


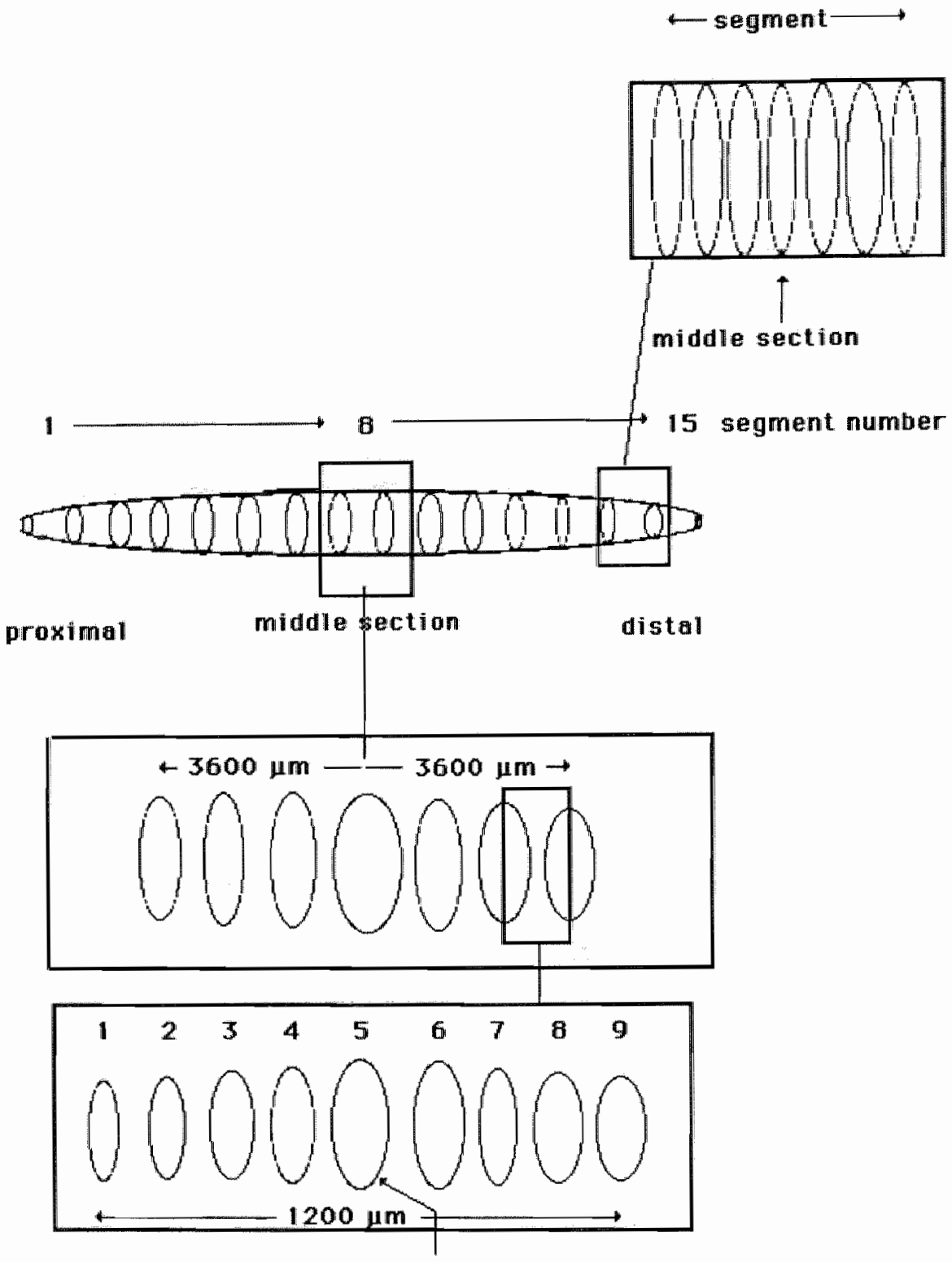

5 th mid cross section

FIGURE 8.1. Schematic description of the soleus muscle for studying muscle damage along the longitudinal axis and in the transverse plane. 
part). From the 15 segments in which each muscle was divided the middle cross section of segment number 8 was taken as midpoint of the muscle. Using the distance between serial sections $(150 \mu \mathrm{m})$ a part of the muscle, $7200 \mu \mathrm{m}$ in length was selected, by following serial sections $3600 \mu \mathrm{m}$ distally and proximally from the middle cross section. Consecutively, the $7200 \mu \mathrm{m}$ was divided into 6 segments of $1200 \mu \mathrm{m}$ each. From each of the 6 segments 9 cross sections were selected. The total secondary changes of each segment was assessed by projecting the secondary changes of the cross sections 1-4 and 6-9 on the 5 th mid cross section. In this way section number 5 contained the summation of affected fibres in each segment.

\section{Statistical analysils}

To test the influence of exercise duration and gender on amount of secondary changes and number of affected fibres, the Wilcoxon rank-sum test was used. To compare the length of segments over which muscle fibres were affected the Student t-test was used. The level of significance was set at $\rho<0.05$.

\subsection{RESULTS}

Table 8.1 shows that both exercise protocols elicited secondary changes in the soleus muscles, in male as well as in female rats. Compared with 1.5 $\mathrm{h}$ exercise $2.5 \mathrm{~h}$ exercise elicited a significant and disproportionate increase in secondary changes in both sexes. With longer exercise duration in both sexes the number and mean length of affected segments increased significantly. The affected fibres consisted primarily of an accumulation of inflammatory cells, which could also be involved in the surrounding connective tissue. No secondary changes were found in the soleus muscles of nonexercised control rats.

As can be seen in Figure 8.2 the highest number of affected fibres were found in the centre part of the soleus muscles. The changes, expressed as a percentage of total muscle area were equally distributed throughout the soleus muscle.

A great variability in the extent of secondary changes in the soleus muscles was found, as shown in Figure 8.3. The secondary changes were randomly distributed in the transverse plane.

\subsection{DISCUSSION}

The aim of the present study was to investigate the amount of secondary changes, the number of affected fibres, the length of the segment over which fibres were alfected and the spatial distribution of affected fibres in the soleus muscle in male and female rats after running uphill for different durations. 
4
4
4
4

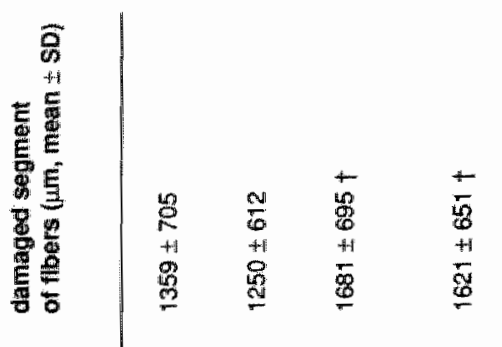

5

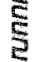

过

도

$\frac{9}{6}$

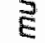

$\frac{5}{8}$

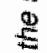

E

कै

E

8 는

क

量

万菅

o

Q 5

क 8

(i) 5

35

is 8

तै ते

32

08

- 40

440

की $V w$

$5 a$

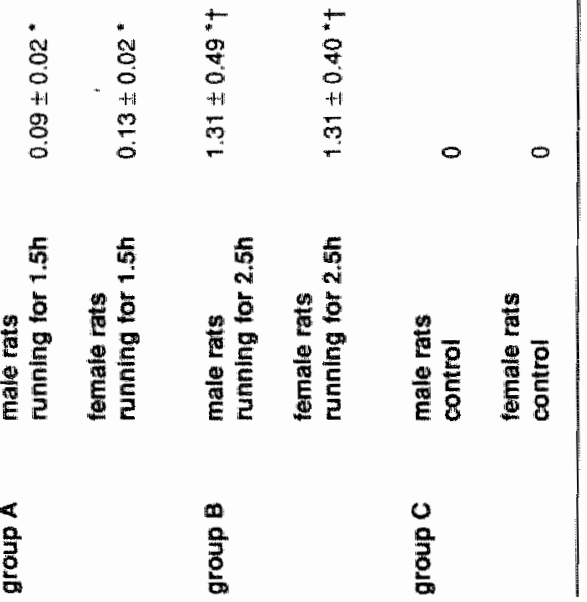




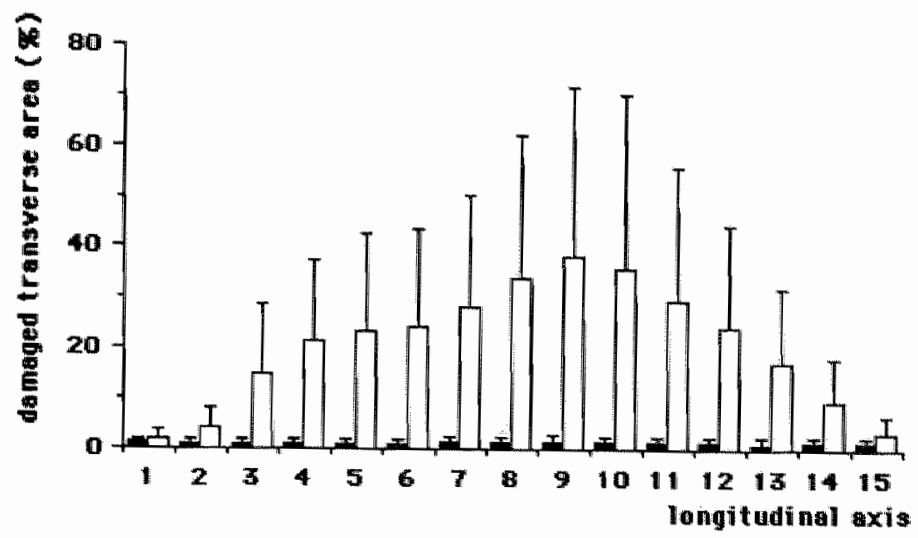

FIGURE 8.2. Distribution of muscle damage along the longitudinal axis from proximal (left) to distal (night) after $2.5 \mathrm{~h}$ running. Muscle damage is expressed as \% (mean $\pm S D$ ) of the damaged muscle area in the transverse plane (,$n=32)$ and as the total number of damaged muscle fibres in the transverse plane $(\square, n=$ 32) in corresponding in cross sections.
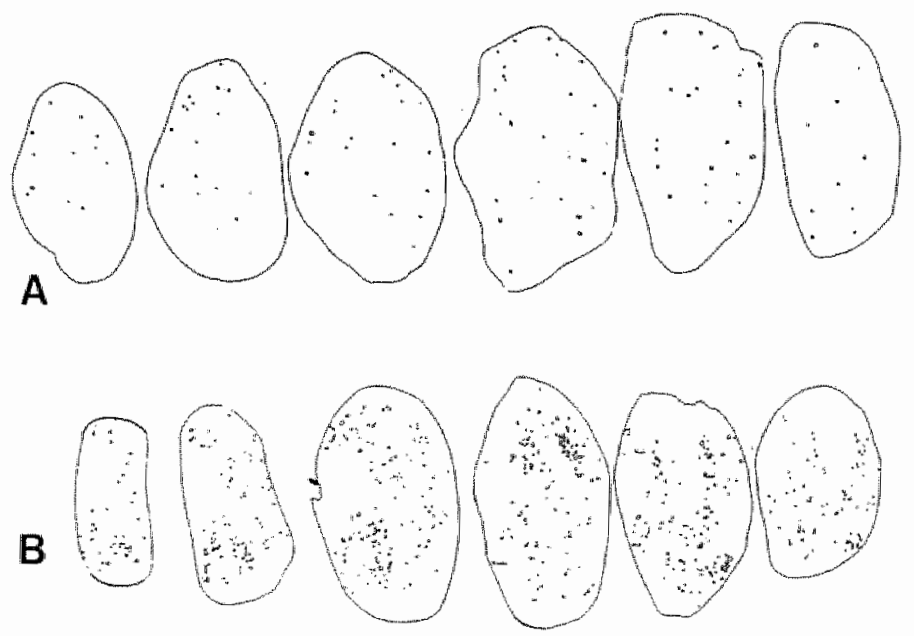

FIGURE 8.3. Damage in exercised soleus muscle for $1.5 \mathrm{~h}(\mathrm{~A})$ and 2.5 $h(B)$. The damaged muscle fibres are summatively projected in equidistant transverse planes $(1200 \mu \mathrm{m})$. 
A significant and disproportionate increase of secondary changes was found with longer exercise duration. This was true for both sexes and the increase of secondary changes was primarily attributable to an increased number of affected fibres. It might be argued that an increase of secondary changes after longer exercise originated from the electrical stimulation since the times that the animals had contact with the grid increased with longer exercise duration. However, it was found that the contact with the grid occurred most frequently during the first phase. With longer exercise time the rats apparently adjusted to the constancy of the pattern of stimulation and quickly learned to avoid the electrical current. Another explanation for the increase in secondary changes might be depletion of glycogen in the active muscle fibres. It is conceivable that with longer exercise duration certain fibres became glycogen depleted, resulting in the recruitment of fibres that are normally not involved in this type of exercise. Since these additionally recruited fibres might not have been adjusted to the exercise stress, a disproportionate increase in secondary changes may be explained. Based on the glycogen depletion pattern (unpublished observation), it is likely that specifically type I fibres were recruited during the early phase of running. The affected muscle fibres consisted of about $90 \%$ of type I fibres in rats that ran for $1.5 \mathrm{~h}$. After the $2.5 \mathrm{~h}$ exercise an increased portion of the affected fibres consists of type II fibres, which suggest that recruitment af this fibre type rather than selective vulnerability is important for the damage to specific fibre types. Jennische (1985) showed that in muscles that were subjected to ischaemia in combination with glycogen depletion, type II fibres seemed to be more vulnerable than type I fibres. In the $2.5 \mathrm{~h}$ running group a large variability in amount of histological changes was found. Although certain rats had obviously more difficulty in completing the $2.5 \mathrm{~h}$ no clear relationship was found between the ability to run and the extent of secondary changes. This suggests that the inability to continue the run is primarily determined by fatique and to a lesser extent to muscle damage. Therefore, factors related to fatigue, such as lactate, decreased $\mathrm{pH}$ and oxygen shortage seems nol to contribute in eliciting muscle damage.

The more extensive changes after $2.5 \mathrm{~h}$ exercise were also attributable to an increased length of the affected segments. Although the present study does not allow conclusions as to this phenomenon, it might be speculated that the "walling off" of the primary affected site, as shown by Carpenter and Karpati (1984) is inhibited during exercise. This would result in extension of the primary affected segment in proximal and distal direction.

The affected fibres were equally distributed throughout the muscle. This does not concur with the study of Ogilvie et al. (1988), who found most affected fibres in the rat soleus muscle proximally. The authors explained their findings by assuming that the force was concentrated towards both ends because the cross sectional area of the muscle was smaller here. It thas also been suggested that the focal appearance of the fibre changes is associated with capillary supply and ischaemia. However, with ischaemia 
clustering of affected fibres might have been expected which was not the case in the present study. A study by Peeze Binkhorst et al. (1989) suggested that it is unlikely that ischaemia is primarily related to exercise-induced muscle fibre degeneration. Furthermore, we and others assume that the mechanical load on the fibres is of primary importance lor eliciting secondary changes (Armstrong et al., 1983). Despite the fact that the rats ran uphill, it cannot be excluded that when placing the foot against an incline an eccentric component in the soleus muscle does occur (Margaria, 1972) Since in eccentric work less fibres are recruited (Stauber, 1989) the recruited fibres have to deal with greater force than in concentric work. The location where the myofibrils break or is affected is probably random.

The equal distribution of secondary changes along the longitudinal axis as well as in the transverse plane suggest that the fibres were equally recruited throughout the soleus muscle. This seems to be confirmed by PAS staining, which demonstrated an even glycogen loss throughout the soleus muscle (unpublished observation). A significant correlation between amount of damage between left and right soleus muscles in the same animals was found. This indicates that both muscles are similarly involved when exercising on a treadmill. This would imply that the amount of damage assessed in one leg can be extrapolated to the contralateral muscles.

In the present study no difference in the amount of secondary changes between male and female rats was found. Based on a higher CK release in male compared with female rats, Amelink and Bär (1986) suggested that male rats would have had more secondary changes. The findings of the present study demonstrate that male and female rats have a similar amount of secondary changes in spite of differences in enzyme release. Since the mechanical stress in the soleus muscles is probably related to the muscle to body weight ratio, a similar amount of damage was anticipated since the soleus to body weight ratio ( $\mathrm{mg}$ vs $\mathrm{g}$ ) was equal in both sexes (males: 0.915 vs females: 0.936).

In summary, it was found that after submaximal uphill running of different duration, the longer exercise resulted in disproportionately more secondary changes, that could primarily be attributed to an increased number of affected fibres. The mean length over which muscle fibres were affected also increased. The affected muscle fibres were randomly distributed in the soleus muscle and no gender difference in amount of secondary changes was found. 
, 


\section{General discussion}

The main objective of the present study was to increase the knowledge about morphological, biochemical and functional aspects of exercise-induced muscle damage. Taking the time into account, muscle damage can histologically be characterized as primary damage (A-band and Z-line damage) and secondary changes (inflammation and degeneration) (Armstrong et al., 1983; Fridén et al., 1981, 1983b; Kuipers et al., 1983; Ogilvie et al., 1988). The appearance of muscle damage is local and focal (Kuipers et al., 1983; Ogilvie et al., 1988).

The exercise model was developed to induce muscle damage by forced lengthening of the rat tibialis anterior muscle in situ and was a modification of a similar model as used in mice by Faulkner and Jones (1985; Chapter 2). Control experiments consisting of passive stretch, isometric exercise and concentric exercise showed that only forced lengthening resulted in a significant amount of muscle damage indicating the necessity of lengthening during activation of the contractile apparatus. Since the damage and its time course is similar to those as reported by other investigators (Armstrong et al., 1983; Fridén et al., 1981, 1983b; Kuipers et al., 1983; Ogilvie et al., 1988), the model used in the present study seems satisfactory to study muscle damage induced by forced lengthening. Immediately after forced lengthening A-band and $Z$-line damage was found. Muscles studied $6 \mathrm{~h}, 1$ and 3 days post-exercise revealed that muscle fibres were infiltrated by inflammatory cells following the primary damage. Ten days post-exercise signs of regeneration were found, reflected in the presence of many satellite cells.

The initial damage consisted of damage to $A$-bands and $Z$-lines, both being part of the contractile apparatus. This strongly suggests that a mechanical factor is mainly responsible for eliciting muscle damage (Chapter 3). The results suggest that during forced lengthening the contractile elements are torn apart. Since the speed of lengthening seems to be a determining factor for eliciting damage, McCully and Faulkner (1986) assumed that at high lengthening speeds the cross bridge cycling cannot keep pace with the change in length. However, also with isometric exercise some signs of initial damage were found, suggesting that the strain put on the contractile elements with only a small change in sarcomere length, is able to elicit some minor primary damage (McCully and Faulkner, 1985).

The model showed that for the amount of damage not only force, vellocity of stretch, and number of contractions (McCully and Faulkner, 1986), but also the initial length is a contributing factor (Chapter 3 ). This is explained by the finding that at the small angle of the ankle joint the change in sarcomere length is less compared with the larger angle of the ankle joint. 
These results confirm results of other investigators who demonstrate that a greater decrease in muscle force and more pain was found when muscles were eccentrically exercised allong length than at short llength (Jones et al., 1989; Newham et al., 1988).

The present study suggests that primary damage is not necessarily followed by secondary changes (Chapter 3 ). This suggests that part of the initial damage is repaired within $24 \mathrm{~h}$. It is speculated that a given amount of intlial damage has to be exceeded to trigger the changes leading to degenerative and inllammatory changes.

One of the major findings of the present study is that in the rat muscle changes in compliance after exercise could be measured. Within the first few days after forced lengthening the presence of muscle damage seems to be related with a decreased compliance (Chapter 4), since in isometrically exercised muscles complianice was lower as well as the amount of primary damage. Further studies are needed to identify which factor is responsible for the initial changes in compliance. The results of the present study strongly suggest the decreased compliance 10 days post-exercise is attributable to thickening of the connective tissue.

Thickening of the connective tissue may also contribute to the reducthon of the amount of muscle damage when forced lengthening is repeated after a bout of forced lengthening contractions 3 weeks earlier (Chapter 5), as suggested by Clarkson and Tremblay (1988) and Newham et al. (1987). It remains to be established whether and how long the increased stiffness lasts beyond 10 days post-exercise.

Forced lengthening not only elicited muscle damage, but also resulted in a decreased intracellular ATP content in the forcibly lengthened muscles (Chapter 6). In the isometrically exercised muscles neither muscle damage nor a decrease in ATP content was found. Therefore, it is concluded that muscle damage is accompanied with an unexplained reduction in ATP concentration as was shown by others in ischaemia-induced muscle damage (Hlarris et al., 1986). Although calcium was not studied in the present study, it is supposed that calcium plays a crucial role in eliciting muscle damage and that calcium accumulation will lead to a decreased mitochondrial function, resulting in an impaired ATP generation. Further studies are necessary to elucidate the role of calcium in exercise-induced muscle damage. Both lorced lengthening and isometric exercise resulted in reduced glycogen levels, that were restored 6 h after both types of exercise. However, glycogen levels were reduced again $24 \mathrm{~h}$ after both types of exercise. The glycogen reduction $24 \mathrm{~h}$ post-exercise seems to be unrelated to the presence of muscle damage. This contrasts with the findings of some authors who have suggested a relationship between glycogen depletion and the presence of muscle damage (O'Reilly et al., 1987; Costill et al., 1990). The results of the present study and a previous study of Kuipers et al. (1985) demonstrate that the decrease in glycogen and muscle damage are not necessarily related. 
Often plasma CK activity is used as marker for the amount of muscle damage (Apple and Rhodes, 1988; Janssen et al., 1989). Based on gender differences in plasma $\mathrm{CK}$, it has been shown that female sex hormones do protect against muscle damage (Amelink and Bär, 1986; Amelink et al., 1990; Bär et al., 1988). It was shown in the present study that exercise of the same duration did elicit more enzyme release (CK, AST and LD) in male rats than in female rats (Chapter 7). However in both sexes the same amount of muscle damage was found. In addition, there was a discrepancy between the amount of enzyme released and the amount of muscle damage. This suggests that enzyme rellease reflects changes in membrane permeability rather than structural damage to the cellular content. This is supported by an in vitro study using chemical-induced muscle damage (Duncan and Jackson, 1987). This study showed that evoking damage to the sarcolemma, which is associated with enzyme release, is independent from damage of intracellular structures.

Both the amount of damage and enzyme released increased disproportionately in relation with exercise duration (Chapter 8 ). This suggests that a minimum amount of exercise has to be done before enzyme release occurs (Berg and Keul, 1979; Janssen et al., 1989). The increase in amount of damage is primarily attributable to an increase in number of damaged muscle fibres and the increase in muscle damage is similar in male and female rats (Chapter 8).

In conclusion, the major findings of the present study are:

- the exercise model enabled us to study primary damage and secondary changes by forced lengthening of the rat tibialis anterior muscle in situ.

- the amount of muscle damage was dependent on the initial muscle length and range over which the muscle is forcibly lengthened.

- after forced lengthening a decreased muscle compliance was found. Until 3 days post-exercise the change in passive stiffness can be attributed to muscle damage. The increased passive stiffness 10 days postexercise is probably attributable to thickening of the connective tissue.

- forced lengthening that was preceded 3 weeks before by one bout of forced lengthening resulted in a decreased amount of secondary changes, suggesting a peripheral adjustment.

- forced lengthening resulted in a decreased ATP content that can probably be attributed to changes associated with muscle damage. Isometric exercise showed that a decrease in glycogen content was independent of muscle damage. 
- in male rais compared with female rats that ran uphill on a treadmill a greater increase of muscle enzyme activity (CK, AST and LD) in plasma was found. The amount of muscle damage, however, was similar in both sexes.

- a longer exercise duration resulted in a disproportionate increase in enzyme release and muscle damage, attributable to a higher number of fibres affected and an increase in length of the segments over which the fibres are affected. 


\section{References}

Abbott $\mathrm{BC}$, Bigland $\mathrm{B}$, Ritchie JM. The physiological cost of negative work. J Physiol (London) 117: 380-390, 1952

Abraham WB. Factors in delayed muscle soreness. Med Sci Sports Exerc 9: 11-20, 1977

Aldridge $R$, Cady EB, Jones DA, Obletter $G$. Muscle pain after exercise is linked with an inorganic phospthate increase as shown by $31 \mathrm{P}$ NMR. Biosci Reports 6: 663667,1986

Allbrook D. Skeletal muscle regeneration. Muscle Nerve 4:234-245, 1981

Altland PD, Highman B. Effects of exercise on serum enzyme values and tissues of rats. Am J Physiol 201: 393-395, 1961

Amelink GJ, Bär PR. Exercise-induced muscle protein leakage in the rat. Effects of hormonal manipulation. Neurol Sci 76:61-68, 1986

Amelink GJ, Kamp HH. Bär PR. Creatine kinase isoenzyme profiles after exercise in the rat: sex-linked differences in leakage of CK-MM. Pflügers Arch 412: 417421, 1988

Amelink GJ. Exercise-induced muscle damage. Dissertation. University of Utrecht, The Netherlands. 1990

Amelink GJ, Koot RW, Erich WBM, van Gijn J, Bär PR. Sex-linked variation in creatine kinase release, and its dependence on oestradiol, can be demonstrated in an in-vitro rat skeletal muscle preparation. Acta Physiol Scand 138: 115-124, 1990

Amelink GJ, van der Kallen JH, Wokke JHJ, Bär P.R. Dantrolene sodium diminishes exercise-induced muscle damage in the rat. Eur J Pharmacol 179: 187-192, 1990

Appell H-J, Forsberg $\mathrm{S}$, Hollman W. Satellite cell activation in human skeletal muscle after training: evidence for muscle fibre neoformation. Int J Sports Med 9: 297299, 1988

Appell $\mathrm{H}-\mathrm{d}$. Muscular atrophy following immobilisation. A review. Sports Med 10: $42-$ 58,1990

Apple FS, Rogers MA, Sherman WM, Ivy JL. Comparison of serum creatine kinase MB activities post marathon race versus post myocardial infarction. Clin Chim Acta 138: 111-118, 1984

Apple FS, Rogers MA. Skeletal muscle lactate dehydrogenase isoenzyme alterations in men and women marathon runners. J App Physiol 61: 477-481, 1986

Apple FS, Rhodes M. Enzymatic estimation of skeletal muscle damage by analysis of changes in serum creatine kinase. J Appl Physiol 65: 2598-2600, 1988

Apple FS, Hellsten Y, Clarkson PM. Early detection of skeletal muscle injury by assay of creatine kinase MM isoforms in serum after acute exercise. Clin Chem 34; $1102-1104,1988$

Armstrong $\mathrm{AB}$, Marum P. Saubert CW, Seeherman HJ, Taylor CR. Muscle fiber activity as a function of speed and gail. J Appl Physiol 43: 672-677, 1977

Armstrong RB, Taylor CR. Relationship between muscle force and muscle area showing glycogen loss during locomotion. J Exp Biol 97: 411-420, 1982

Armstrong RB, Ogilvie RW, Schwane JA. Eccentric exercise-induced injury to skeletal muscle. J Appl Physiol 54: 80-93, 1983 
Armstrong $\mathrm{RB}$, Phelps RO. Muscle fiber type composition of the rat hindlimb. Am J Anat $171: 259-272,1984$

Armstrong RB. Mechanisms of exercise-induced delayed onset muscular soreness: a brief review. Med Sci Sports Exerc 16:529-538, 1984

Armstrong $\mathrm{RB}$. Initial events in exercise-induced muscular injury. Med Sci Sports Exerc $22: 429 \cdot 435,1990$

Asmussen E. Positive and negative muscular work. Acta Physiol Scand 28: 364-382, 1952

Asmussen E. Observations on experimental muscle soreness. Acta Rheumatologica Scand 1: $109-116,1956$

Băr PR, Amelink GJ, Oldenburg B, Blankenstein MA. Prevention of exercise-induced muscle membrane damage by oestradiol. Life Sci 42: 2677-2681, 1988

Baracos VE, Wilson EJ, Goldberg AL. Effects of temperature on protein turnover in isolated rat skeletal muscle. Am J Physiol 246: C125-C130, 1984

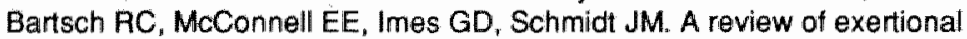
rhabdomyolysis in wild and domestic animals and man. Vet Pathol 14: 314324,1977

Basmajian JR. Muscles alive: their function revealed by electromyography, 2nd edn. p 221, Williams and Wilkins, Baltimore, 1967

Berg $A_{1}$ Haralamble $G$. Changes in serum creatine kinase and hexose phosphate isomerase activity with exercise duration. Eur J Appl Physiol 39: 191-201, 1978

Berg A, Keul J. Körperbelastung und Serumenzyme. D Z Sportmed 5: 128-134, 1979

Berg A, Keul J. Physiological and metabolic responses of female athletes during laboratory and field exercise. Med Sports 14: 77-96, 1981

Berg A, Keul J. Serumenzymkinetik wăhrend und nach intensiver Langzeitbelastung. Deutsche Zeitschrift für Sportmedizin 1: 12-17, 1982

Bigland B, Lippold OCJ. The rellation between force, velocity and integrated electrical activity in human muscles. J Physiol (London) 123: 214-224, 1954

Bigland-Ritchie $\mathrm{B}$, Woods JJ. Integrated EMG and $\mathrm{O}_{2}$ uptake during positive and negative work. J Physiol (London) 260: 267-277, 1976

Bilsen van $M$. The significance of myocardial non-esterified fatty acid accumulation during ischemia and reperfusion. Dissertation. University of Maastricht, The Netherlands, 1988

Bobbert MF, Hollander AP, Huijing PA. Factors in delayed onset muscular soreness of man. Med Scil Sports Exerc 18: 75-81, 1986

Braughler JM. Calcium and lipid peroxidation. In: Oxygen Radicals and Tissue Injury, edited by B Halliwell. Bethesda, MD: Fed Am Soc Biol pp 99-10.4, 1988

Brendstrup P. Late edema after muscular exercise. Arch Phys Med Rehabill 43: 401405,1962

Brody IA. Muscle contracture induced by exercise. N Engl J Med 281: 187-192, 1969

Brooks SV. Faulkner JA. Contraction-induced injury: recovery of skelletal muscles in young and old mice. Am J Physiol 258: C436-C442, 1990

Byrnes WC, Clarkson PM, White JS, Hsieh SS, Frykman PN, Maughan RJ. Dellayed anset muscle sareness following repeated bouts of downhill running. J Appl Physiol 59: 710-715, 1985

Campion DR. The muscle satellite cell: a review. Int J Rlev Cytol 87: 225-251, 1984

Carlson BM, Faulkner JA. The regeneration of skeletal muscle fibers following injury: a review. Med Sci Sports Exerc 15: 187 198, 1983

Carpenter S. Karpati G. Pathology of skeletal muscle. Churchill Livingstone. New York, 1984 
Clarkson PM, Kroll W, Graves J; Record WA. The relationship of serum creatine kinase, fiber type, and isometric exercise. Int J Sports Med 3:145-148, 1982

Clarkson $\mathrm{PM}_{*}$ Litchfeld $\mathrm{P}$, Graves J, Kinwan J, Byrnes WC. Serum creatine kinase activity following forearm flexion isometric exercise. Eur $\mathrm{J}$ Appl Physiol Oocup Physiol 53: 368-371, 1985

Clarkson PM, Byrnes WC, MCCormick KM, Turcotte LP, White JS. Muscle soreness and serum creatine kinase activity following isometric, eccentric and concentric exercise. Int J Sports Med 7: 152-155, 1986.

Clarkson PM, Apple FS, Byrnes WC, McCormick KM, Triffletti P. Creatine kinase isoforms following isometric exercise. Muscle Nerve 10:41-44, $11987 \mathrm{a}$

Clarkson PM, Byrnes WC, Gillison E, Harper E. Adaptation to exercise-induced muscle damage. Clin Sci 73: 383-386, $1987 \mathrm{~b}$

Clarkson PM, Ebbeling C. Investigation of serum creatine kinase variability after muscle damaging exercise. Clin Sci 75: 257-261, 1988

Clarkson PM, Tremblay I. Exercise-induced muscle damage, repair, and adaptation in humans. 1 Appl Physiol 6.5: 1-6, 1988

Clarkson PM. Too much too soon: the aftermath of overexertion. Sports Sci Exchange 21: $1-5,1990$

Comola M, Johnson MA, Howel D, Brunsdon C. Spatial distribution of muscle necrosis in biopsies from patients with inflammatory muscle disorders. $\mathrm{J}$ Neurol Sci 82 : $229-244,1987$

Costill DL, Pascoe DD, Fink WJ, Robergs RA, Barr SI, Pearson D. Impaired muscle glycogen resynthesis after eccentric exercise. J Appl Physiol 69: 46-50, 1990

Critz JBB, Cunningham DA. Plasma enzyme levels in man after different physical activities. J Sports Med 12: 143-149, 1972

Darr KC, Schultz E. Exercise-induced satellite cell activation in growing and mature skelletal muscle. J Appl Physiol 63: 1816-1821, 1987

Davies CTM, Barnes C. Negative (eccentric) work. I. Effects of repeated exercise. Ergonomics 15: 3-15, 1972a

Davies CTM, Barnes C. Negative (eccentric) work. II. Physiological responses to walking uphill and downhill on a motor-driven treadmill. Ergonomics 15:121$131,1972 \mathrm{~b}$

Davies CTM, White MJ. Muscle weakness following eccentric work in man. Pflügers Arch 392: 168-171, 1981

Davies CTM, White MJ. Muscle weakness following dynamic exercise in humans. J Appl Physiol 53: R236-R241, 1982

Davies KJA, Quitanilha AT, Brooks GA. Free radicals and tissue damage produced by exercise. Biochem Biophys Res Comm 107:1198-1205, 1982

DeVries HA. Quantitative ellectromyographic investigation of the spasm theory of muscle pain. Am J Phys Med 45: 119-134, 1966

Drahota $Z_{3}$ Caratoll $E$, Rossi CS, Gamble RL, Lehninger AL. The steady state maintenance of accumulated $\mathrm{Ca}^{2+}$ in rat liver mitochondria. $J$ Biol Chem 240: $2712-2720,1965$

Driessen-Kletter MF, Amelink GJ, Bär PR, van Gijn J. Myoglobin - a sensitive marker of an increased muscle membrane vulnerability studied in Duchenne Muscular Dystrophy carriers. J Neurol 237: 234-238" $\| 990$

Duan C, Delp MD. Hayes DA, Delp PD. Armsirong RB. Rat skeletal muscle mitochondrial $\left(\mathrm{Ca}^{2+}\right)$ and injury from downhill walking. J Appl Physiol 68:1241. 1251,1990 
Dubowitz V, Brooke M. Muscle biopsy: a modem approach. Philadelphia, PA:

Saunders, 1973

Dudley $G A$. Terjung RL. Influence of anaerobic metabolism on IMP accumulation in tast-twitch muscle. Am J Physiol 248: C37-C42, $1985 \mathrm{a}$

Dudiey $G A_{\text {, Terjung }}$ RL Influence of acidosis on AMP activity in contracting fast-twitch muscle. Am J Physiol 248: C43-C50, $1985 \mathrm{~b}$

Duncan $\mathrm{CJ}$, Jackson MJ. Different mechanisms mediate structural changes and intracellullar enzyme efflux following damage to skeletal muscle. J Cell Sci 87: $183-188,1987$

Duncan $C_{\mathrm{J}}$ : Role of calcium in triggering rapid ultrastructural damage in muscle: a study with chemically skinned fibres. J Cell Sci $87: 581-594,4987$

Ebbeling $\mathrm{CB}$, Clarkson PM. Exercise-induced muscle damage and adaptation. Sports Med 7: 207-234, 1989

Ebbeling CB, Clarkson PM. Muscle adaptation prior to recovery following eccentric exercise. Eur J Physiol 60: 26-31, 1990

Evans WJ, Meredith CN, Cannon JG, Dinarello CA, Frontera WR, Hughes VA, Jones $\mathrm{BH}$. Knuttgen $\mathrm{HG}$. Metabolic changes following eccentric exercise in trained and untrained men. J Appl Physiol 61: 1864-1868, 1986

Faulkner JA, Jones DA. An apparatus for unilateral in situ exercise of the lower limb muscles of small mammals. J Physial 365:11P, 1985

Faulkner JA, Jones DA. Round JM. Injury to skeletal musicles of mice by forced lengthening during contractions. Q J Exp Physiol 74: 661-670, 1989

Fridén $J_{\text {, Sjöström } M}$, Ekblom $B$. A morphological study of delayed muscle soreness. Experientia 37: 506-507, 1981

Fridén J, Seger J, Sjöström M, Ekblom B. Adaptive response in human skeletal muscle subjected to prolonged eccentric training. Int J Sports Med 4: 177-183, $1983 a$

Fridén J, Sjöström M, Ekblom B. Myofibrillar damage following intense eccentric exercise in man. Int $\mathrm{J}$ Sports Med 4: 170-176, 1983b

Fridén J. Changes in human skeletal muscle induced by long-term eccentric exercise. Cell Tissue Res 236: 365-372, 1984a

Fridén J. Muscle soreness after exercise: implications of morphological changes. Int J Sports Med 5: 57-66, 1984b

Fridén J, Kjörell U, Thornell L-E. Delayed muscle soreness and cytoskeletal alterations: an immunocytological study in man. Int $\mathrm{J}$ Sports Med 5: 15-18, 1984

Fridén J, Sfakianos PN, Hargens AR. Muscle soreness and intramuscular fluid pressure: comparison between eccentric and concentric load. J App\| Physiol $61: 2175-2179,1986$

Fridén J, Sfakianos PN, Hargens AR, Akeson WH. Residual muscular swelling after repetitive eccentric contractions. J Orthopaed Res $6: 493-498,1988$

Friden J, Stakianos PN, Hargens AR. Blood indices of muscle injury associated with eccentric muscle contractions. J Orthopaedic Ples 7: 142-145, 1989

Fritz VK, Stauber WT. Characterization of muscles injured by forced lengthening. III. Proteoglycans. Med Sci Sports Exerc 20: 354-361, 1988

Furuno $K_{\text {" Goldberg }} \mathrm{AL}$. The activation of protein degradation in muscle by callium or muscle injury does not involve a lysosomal mechanism. Biochem J 237: 859864,1986 
Garbus $\mathrm{J}$, Highman B. Altland PD. Serum enzymes and lactic dehydrogenase after exercise and training in rats. Am J Physiol 207: 467-472, 1964

Gardiner KR, Gardiner PF, Edgerton VR. Guinea pig soleus and gastrocnemius electromyograms at varying speeds, grades and loads. I Appl Physiol 52: 451457, 1982

Gardiner GW, Bratton A, Chowdhurry SR, Fowler, WM, Pearson CM. Effect of exercisie on serum enzyme levels in trained subjects. J Sponts Med Phys Fitness 4: $103-110_{\text {wi }} 1964$

Garrett WE, Nikalaou PK, Ribbeck BM, Glisson RR, Seaber AV. The effect of muscle architecture on the biochemical failure properties of skeletal muscle under passive extension. Am J Sports Med 16:7-12, 1988

Geller SA. Extreme exertion thabdomyolysis. Hum Patholl 4:241-250, 1973

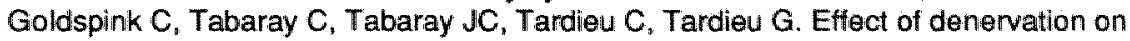
the adaptation of sarcomere number and muscle extensibility to the functional length of the muscle. J Physiol 236: 733-742, 1974

Goodman MN. Differential effects of acute changes in cell calcium concentration on myofibrillar and nonmyofibrillar protein breakdown in the rat extensor digitorum longus muscle in vitro. Biochem J 241: 121-127, 1987

Gomori G. A rapid one-step trichrome stain. Am J Clin Path 20: 661, 1950

Gronert GA. Malignant hyperthermia. Anaesthesiology 53: 395-421, 1980

Graves J, Clarkson PM, Kirwan J, Litchfield P. Serum creatine kinase levels following three different ilsometric regimens. Med Sci Sports Exerc 16: 186-187, 1984

Gulati AK, Reddi AH, Zallewski AA. Changes in the basement membrane zone components during skeletal muscle fiber degeneration and regeneration. $J$ Cell Biol 97: 957-962, 1983

Häkkinen $K$, Alén M. Training volume, androgens use and serum creatine kinase activity. Br J Sports Med 23: 188-189, 1989

Hamilton AW, Gardner LB, Penn AS, Goldberg M. Acute tubular necrosis caused by exercise-induced myoglobinuria. Ann Intern Med 77: 77-82, 1972

Harris K, Walker PM, Mickle DAG, Harding R, Gatley R, Wilson GJ, Kuzon B, McKee $\mathrm{N}$, Romaschin AD. Metabolic response of skeletal muscle to ischemia. Am J Physial 250: H213-H220, 1986

Hattori A, Takahashi K. Calcium-induced weakening of skeletal muscle Z-discs. J Biochem 92: 381-390, 1982

Highman B, Altland PD. Effects of exercise and training on serum enzyme and tissue changes in rats. Am J Physiol 205: 162-166, 1963

Hikida RS, Staron RS, Hagerman FC. Sherman WM, Costill DL. Muscle fiber necrosis associated with human marathon runners. J Neurol Sci 59: 185-203, 1983

Hoppeler H. Exercise-induced ultrastructural changes in skeletal muscle. Int J Sports Med 7: 187-204, 1986

Hoppeler $\mathrm{H}$. The situctural composition of muscle tissue and its changes with different types of exercise. Gieneeskd and Sport 20:56-64, 1987

Hortobágyi T, Denahan T. Variability in creatine kinase: methodological, exercise, and clinically related factors. Int J Sports Med 10:69-80, 1989

Hough T. Ergographic studies in muiscular soreness. Am J Physiol 7: 76-92, 1902

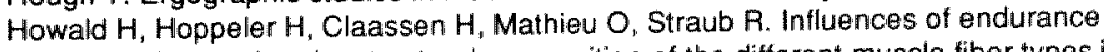
training on the ultrastructural composition of the different muscle fiber types in humans. Pflügers Arch 403: 369-376, 1985 
Howell JN, Chila AG, Ford $G_{1}$ David D, Gates T. An electromyographic study of elbow motion duning postexercise muscle soreness. I Appl Physial 58: 1713-1118, 1985

Hunter $J B_{i}$ Critz JB. Effect of training on plasma enzyme levels in man. $J$ Appl Physiol 31: 20:23, 1971

Irintchev $\mathrm{A}$, Wernig $\mathbf{A}$. Muscle damage and repair in voluntarily running mice: strain and muscle differences. Cell Tissue Res 249: 509-521, 1987

Jackson $M J_{\text {, Jones }} \mathrm{DA}_{\mathrm{v}}$ Edwards RHT. Experimental skeletal muscle damage: the nature of the calcium-activated degenerative processes. Eur $\mathrm{J}$ Clin Invest 14 : $369-374,1984$

Jackson MJ, Round $\mathrm{JM}_{1}$ Newham DJ, Edwards RHT. An examination of some factors influencing creatine kinase in the blood of patients with muscular dystrophy. Muscle Nerve 10: 15-21, 1987

Janssen GME, Kuipers H, Willems GM, Does RJMM, Janssen MPE, Geurten P. Plasma activity of muscle enzymes: quantification of skeletal muscle damage and relationship with metabolic variables. Int J Sports Med 10: S160-S168, 1989

Jenkins RR. Free radical chemistry. Sports Med 5: 156-170, 1988

Jennische $E$. Ischaemia-induced injury in glycogen-depleted skeletal muscle. Selective vulnerability of FG-fibres. Acta Physiol Scand 125: 727-734, 1985 Jockers-Wretou E. Pfleiderer G. Quantification of creatine kinase isoenzymes in human tissues and sera by an immunological method. Clin Chim Acta 58: 223, 1975

Jones DA, Jackson MJ, Edwards. RHT. Release of intracellular enzymes from an isolated mammalian skeletal muscle preparation. Clin Sci 65: 193-201, 1983

Jones DA, Newham DJ, Round JM, Tolfree SEJ. Experimental human muscle damage: morphological changes in relation to other indices of damage. J Physiol 375: $435-448,1986$

Jones DA, Newham DJ, Clarkson PM. Skeletal muscle stiffness and pain following eccentric exercise of the elbow flexors. Pain 30: 233-242, 1987

Jones DA, Newham DJ, Torgan C. Mechanical influences on long-lasting human muscle fatigue and delayed-onset pain. I Physiol 412: 415-427, 1989

Kagen Lل, Moussavi S, Miller SL, Tsairis P. Serum myoglobin in muscular dystrophy. Muscle Nerve 3: 221-226, 1980

Kasparek GJ, Snider RD. Increased protein degradation after eccentric exercise. Eur $J$ Appl Physiol 54: 30-34, 1985a

Kasparek GJ, Snider RD. The susceptibility to exercise-induced muscle damage increases as rats grow larger. Experientia 41:616-617, $1985 b$

Kinwan JP, Clarkson PM, Graves JE, Litchfield PL, Byrnes WC. Levels of serum creatine kinase and myoglobin in women after two isometric exercise conditions. Eur J Appl Physiol 55: 330-333, 1986

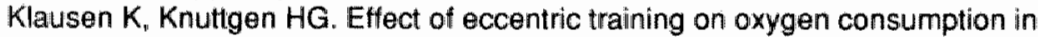
negative muscular work. Acta. Physiol Scand 83: 319-323, 1971

Knuttgen $H G$, Bonde-Peterson $F$, Klausen $K$. Oxygen uptake and heart rate response to exercise pertormed with concentric and eccentric muscle contractions. Med Sci Sports 3: $1-5,197$.

Knuttgen HG. Human performance in high-intensity exercise with concentric and eccentric muscle contractions. Int J Sports Med 7: S6-S9, 1986

Komi PV. Buskirk ER. Effect of eccentric and concentric muscle conditioning on tension and electrical activity in human muscie. Ergonomics 15: 417-434, 1972 
Komi PV, Rusko H. Quantitative evaluation of mechanical and electrical changes duning fatigue loading of eccentric and concentric work. Scand J Rehabil Med, Suppl 3: $121-126,1974$

Komi PV. Viitasalo JT. Changes in motor unit activity and metabolism in human skelettal muscle during and after repeated eccentric and concentric contractions. Acta Physiol Scand 100: 246-254, 1977

Kuipers H, Drukker J, Frederik PM, Geurten P. van Kranenburg Gi. Muscle degeneration after exercise in rats. Int $J$ Sports Med 4: 45-51, 1983

Kuipers $H$, Keizer HA, Verstappen FTJ, Costill DL. Influence of a protaglandin-inhibiting drug on muscle soreness after eccentric work. Int J Sparts Med 6: 336-339, 1985

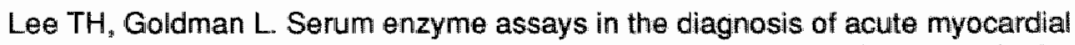
infarction. Recommendations based on a quantitative analysis. Ann Int Med 105: $221-233,1986$

Lileber RL, Fridén J. Selective damage of fast glycolytic muscle fibres with eccentric contraction of the rabbit tibialis anterior. Acta Physiol Scand 133: 587-588, 1988

Lijnen P, Hespel P, Fagard R, Lysens R, VandenEynde $\mathbb{E}$, Goris $M_{3}$, Goossens W, Lissens W. Amery A. Indicators of cell breakdown in plasma of men during and after a marathon race. Int J Sports Med 9: 108-113, 1988

Loll $\mathrm{H}$, Hilscher A. Die Bedeutung der Serum-Enzyme and Substrat-Bestimmungen bei Lebererkremkungen. Aitliche Forschung 12: 304-308, 1958

Lott JA. Serum enzyme determinations in the diagnosis of acute myocardial infarction: an update. Hum Pathol 15: 706-716, 1984

Luginbuhl AJ, Dudley GA, Staron RS. Fiber type changes in rat skeletal muscle after intense intervall training. Histochem $81: 55-58,1984$

MacDougall JD, Sale DG, Elder GCB, Sutton JR. Muscle ultrastructural characteristics of elite powerlifters and bodybuilders. Eur J Appl Physiol 48: 117-126, 1982

Margaria $R$. Positive and negative work performances and their efficiencies in human locomotion. In: Environmental effects and work performance. Cummings GR, Snidal D, Taylor AW (eds). Toronto, Canada: Canadian Association of Sponts Sciences, pp 215-228, 1972

McCully KK. Faulkner JA. Injury to skeletal muscle fibers of mice following lengthening contractions. J Appl Physiol 59: 119-126, 1985

McCully KK, Faulkner JA. Characteristics of lengthening contractions associated with injury to skeletal muscle fibers. J Appl Physiol 61: 293-299, 1986

McCully KK, Argov Z, Boden BP. Brown RL, Bank WJ, Chance B. Detection of muscle injury in humans with $31 . \mathrm{P}$ magnetic resonance spectroscopy. Muscle Nerve $11: 212-216,1988$

Mellgren RL. Calcium-dependent proteases: an enzyme system active at cellular membranes? FASEB J $1: 110-115,1987$

Meyer RA, Terjung RL. Differences in ammonia and adenylate metabolism in contracting fast and slow muscle. Am J Physiol 6: C111-C118, 1979

Miline CJ. Rhabdomyolysis, myoglobinuria and exercise. Sports Med 6: 93-106, 1988

Mokri B, Engel AG. Duchenne dystrophy: Electron microscopic findings pointing to a basic or early abnormality in the plasma membrane of the muscle fiber. Neurol 25: $1111-1120,1975$ 
Morelli $\mathrm{PL}_{\mathrm{w}}$ Carlson J, Emilson B, Abenschein DR, Rapaport $\mathrm{E}$. Serum creatine kinase MM isoenzyme sub-bands after acute myocardial iniarction in man. Circulation 67: $1283-1289,1983$

Nadel $E F_{1}$ Bergh $U$, Saltin $B$. Body temperatures during negative work exercise. J Appl Physiol 33: $553-558,1972$

Nanji A. Serum creatine kinase isoenzymes: a review. Muscle Nerve 6: 83-90, 1983

Newham DJ, Jones DA, Edwards RHT. Large delayed plasma creatine kinase changes after stepping exercise. Muscle Nerve 6:380-385, 1983a

Newham DJ McPhail G, Mills KR, Edwards RHT. Ultrastructural changes after concentric and eccentric contractions of human muscle. J Neurol Sci $61: 109$ $122,1983 b$

Newham D. Mills KR, Quigley BM, Edwards RHT. Pain and fatigue after concentric and eccentric muscle contractions. Clin Sci $64: 55-62,1983 \mathrm{c}$

Newham DJ, Jones DA, Edwards PHT. Plasma creatine kinase changes after eccentric and concentric contractions. Muscle Nerve 9:59-63, 1986a

Newham DJ, Jones DA, Tolfree SEJ, Edwards RHT. Skeletal muscle damage: a study of isotope uptake, enzyme efflux and pain after stepping. Eur J Appl Physiol 55: $106-112,1986 \mathrm{~b}$

Newham DJ, Jones DA, Clarkson PM. Repeated high-force eccentric exercise: effects on muscle pain and damage. J Appl Physiol 63: 1381-1386, 1987

Newham DJ. The consequences of eccentric contractions and their relationship to delayed onsiet muscle pain. Eur J Appl Physiol 57: 353-359, 1988

Newham DJ, Jones DA, Ghosh G, Aurora P. Muscle fatigue and pain after eccentric contractions at long and short length. Clin Sci 74: 553-557, 1988

Noakes TD. Effects of exercise on serum enzyme activities in humans. Sports Med 4: 245-267, 1987

Nutall $F Q$, Jones B. Creatine kinase and glutamic oxalacetic transaminase activity in serum kinetics of change with exercise and effect of physical conditioning. $J$ Lab Clin Med 71: 847-854, 1968

Ogilvie RW, Armstrong $\mathrm{AB}$, Baird KE. Bottoms $\mathrm{CL}$. Lesions in the rat soleus muscle following eccentrically biased exercise. Am J Anat 182" 335-346, 1988.

O'Reilly KP, Warhol MJ, Fielding RA, Frontera WR, Meredith CN, Evans WJ. Eccentric exercise-induced muscle damage impairs muscle glycogen repletion. J Appl Physiol 63: 252-256, 1987

Padylkula HA, Herman E. The specificity of the histochemical method of adenosine triphosphatase. J Histochem Cytochem 3: 170-195, 1955

Palmer RM, Reeds PJ, Atkinson T, Smith RH. The influence of changes in tension on protein synthesis and prostaglandin release in isolated rabbit muscles. Biochem J $214: 1011-1014,1983$

Papadopoulos NM "Leon AS, Bloor CM. Effects of exercise on plasma and tissue levels of lactate dehydrogenase and isoenzymes in rats. Proc Soc Exp Biol Med 125: $999-1002,1967$

Passoneau JV. Lactate. Fluorometric method, in Bergmeyer HU (ed): Methods of enzyme analysis. Now York, Academic Press pp 1468-1472, 1974

Poeze Binkhorst FM, Kuipers $H$. Heymans J "Frederik PM, Slaaf DW, Tangelder G-J, Reneman RS. Exercise-induced focal skeletal muscle fiber degeneration and capillany morphology. J Appl Physiol 66: 2857-2865, 1989 
Peeze Binkhorst FM, Slaaf DW, Kuipers H, Tangelder G-J, Reneman RS. Exerciseinduced swelling of rat soleus muscle: its relationship with intramuscular pressure. J Appl Physiol 69: 67-73, 1990

Perryman MB, Knell JD, Roberts $\mathrm{R}$. Molecular mechanism for the production of multiple forms of MM creatine kinase. Experientia 40:1275-1277, 1984

Podolsky RJ and Schoenberg M. Force generation and shortening in skeletal muscle. In: Peachey et al (eds). Handbook of Physiology vol 10, skeletal muscle, pp 173 187. American physiological society. Betherda MD, 1983

Prince FP, Hikida RS, Hagerman FC, Staron RS, Allen WH. A morphometric analysis of human muscle fibers with relation to fiber types and adaptation to exercise. $J$ Neurol Sci 49: 165-179, 1981

Roe CR. Validity of estimating myocardial infarct size from serial measurements of enzyme activity in the senum. Clin Chem 23: 1897-1812, 1977

Rogers MA, Stull GA, Apple FS. Creatine kinase isoenzyme activities in men and women following a marathon race. Med Sci Sports Exerc 17:679-682, 1985

Romeis B. Mikroscopische Technik, München-Wien, A Oldenburgher Verlag. 1968 Found JM, Jones DA, Canbridge $\mathrm{G}$. Cellular infiltrates in human skeletal muscle: exercise induced damage as a model for inflammatory muscle disease? $\mathrm{J}$ Neurol Scil 82: 1-11, 1987

Rowland LP, Penn AS. Myoglobinuria. Med Clin North Am 56" 1233-1256, 1972

Salminen $A$, Hongkisto $K$, Vihko $V$. Lysosomal changes rellated to exercise injuries and training-induced protection in mouse skeletal muscle. Acta. Physiol Scand 120:15-19, 1984

Salminen A. Lysosomal changes in skeletal muscles during the repair of exercise injuries in muscle fibers. Acta Physiol Scand 124: 4-31, Suppl 539, 1985

Sargeant $A J$ " Dolan $P$. Human muscle function following prolonged eccentric exercise. Eur J Appl Physial 56: 704-711, 1987

Schultz E, Jaryszak DL, Valliere CR. Response of satellite cells to focal skeletal muscle injury. Muscle Nerve 8: 217-222, 1985

Schwane JA, Armstrong RB. Effect of training on skeletal muscle injury from downhill running in rats. IAppl Physial 55: 969-975, 1983

Schwane JA, Johnson SR, VandenAkker CB, Armstrong RB. Delayed-onset muscular soreness and plasma CPK and LDH activities after downhill running. Med Sci Sports Exerc 15: $51-56,1983$

Sicrimgeour AG, Noakes TD, Adams B, Myburgh K. The influence of weekly training distance on fractional utilization of maximum aerobic ciapacity in marathon and ultramarathon runners. Eur J Appl Physiol 55: 202-209, 1986

Shell WE, Lavelle JF, Covell JW, Sobel BE. Early estimation of myocardial damage in conscious dogs and patients with evolving acute myocardial infarction. J Clin Invest 52: 2579-2590, 1973

Shumate JB, Brooke MH, Carroll JE, Davis JE. Increased serum creatine kinase after exercise: a sex-linked phenomenon. Neurol 29: 902-904, 1979

Sjödin B, Westing YH, Apple FS. Biochemical mechanisms for oxygen free radical tormation during exercise. Sports Med 10: 236-254, 1990

Sjöström M, Änquist K-A, Byland A-C, Fridén J, Gustavson L, Scherstên T. Morphometric analysis of humam muscle fiber types. Muscle Nerve 5: 536- 553, $1982 a$ 
Sjôström M, Küdman S, Larsén KH, Änquist K-A. Z- and M-band appearance in different histochemically defined types of human skeletal muscle fibers. J Histochem Cytochem 30:1-11, 1982b

Sjóström $\mathrm{M}$, Friden J, Ekblom $\mathrm{B}$. Endurance, what is it? Muscle morphology after an extreme long distance run. Acta Physiol Scand 130: 513-520, 1987

Smith $M$, Jones TC. The musculoskeletal system. In: Veterinary Pathology. Lea and Fobriger, Philadelphia, pp 812-815, 1966

Snyder AC, Lamb DR, Salm CP, Judge MD, Aberle ED, Mills EW. Myofibrillar protein degradation after eccentric exercise. Experientia 40:69-70, 1984

Sobel BE, Roberts R, Larson KB. Estimation of infarct size from serum MB creatine phosphokinase activity: applications and limitations. Am J Cardiol 37: 474- 485, 1976

Sobel BE, Kjekhus JK, Roberts R. Enzymatic estimation of infarct size. In: Hearse DJ and De Leiris J, eds. Enzymes in cardiology diagnosis and research. New York: John Wiley, pp 257-318, 1979

Stauber WT, Fritz VK, Vogelbach DW, Dahimann B. Characterization of muscles injured by forced lengthening. I. Cellular infiltrates. Med Sci Sports Exerc 20: $345-353,1988$

Stauber WT. Eccentric action of muscles: physiology, injury, and adaptation. Exerc and Sports Sci Rev 17: 157-185, 1989

Stauber WT . Clarkson PM, Fritz VK, Evans WJ. Extracellular matrix disruption and pain after eccentric musicle action. J Appl Physiol 69: 868-874, 1990

Steffens $A B$. A method for frequent sampling of blood and continuous infusion of fluids in the rat without disturbing the animals. Physiol Behav 4: 833-836, 1969

Thomson WHS, Smith I. Effects of oestrogens on erythrocyte enzyme efflux in normal men and women. Clin Chim Acta 103: 203-208, 1980

Tiidus PM, lanuzzo CD. Effects of intensity and duration of muscular exercise on delayed soreness and serum enzyme activities. Med Sci Sports Exerc 15: 461 465,11983

Trifflettl P, Litchfield PE, Clarkson PM, Byrnes WC. Creatine kinase and muscle soreness after repeatted isometric exercise. Med Sci Sports Exerc 20: 242-248, 1988

Tsung SH. Creatine kinase isoenzyme patterns in human tissue obtained at surgery. Cllin Chem 22: 173, 1976

Tullson PC, Terjung RL. Adenine nucleotide degradation in striated muscle. Int $J$ Sports Med 11: S47-S55, 1990

Väănänen HK Takala TES, Tolonen U, Vuori J, Myllyla VV. Muscle specific carbonic anhydrase III is a more specific marker of muscle damage than creatine kinase in neuromuscullar disorders. Arch Neurol 45: 1254-1256, 1988

Vejlajiva A, Taesdale GM. Serum creatine kinase and physical exercise. Br Med J 1: $1653-1654,1965$

Vinko V, Rantamäki $\mathrm{J}$, Salminen A. Exhaustive physical exercise and acid hydrolase activity in mouse skelletal muscle. Histochem 57: 237-249, 1978a

Vihko V, Salminen A, Rantamäki J. Acid hydrolase activity in red and white skelletall muscle of mice during a two-week period following exhausting exercise. Pflügers Arch 378: 99-106, 1978b

Vihko $V$, Salminen $A_{\|}$Rantamäki J. Exhaustive exercise, endurance training, and acid hydrolase activity in skeletal muscle. J Appl Physiol 47: 43-50, 1979 
Vusse van der GJ, Coumans WA, van der Veen FH, Drake A, Flameng W, Suy R. ATP, creatine phosphate and glycogen content in human myocardial biopsies: markers for the efficacy of cardioprotection during aortacoronary bypass surgery. Vasc Surg 18: 127-134, 1984

Vusse van der GJ, Janssen GME, Coumans WA, Kuipers H, Does RJMM, ten Hoor F. Effect of training and $15-, 25 \%$, and $42-\mathrm{km}$ contests on the skeletal muscle content of adenine and guanine nucleotides, creatine phosphate, and glycogen. Int J Sports Med 10: S1 46-S152, 1989a

Vusse van der GiJ, van Bilsen M, Reneman RS. Is phospholipid degradation a virtual event in ischemia and reperfusion-induced damage. NIPS 4:49-53, $1989 \mathrm{~b}$

Waimsley B, Hodgson JA, Burke RE. Forces produced by medial gastrocnemius and soleus muscles during locomotion in freely moving cats. J Neurophysiol 41: $1203-1216,1978$

Warhol MJ, Siegel AJ Evans W, Silverman LM. Skeletal muscle injury and repair in marathon runners after competition. Am J Pathol 118:331-339, 1985

Weibel ER. Point counting methods. In: Weibel ER (ed): Stereological mathods vol $\|_{\text {, }}$ Academic Press pp 101-161, 1979

Willems GM, Muytjens AMM, Lambi FHH, Hermens WTh. Estimation of circulatory parameters in patients with acute myacardial inflarction. Significance for calculation of enzymatic infarct size. Cardiovasc Res 13: 578-587, 1979

Willems $G M_{4}$ van der Veen FH, Huysmans HA, Flameng $W_{0}$ de Meyere $R$, van der

Laarse A, van der Vusse GJ, Hermens WTh. Enzymatic assessment of myocardial necrosis after cardiac surgery: Differentiation from skeletall muscle damage, hemolysis, and liver injury. Am Heart J 109: 1243- 1252, 1985

Wijnants $J$, wan Belle $H$. Single-run high performance liquid chromattography of nucleotides, nucleosides and major purine bases andits application to different tissue extracts. Anall Biochem 144: 258-266, 1985

Wrogemann $K_{n}$ Pena SDJ. Mitachondrial calcium overload: a general mechanism for cell-necrosis in muscle diseases. Lancet 2: 672-673, 1976

Yale $C E$, Terhorst $J B$. Critical bleeding and plasma volumes of adult germ-free rats. Lab Anim Sci 22: 497-502, 1972

Yasminen WG, Yamada MK, Cohn JN. Postsynthetic variants of creatine kinase MM. J Lab Clin Med 98: 109-118, 1981

Yokota J, Minei JP, Fantini GA, Shires GT. Role of leukocytes in reperfusion injury of skeletal muscle after partial ischemia. Am J Physiol 257: H1068-H1075, 1989

Zerba E, Komorowski TE. Faulkner JA. Free radical injury to skeletal muscles of young. adult, and old mice. Am J Physiol 258: C429-C435, 1990 


\section{Samenvatting}

Spieren zijn opgebouwd uit spiervezels. Na activatie treedt er een verkorting van de spiervezels en dus van de spier op waardoor er een beweging plaats kan vinden. Bij een gemiddelde inspanning is de spier aangepast aan de belasting die wordt gevraagd. Echter, indien er sprake is van overmatige belasting kan schade onstaan aan structuren die zich in en om de spiervezels bevinden. In de spiervezel zijn het met name de contractiele elementen, welke voor verkorting van de spiervezels verantwoordelijk zijn, die kunnen worden beschadigd. Deze schade kan worden gevolgd door een ontstekingsreactie, waarbij de beschadigde structuren worden opgeruimd. Het degeneratieproces wordt afgesloten met regeneratie, waardoor de spiervezel en daarmee de spier weer normaal kan functioneren. Beschadigde spiervezels komen verspreid in de spier voor en de schade beperkt zich tot een klein deel van de vezels. Verschijnselen die worden waargenomen na overbelasting en in verband kunnen worden gebracht met spierschade zijn lekkage van spierenzymen, spierzwelling, spierverkorting, spierstijtheid en afname in spierkracht. In dit proefschrift worden facetten beschreven die verband houden met oorzaak en gevolg van spierschade en welke onderzocht zijn door middel van dierexperimenteel onderzoek.

In Hootdstuk 2 wordt een model beschreven waarmee in de $\mathrm{m}$. tibialis anterior (TA) schade kan worden opgewekt. De TA spier bevindt zich aan de voorzijde van de achterpoot en zorgt bij activatie voor het optrekken van de voet. Spierschade werd opgewekt door de voet naar beneden te bewegen en tegelijkertijd de spier electrisch te stimuleren via de zenuw. Meteen na de inspanning was schade zichtbaar aan contractiele elementen, gevolgd door onstekingsinfiltraat. Na 10 dagen was herstel opgetreden. Uit vergelijking met controle experimenten, die bestonden uit spierarbeid waarbij de spierlengte resp. gelijk bleef of afnam tijdens stimulatie en passieve verlenging van de spier bleek dat alleen door actieve verlenging van de spier schade werd veroorzaakt. Bij statische belasting was er slechts een geringe hoeveelheid schade, zichtbaar tot enkele uren na belasting. Dit wijst op mechanische overbelasting als belangrijkste oorzaak van schade.

In Hoofdstuk 3 is gekeken naar de invloed van de beginlengte en het traject waarover de TA spier actief werd vertengd op het soort en de hoeveelheid schade en op de hoeveelheid ontstekingsinfiltraat. Er werd gevonden dat naarmate de spler over een groter traject actief werd verlengd, er meer schade aan contractiele elementen en meer ontstekingsinfiltraat in de spier werd aangetroffen. In de spier werd na actieve vertenging bovendien meer schade gevonden wanneer de beiginlengte groter was dan wanneer de beginlengte kleiner was. Dit suggereent een lengteafhankelijke component. Voor wat betreft het soort schade aan de contractiele elementen waren de beginlengte en het traject waarover de spier actief werd verlengd niet van belang. Dit duidt erop dat niet een specifiek onderdeel van de contractiele elementen kan worden aangeduid als de zwakste schakel, zoals door sommige onderzoekers is gesuggereerd. 
In Hoofdstuk 4 wordt een methode beschreven waarbij de passieve stijfheid van de TA spier kan worden gemeten. Dit werd gedaan door gewichtjes met toenemende massa aan de TA spier te hangen. De spierstijfheid werd uitgedrukt als de lengtetoename van de spier gedeeld door de massa die aan de spier trok. Vervolgens werd de passieve spierstijfheid gemeten op verschillende tijdstippen na actieve verlenging van de TA spier, waarvan bekend was dat er in ruime mate spierbeschadiging werd opgewekt. Er werd een vergelijking gemaakt met spierbelastingen waarbij de spierlengte gelijk bleef en er zeer weinig schade werd aangetroffen en met passieve verlenging waarbij er helemaal geen schade werd opgewekt. Er werd gevonden dat een toename van schade in de spier overeenkwam met een toename in passieve spierstijfheid. Dat gold in elk geval tot drie dagen na inspanning. De toegenomen stijfheid die 10 dagen na belasting werd gevonden, werd waarschijnlijk veroorzaakt door een toename van bindweeefsel

In Hoofdstuk 5 is de preventieve invloed van een éénmalige belasting, bestaande uit een serie actieve verlengingen wan de TA spier op de hoeveelheid ontstekingsinfiltraat in de spier bestudeerd. Als controle werd gekozen voor statische belasting. Beide spieren werden 3 weken later opnieuw belast, nu echter beide met actieve verlenging. Het bleek dat éénmalige actieve verlenging leidde tot een verminderde hoeveelheid ontstekingsinfiltraat vergeleken met spieren die vooraf statisch werden belast. De verminderde hoeveelheid ontstekingsinfiltraat kwam tot uiting in een geringer krachtsverlies, vergeleken met de spier die de eerste keer statisch werd belast. Dit wijst erop dat er in de spier zelf aanpassing plaats kan vinden, die de kwetsbaarheid voor actieve verlenging kan verminderen.

In Hoofdstuk 6 is de invloed van actieve verlenging en statische belasting van de TA spier op biochemische parameters die een indruk geven van de energiehuishouding van de spier, over een periade van 24 uur na inspanning onderzocht. De verwachting was dat spierbeschadiging, als gevolg van actieve spierverlenging, vergezeld ging van verstoring van die energiehuishouding. Erwerd gevonden dat onmiddellijk na beide vormen van inspanning het IMP-gehalte, een teken van ATP gebruik, toenam. Het ATP gehalte nam alleen na actieve verlenging van de spier af, hetgeen wellicht te maken had met spierschade die bij deze vorm van inspanning ontstond. Het glycogeengehalte nam bij beide vormen van spierbelasting onmiddellijk nainspanning af. Een dag na beide vormen van inspanning trad er opnieuw een daling van glycogeen op. De glycogeendaling kon niet enkel en alleen worden verklaard uit de aanwezigheid van spierschade.

In Hoofdstuk 7 is gekeken naar de relatie tussen de hoeveeltheid spierschade en de hoeveelheid enzym die uit die kapotte spiercellen in het bloedplasma liekt. Gebruikt zijn creatine kinase (CK), een specifiek spierenzym en aspartate aminotransferase (AST) en lactate dehydrogenase (LD), die minder specifiek zijn. Spierschade werd opgewekt in vrouwelijke en mannelijke ratten die op een loopband renden. Het spiervolume dat beschadigd was werd morfometrisch bepaald. Bloed werd afgenomen op verschillende tijdstippen na inspanning met behulp van een hartcatheter. Met behulp wan een rekenkundige formule die was gebaseerd op cumulatieve enzymafgifte, afbraaksnelheid van enzym in het bloedplasma en 
hoeveelheid bloedplasma werd de absolute hoeveelheil enzym in het bloedplasma na inspanning berekend. Het bleek dat de hoeveelheid enzym die in het bloedplasma werd gevonden groter was dan de hoeveelheid die was gelekt uit de beschadigde spiervezels. Het gebruik van plasma-activiteit van enzymen is daardoor niet geschikt om de hoeveelheid spierschade te schatten. Verder bevestigde dit onderzoek al bestaande resultaten waaruit bleek dat bij vrouwelijke ratten minder enzym in het bloed terecht kwam dan bij mannelijke ratten die een gelijke inspanning hadden verricht. Daarentegen was de hoeveelheid spierschade bij beide geslachten echter gelijk. De toename van hoeveelheid schade en enzymafgifte namen onevenredig toe met de toename van de duur van inspanning.

In Hoofdstuk 8 is gekeken naar de samenstelling en de verdeling van beschadigde spiervezels in de soleus spier bij vrouwelijke en mannelijke ratten die gedurende 1.5 of 2.5 uur op een loopband omhoog liepen. Het bleek dat bij een toename van de loopduur de hoeveelheld schade toenam, hetgeen tot uitdrukking kwam in zowel het aantal beschadigde spiervezels als de segmenten waarover de spiervezels beschadigd waren. Er werden geen verschillen tussen mannelijke en vrouwelijke ratten gevonden. De beschadigde spiervezels werden at random in de soleus spier aangetroffen. 


\section{Curriculum vitae}

De schrijver werd geboren op 15 november 1956 te Akkrum. Na het doorlopen van het WWO aan de Filksscholengemeenschap te Heerenveen en én jaar militaire dienst, volgde in 1978 de studie biologie aan de Rijksuniversiteit van Groningen. Na het behaien van het kandidaatsexamen in 1982 werd diertysiologie als hoofdrichting gekozen. Hootdvak was gedragstysiollagie, bijvak was neurofysiologie. Bij de vakgroep dierfysiologie werden cok enkele studentassistentschappen verricht. Tevens werd de eerstegraadslesbevoegdheid biologie verkregen. In 1986 werd de studie biologie afgerond met het doctoraalexamen. In 1986 werd tevens begonnen als assistent in opleiding (AIO) bij de faculteit der Gezondheidswetenschappen aan de Pijksuniversiteit Limburg. 



\section{List of publications}

De relathe tussen skeletspierschade en enzymuitstorting $\mathrm{JH}$ van der Meulen, H Kuipers

Ned Tijdschr Geneeskd 132: 1507, 1988 (abstract)

Muscle damage and enzyme release in relation with exercise duration $\mathrm{JH}$ van der Meulen, $\mathrm{H}$ Kuipers

Pllügers Arch 412: S2, 1988 (abstract)

Relation between exercise-induced muscle damage and enzyme release in male and female rats

$\mathrm{JH}$ van der Meulen, $\mathrm{H}$ Kuipers, J Drukker.

J Appl Physiol 71: 999-1004, 1991

High energy phosphates, $\mid \mathrm{MP}$ and glycogen in the rat tibialis anterior muscle after forced lengthening and isometric contractions

$\mathrm{JH}$ van der Meulen, H Kuipers, GJ van der Vusse, FRM Stassen, HA Keizer Pfiügers Arch (accepted for publication)

Spatial distribution of exercise-induced muscle damage in the rat soleus. $\mathrm{JH}$ van der Meulen, H Kuipers, JC van der Wal, J Drukker J Anat 173: 245-246, 1990 (abstract)

Relation between initial muscle length and amount of structural damage with forced lengthening contractions IH van der Meulen, $H$ Kuipers, FRM Stassen Med Sci Sports Exerc 23 (4): $\$ 148,1991$ (abstract)

Peripheral adjustment in the rat tibialis anterior muscle after one bout of forced lengthening contractions FRM Stassen, JH van der Meulen, H Kuipers Med Sci Sports Exerc 23 (4): S111, 1991 (abstract) 



\section{Nawoord}

Eindelijk! Bijna 5 jaar nadat ik in Maastricht ben begonnen is het nu zo ver dat het onderzoek voor een ieder is te lezen. Ook voor mij geldt dat het zonder hulp van derden niet gelukt zou zijn om dit werk te voltooien. Daarom wil ik een aantal mensen bedanken voor het tot stand komen van dit proefschrift.

Te beginnen met de promotor, prof. dr. J. Drukker. Beste Jan, het was me een genoegen om in de eindfase met jouw het manuscript door te nemen.

Vervolgens de co-promotor, dr. H. Kuipers. Beste Harm, door jouw stimulerende invloed en je enthousiasme is het me toch gelukt de finish te halen.

Gerrit en Peter wil ik bedanken voor de hulp en de prettige samenwerking op het inspanningslab. Gerrit voor het verrichten van de enzymbepalingen, Peter voor het snijden en kleuren van spiermateriaal. Eric, ik heb dankbaar gebruik gemaakt van je kennis van lay-out programma's. In dit rijtje mag natuurlijk Frank niet ontbreken. We hebben samen heel wat uurtjes op het lab doorgebracht.

Tevens wil ik Carla, Els, Johan, en Paul van anatomie/embryologie bedanken voor het ter beschikking stellen van faciliteiten en kennis. Nog bedankt voor de pilsjes aan het einde van vele werkdagen.

De medewerking van de vakgroepen anatomie/embryologie, bewegingswetenschappen en fysiologie werd door mij zeer gewaardeerd. Zonder iemand te kort te willen doen wil ik toch een aantal mensen met name noemen. Chris Hannen en Theo Gulikers van de mechanische werkplaats, Jan Geilen van de electronische werkplaats, Jacques Lambrechts van fysiologie. Paul Bomans van electronenmicroscopie, Ruud Boechholz van pathologie en de studenten Joost Frederiks en Marielle Daemen voor het berekenen van spierschade.

Tot slot wil ik de beoordelingscommissie bedanken voor het kritisch lezen van dit proefschrift. 